\title{
WestVirginiaUniversity
}

THE RESEARCH REPOSITORY @ WVU

Graduate Theses, Dissertations, and Problem Reports

2013

\section{Regulation of anoikis by oncogenic pathways}

\author{
Sun Hee Park \\ West Virginia University
}

Follow this and additional works at: https://researchrepository.wvu.edu/etd

\section{Recommended Citation}

Park, Sun Hee, "Regulation of anoikis by oncogenic pathways" (2013). Graduate Theses, Dissertations, and Problem Reports. 3658.

https://researchrepository.wvu.edu/etd/3658

This Dissertation is protected by copyright and/or related rights. It has been brought to you by the The Research Repository @ WVU with permission from the rights-holder(s). You are free to use this Dissertation in any way that is permitted by the copyright and related rights legislation that applies to your use. For other uses you must obtain permission from the rights-holder(s) directly, unless additional rights are indicated by a Creative Commons license in the record and/ or on the work itself. This Dissertation has been accepted for inclusion in WVU Graduate Theses, Dissertations, and Problem Reports collection by an authorized administrator of The Research Repository @ WVU.

For more information, please contact researchrepository@mail.wvu.edu. 


\title{
Regulation of anoikis by oncogenic pathways
}

\author{
By \\ Sun Hee Park \\ Dissertation submitted to the School of Medicine at West Virginia University \\ in partial fulfillment of the requirements for the degree of \\ Doctor of Philosophy in Cancer Cell Biology \\ Michael Schaller, Ph.D, Committee Chairperson \\ John Michael Ruppert, M.D., Ph.D \\ Alexey Ivanov, Ph.D \\ Lisa Salati, Ph.D \\ Laura Gibson, Ph.D \\ Steven M Frisch, Ph.D, Mentor \\ Cancer Cell Biology Program \\ Morgantown, West Virginia \\ 2013
}

Keywords: DBC1, IKK $\beta$, NF-kB, EMT, NRAGE, Tbx2, p14ARF, Anoikis, Metastasis.

Copyright 2013 Sun Hee Park 


\title{
ABSTRACT \\ Regulation of anoikis by oncogenic pathways
}

\author{
Sun Hee Park
}

Detachment of epithelial cells from matrix or attachment to an inappropriate matrix engages an apoptotic response known as anoikis, which prevents metastasis.

Anoikis-resistance of tumor cells is critical for anchorage-independent growth and metastasis. Here we show two novel oncogenic pathways that confer resistance to anoikis in tumor cells. One pathway (chapter 2) signifies a new link between EMT and anoikis-resistance. In chapter 3, we present a new connection between inflammatory signaling pathways and anoikis-resistance. Cellular sensitivity to anoikis is compromised during the oncogenic epithelial-to-mesenchymal transition (EMT), through various mechanisms.

Chapter 2 introduces a novel mechanism (NRAGE/TBX2/p14ARF) that is induced upon loss of E-cadherin and EMT, mediating anoikis resistance.

The inflammatory-response transcription factor, NF- $\mathrm{BB}$, contributes to anoikis-resistance and metastatic progression, through mechanisms that are understood incompletely. Deleted in Breast Cancer (DBC1) is over-expressed in several tumor types and correlates with a poorer prognosis in some cases. DBC1 suppressed anoikis in normal epithelial and breast cancer cell lines. Chapter 3 introduces a novel mechanism: DBC1 suppresses anoikis through enhancing canonical $\mathrm{NF}-\kappa \mathrm{B}$ signaling. This study will provide mechanisms for $\mathrm{DBC} 1$ to act as a tumor promoter, by providing a link between inflammation and anoikis-resistance and providing a potential target for anti-NF-kB/anti-cancer drugs. 


\section{ACKNOWLEDGMENTS}

I am very grateful to the following individuals for their constant support and guidance:

Dr. Steven Frisch, my mentor, whose excellent advice was vital for completion of my graduate degree.

The dissertation committee members: Drs. Mike Schaller, Alexey Ivanov, Mike Ruppert, Lisa Salati, and Laura Gibson

Dr. Scott Weed, for his invaluable counsel and encouragement throughout the graduate years.

Dr. Therwa Hamza, my best friend, always there to help, encourage, and inspire me.

And lastly, I extend a heartfelt thanks to my friends and family members for their unconditional support and constant motivation. 


\section{TABLE OF CONTENTS}

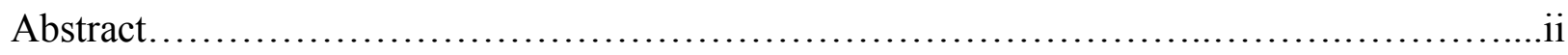

Acknowledgments....................................................................

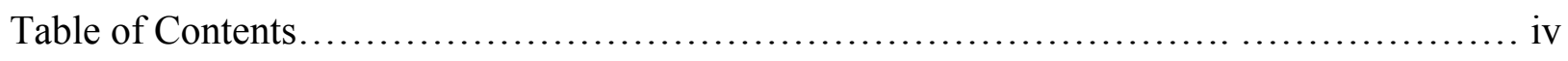

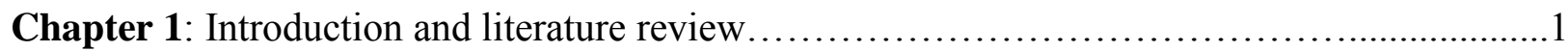

Part I. Inflammation and cancer, NF- $\kappa \mathrm{B}$, and DBC1

Part II. Anoikis regulation, EMT, and Metastasis

Chapter 2: Regulation of anoikis through a novel pathway induced by E-cadherin and EMT....36

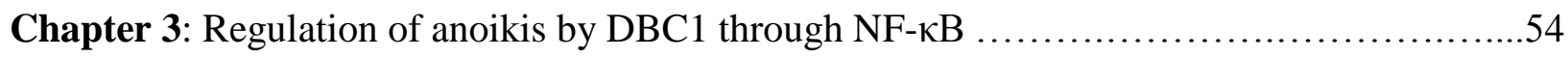

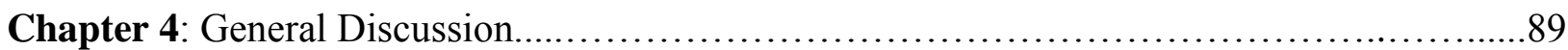

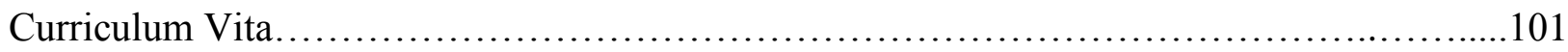




\section{CHAPTER 1}

Introduction and Literature Review 


\section{PART I}

\section{Inflammation and cancer}

Inflammation is a protective reaction activated when body tissue becomes infected, irritated, or injured [1]. When inflammation becomes chronic, it can lead to the development of many types of cancer including bladder, cervical, gastric, ovarian, prostate, thyroid, intestinal and esophageal cancer [1, 2]. Chronic inflammation has been linked to numerous steps of tumorigenesis, including tumor cell survival, proliferation, invasion, angiogenesis, and metastasis [1]. The cytokines released from the activated immune cells stimulate tumor growth and progression [3]. In addition, the immune cells are recruited to the tumor microenvironment through interaction with stromal and malignant cells and the pro-inflammatory cytokines such as TNF- $\alpha$, IL- $1 \beta$, IL6, and IL-17, produced from both immune and malignant cells further promote proliferation, invasion, and metastasis [1, 4].

Diseases that have been associated with chronic inflammation includes autoimmune diseases, such as Rheumatoid Arthritis (RA), as well as diabetes, obesity, and the aging process [5-8]. All involve the elevation of pro-inflammatory cytokines, interleukin-6 (IL-6) and/or TNF- $\alpha$ that lead to activation of $\mathrm{NF}-\kappa \mathrm{B}$ signaling which is known to promote inflammatory processes and enhance tumor development and progression [9]. For instance, obesity and insulin resistance have been established as risk factors for cancer development due to dysfunctional adipocytes, which release IL-6 and TNF- $\alpha$. Increased levels of the cytokines then recruit macrophages to the adipose tissues and activate NF- $\mathrm{BB}$ signaling to further promote inflammatory responses $[10$, 11]. This persistent cycle of inflammatory response and NF- $\kappa \mathrm{B}$ activation can lead to cancer development. 


\section{NF-kB and Cancer}

$N F-\kappa B:$ structure and family members

NF- $\mathrm{kB}$ (nuclear factor kappa-light-chain-enhancer of activated B cells) was first identified as a B-cell nuclear transcriptional factor that is ubiquitously expressed in all animal cell types. It functions as a major player in immune and inflammation response as well as in cell proliferation, survival and apoptosis [12]. There are five members of the NF- $\mathrm{kB}$ family, including the class I family: p50/p105, and p52/p100 and the class II family: p65/RelA, c-RelA, and RelB, which homo- and hetero-dimerize through their conserved N-terminal Rel homology (RH) domain

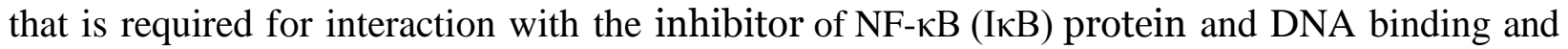
dimerization [13]. The most commonly expressed form is a heterodimer of the p65/RelA and p50 subunits. In addition to the $\mathrm{RH}$ domain, the class II family has a C-terminal transcription activation domain that is not conserved, but activates transcription in variety of species. NF- $\mathrm{kB}$ heterodimers recognize distinct DNA sites (9-10 base pairs) known as $\mathrm{\kappa B}$ sites, resulting in regulation of distinct, but overlapping, sets of target gene expression upon a variety of signals in different cell types $[14,15]$.

Regulation of canonical and non-canonical pathways of $N F-\kappa B$

NF- $\kappa \mathrm{B}$ activation is tightly controlled by canonical and non-canonical pathways that regulate

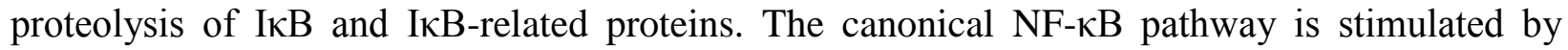
various immune receptors, such as the Toll-like receptors (TLRs), interleukin-1 receptor (IL-1R), tumor necrosis factor receptor (TNFR) and antigen receptors [16]. In addition, a canonical

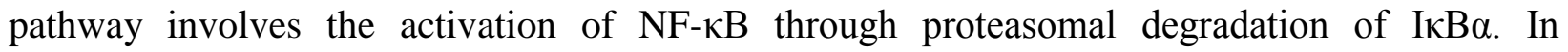
unstimulated normal cells, the NF-kB heterodimer complexes are localized in cytoplasm in an

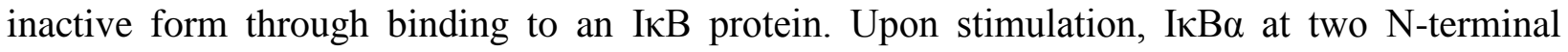


Serine 32/36 residues become phosphorylated mainly by IKK $\beta$, a subunit of IאB kinase (IKK) complex, which also includes IKK $\alpha$ and IKK $\gamma$ (NEMO). Phosphorylated IKB is then degraded in 26S proteasomes which uncovers the nuclear localization signal of NF- $\mathrm{BB}$, resulting in free NF$\kappa \mathrm{B}$ complex to translocate into the nucleus. In the nucleus, the NF- $\kappa \mathrm{B}$ complex binds to the $\kappa \mathrm{B}$ DNA binding sites in the promoter region of target genes and activates transcription $[12,15]$. Therefore, when this pathway is not controlled properly, prolonged NF- $\mathrm{BB}$ activation leads to chronic inflammation and cancer [17].

The non-canonical pathways are induced by a subset of TNF family members and celldifferentiating or developmental stimuli, such as lymphotoxin $\beta$ (LT $\beta)$, B cells activating factor (BAFF), CD40 ligand and receptor activator of NF-kB ligand (RANKL) [17]. Upon stimulation, IKK $\alpha$ activated by NF- $\kappa B$ induces Kinase (NIK) to phosphorylate p100 whose function is analogous to I $\mathrm{KB} \alpha$. This results in ubiquitination and subsequent partial proteolysis by the proteasome to produce p52, which translocates into the nucleus as a complex with RelB [16]. The non-canonical NF-kB pathway regulates important biological functions, such as lymphoid organogenesis, B-cell survival and maturation, dendritic cell activation, and bone metabolism and deregulated non-canonical NF- $\mathrm{BB}$ signaling is associated with lymphoid malignancies $[18$, 19].

\section{Role of $\mathrm{NF}-\kappa \mathrm{B}$ signaling pathways in inflammatory responses}

The body's initial immune response to the presence of cellular stress conditions, including bacterial lipopolysaccharides (LPSs), microbial and viral pathogens, and growth factors, is initially mediated by proinflammatory cytokines, such as TNF $\alpha$ and IL-1 and various pathogen- 
associated molecular patterns (PAMPs), leading to an inflammatory response with the activation of NF- $\kappa \mathrm{B}$ playing a major role [20]. Through the canonical pathway, activated NF- $\kappa \mathrm{B}$ induces expression of genes encoding chemokines (Monocyte chemotactic protein-1 (MCP-1), Macrophage inflammatory protein-1 (MIP-1), IL-8, and eotaxin), cytokines (TNF- $\alpha$ ), adhesion molecules (Intercellular adhesion molecule 1 (ICAM-1), vascular cell adhesion molecule-1 (VCAM-1) and endothelial-leukocyte adhesion molecule 1 (ELAM)), and enzymes such as cyclooxygenase II (COX2), which are involved in innate immune response and migration of the inflammatory and phagocytic cells to the site of tissue that has been infected $[21,22]$. In addition, the canonical NF- $\mathrm{BB}$ pathway is also critical for the survival of macrophages, lymphocytes and B cells during bacterial infections or against LPS and TNF- $\alpha$ induced apoptosis through activating expression of anti-apoptotic genes including Bcl-2 [21, 23]. While the innate immune response is under control of the classical IKK $\beta$-dependent NF- $\kappa \mathrm{B}$ signaling pathway, the IKK $\alpha$-dependent alternative $\mathrm{NF}-\kappa \mathrm{B}$ pathway plays a role in adaptive immune response by generating chemokines such as the secondary lymphoid tissue chemokine (SLC), Epstein-Barr virus-induced molecule 1 ligand CC chemokine (ELC) and stromal cell-derived factor-1 $\alpha$ (SDF$1 \alpha$, which are required for migration of antigen presenting cells (APCs) to the spleen and lymph nodes where T cells and B cells induce further immune response upon encountering with APCs $[21,24]$.

Functional significance of IKK and IKK-related kinase, IKKi/IKKe, in inflammation and cancer Binding of all the inflammatory cytokines and PAMPs to their receptors such as TNFR1 [25], IL-1R [26] and Toll-like receptors (TLRs) [27] results in activation of the IאB kinase (IKK) complex, the endogenous activator of NF- $\kappa \mathrm{B}$ [28]. IKK complex includes two catalytic subunits, 
IKK $\beta$ and IKK $\alpha$ that are structurally similar, and a regulatory subunit, IKK $\gamma$ (NEMO) that lacks kinase activity [29]. In mammalian cells, IKK $\alpha$ and IKK $\beta$ form a stable heterodimer that is tightly associated with the IKK $\gamma$ (NEMO) $[29,30]$.

Studies have shown that depletion in IKK $\gamma$ (NEMO) expression causes a major defect in IкB degradation and NF- $\mathrm{BB}$ activation in response to pro-inflammatory stimuli [31]. Therefore, this regulatory subunit is critical for mainly the activation of IKK complex and NF- $\mathrm{KB}$ [32].

Although IKK $\beta$ and IKK $\alpha$ has highly similar structures and in vitro kinase activities, their functions in inflammation and cancer is very different [33]. For instance, IKK $\alpha$-deficient cells and tissues showed no defect in IKK activation and IкB $\alpha$ degradation in response to TNF- $\alpha$, IL1 , or LPS, which suggests that IKK $\beta$ and IKK $\alpha$ have different physiological functions and that IKK $\alpha$ cannot substitute for $\operatorname{IKK} \beta[33,34]$. IKK $\alpha$ mainly regulates an alternative NF- $\mathrm{B} B$ pathway that is important for lymphoid organogenesis [35]. In addition, IKK $\alpha$ also controls epidermal keratinocyte differentiation and skeletal morphogenesis independent of NF-kB pathway [36, 37]. However, IKK $\beta$ has been known as the major kinase critical for activating the canonical NF-KB pathway, which is critical for the anti-apoptotic pathway and innate immune response. In fact, mice deficient in IKK $\beta$ showed massive liver apoptosis mediated by TNF- $\alpha$ signaling and were very susceptible to infections, which led to their death a short time after birth [38]. Moreover, both the T- and B-cell receptors, as well as TLR4, use this IKK $\beta$ mediated NF- $\kappa B$ pathway to mediate survival and various inflammatory and immune functions [39-41]. Therefore, IKK $\beta / \mathrm{NF}-$ $\kappa \mathrm{B}$ is important for the activation of immune cells and the duration of the period through which they remain functional and viable [38].

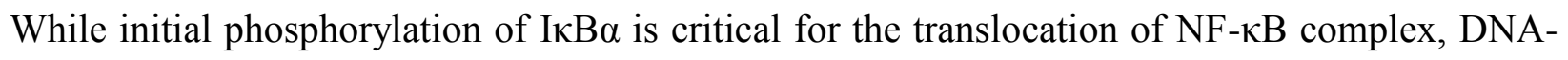
binding ability and transactivation activity of NF- $\mathrm{kB}$ is additionally regulated through the post- 
translational modification such as acetylation and phosphorylation by IKK. For instance, phosphorylation at serine 536 site in the active loop has been shown to be critical for transactivation activity of NF- $\mathrm{B}$ [42]. Interestingly, a number of studies showed that phosphorylation at serine 536 of RelA is mainly regulated by IKK $\beta$ upon TNF- $\alpha$ or LPS stimulation [42-44]. Importantly, the RelA subunit phosphorylated at serine-536 is an independent prognostic factor in colorectal cancer patients [45]. In addition, increased expression of phosphorylation at Ser536 of RelA was positively correlated with more malignant features of colorectal tumors [46].

In addition to IKK $\beta$, which is overexpressed in some cancer cells [47], IKKi/IKKe has shown to be expressed in several cancer cells and maintain constitutive activation of $\mathrm{NF}-\kappa \mathrm{B}$ through phosphorylation of RelA at Ser-536 [48]. However, unlike IKK $\beta$, IKKi/IKKe is not responsible for phosphorylation of $\mathrm{I} \kappa \mathrm{B} \alpha$, suggesting that $\mathrm{IKKi} / \mathrm{IKK} \varepsilon$ regulates a later stage of $\mathrm{NF}-\kappa \mathrm{B}$ response [49]. IKKi/IKKe is an IKK-related kinase that has been discovered through sequence analysis study. Although detailed functions of these two kinases are not completely understood, $\mathrm{IKKi} / \mathrm{IKK} \varepsilon$ has been suggested as a potential therapeutic target in inflammation and cancer [49, 50]. In addition, $\mathrm{IKKi} / \mathrm{IKK} \varepsilon$ has been shown to be critical for invasiveness and growth of breast cancer cells [51].

\section{Link between inflammation and Cancer through NF-кB}

The link between inflammation and cancer is understood incompletely. There are many cases where infections (HBV and HCV, and IBDs) and inflammatory cytokines (TNF, MIF and interleukins) cause development of cancers such as colorectal, breast, lung, and liver cancers. Many studies show that the processes that contribute to the malignant progression involve 
uncontrolled proliferation, invasion, angiogenesis, metastasis, and evasion of apoptosis, which are all regulated by IKK/NF- $\kappa \mathrm{B}$ signaling pathways. Therefore, these studies suggest that $\mathrm{IKK} / \mathrm{NF}-\kappa \mathrm{B}$ is the critical molecule that links inflammation and cancer $[52,53]$.

\section{Overexpression/activation/mutation of $N F-\kappa B$ in lymphoid and solid cancers}

Continuous activation and overexpression of NF- $\mathrm{KB}$ factors has been emerging as a hallmark of various types of solid tumors including breast [54], ovarian [55], colon [55], pancreatic [56], thyroid [57], and melanomas [58]. In addition, gene amplification and rearrangement of $c$-Rel and RelA are found in leukemia and carcinomas [59]. Constitutive activation of NF- $\kappa \mathrm{B}$ results in increased phosphorylation of $\mathrm{I} \kappa \mathrm{B} \alpha$ following accumulation of $\mathrm{NF}-\kappa \mathrm{B}$ in nucleus. Therefore,

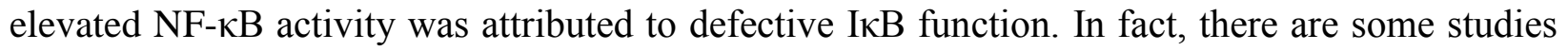
showing inactivating mutations in $I \kappa B \alpha$ and $I \kappa B \varepsilon$ in lymphomas [60-62] indicating the critical

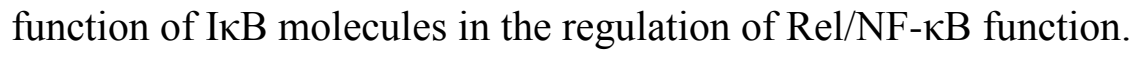

\section{Hyperactive $N F-\kappa B$ because of upstream pathways}

In addition to the amplification or mutation of $\mathrm{NF}-\kappa \mathrm{B}$ pathway molecules, there are many different signaling pathways/molecules that lead to constitutive activation of NF- $\kappa \mathrm{B}$ in cancers [15]. First, NF- $\kappa B$ activity is deregulated by upstream oncogenes and kinases such as Ras [63] and Raf [64]. For instance, oncogenic Ras and Raf, which induce transformation through NF- $\kappa$ B, are also frequently mutated and/or mutated in many human tumors, resulting in constitutive activation of NF- $\kappa \mathrm{B}$ through $\mathrm{PI} 3 \mathrm{~K} / \mathrm{Akt}$ and MAPK/MEKK-1 signaling pathways, causing $\mathrm{I} \kappa \mathrm{B} \alpha$ phosphorylation and nuclear NF- $\mathrm{B}$ accumulation. Secondly, overexpression of upstream receptors such as EGFR and Her2/ ErB2 that are frequently overexpressed in breast cancers, 
leads to constitutive induction of NF- $\mathrm{KB}$ through a PI3-kinase/Akt kinase pathway in a IKK$\mathrm{I} \kappa \mathrm{B} \alpha$ independent manner [65]. In addition, IKK $\beta / \mathrm{NF}-\kappa \mathrm{B}$ signaling is required for EGFR induced proliferation and survival in the EGFR+/ER- subtype of breast cancers [66-68]. Lastly, chronic infections with hepatitis B virus (HBV), hepatitis C virus and chronic inflammatory bowel diseases (IBDs) lead to developing hepatocellular carcinoma (HCC), gastric cancers and

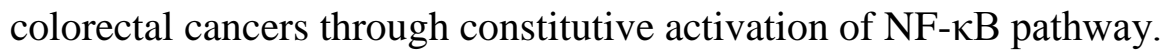

Inflammatory cytokines secreted from the tumor microenvironment promote survival and proliferation while inhibiting apoptosis through the $N F-\kappa B$ pathway

The tumor microenvironment includes immune cells that release inflammatory cytokines such as TNF- $\alpha$ and IL-1 and oxidative stress molecules like reactive oxygen species (ROS) during chronic inflammation. These molecules react with tumor cells to activate NF-кB signaling pathways. Increased activation of NF-kB in these tumor cells leads to enhanced expression of genes that are involved in many different process, such as proliferation, cell survival, invasion, and angiogenesis, resulting in tumor progression and malignancies. For instance, activated NF$\kappa \mathrm{B}$ induces the expression of the genes involved in anti-apoptotic pathways such as c-FLIP [69] and Bcl-xL [70] to promote tumor cell survival. Expression of matrix metalloproteases (such as MMP9) and angiogenic factors like vascular endothelial growth factor (VEGF) that are involved in invasion and angiogenesis also promote a malignant phenotype [71, 72]. Moreover, TNF- $\alpha$ and ROS have been shown to induce epithelial-to-mesenchymal transition (EMT), an oncogenic process that leads to invasive and metastatic phenotype, through increasing expression of Snail while downregulating E-cadherin through NF-אB pathway in a breast tumor cell line [73, 74] . 


\section{Deleted in Breast Cancer 1 (DBC1)}

Basic information about its history, structure, and post-translational regulation

$D B C 1 / K I A A 1967$ was mistakenly identified as a tumor suppressor because it was originally found in a region of chromosome $8 \mathrm{p} 21$ that was frequently deleted in some breast cancer cell lines [75]. However, many recent studies show that DBC1 protein is not deleted in tumor cells, but overexpressed in various cancers $[76,77]$. $\mathrm{DBC} 1$ is composed of $\mathrm{N}$-terminal coiled-coil (zipper) region and multiple conserved globular domains, including a C-terminal inactive EFhand module (Fig. 1).

DBC1 oligomerizes and exhibits a dynamic expression pattern during the cell cycle [78, 79]. In addition, DBC1 has the Nudix domain (Fig. 1) that is catalytically inactive, but might be necessary for binding of ligands such as ADP-sugars, generated by SIRT1 activity $[80,81]$. DBC1 mainly resides in the nucleus except in Hela cells where DBC1 can localize to mitochondria following

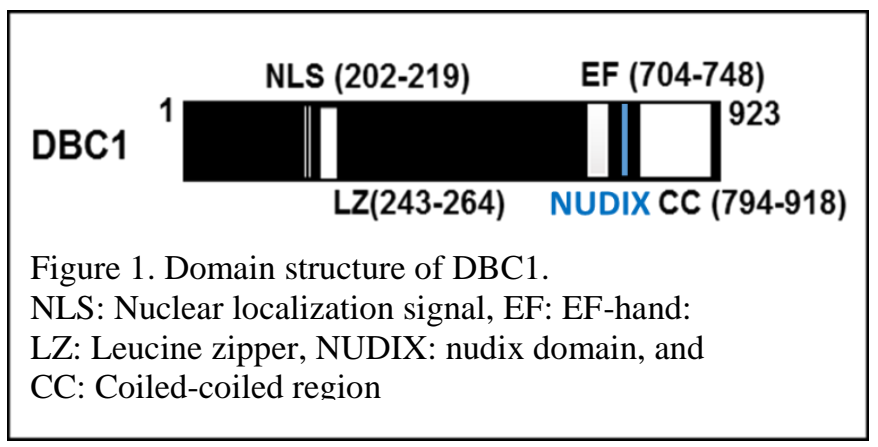
caspase-dependent processing, sensitizing the cells to TNF $\alpha$ mediated apoptosis [82]. There is evidence showing that $\mathrm{DBC} 1$ undergoes posttranslational modification in response to DNA damage: DBC1 becomes phosphorylated at threonine 454 by ataxia telangiectasia-mutated (ATM) and ataxia telangiectasia and Rad3-related (ATR) kinases, which is critical for the interaction with SIRT1 deacetylase [83]. 


\section{Biological functions of $D B C 1$}

The function of DBC1 was initially discovered as a SIRT1 inhibitor [79]. SIRT1 is a histone/protein deacetylase involved in several cellular functions such as longevity, metabolism, cellular stress response and tumorigenesis, which implies that DBC1 might also play a role in these functions through regulating SIRT1 activity [77]. DBC1 directly interacts with and inhibits SIRT1, stabilizing the activity of p53 transcription factor, resulting in an increase in the expression of genes that are involved in apoptotic pathways [79, 84]. DBC1 regulates heat shock response (HSR), the cellular response to protein damaging stress, which is critical in maintaining proteostasis. Through inhibition of SIRT1 activity, DBC1 increased acetylation of HSF1, a known transcriptional factor regulating expression of genes such as Hsp70, which repairs cellular damage due to stress. Acetylated HSF1 then loses its DNA binding ability, which results in decreased transcription of Hsp70, suggesting DBC1 as a new target available for therapeutic regulation of the heat shock response [85]. Secondly, DBC1 interacts with ZNF326 to form part of DBIRD complex and regulates alternative splicing through affecting the transcript elongation rate and density of RNA polymerase II (RNAPII) at the transcription site. DBIRD complex links RNAPII and a messenger ribonucleoprotein (mRNP) particle, integrating transcript elongation with mRNA splicing [86]. Thirdly, DBC1 appears to associate with the COUP-TFI transcriptional factor that is mainly known to function in embryonic development on the promoter of COUP-TFI target genes, and functions to stabilize interaction between Nuclear Receptor co-repressor (NCoR) and COUP-TFI, thus contributing to COUP-TFI-mediated transcriptional repression [87]. DBC1 also stimulated the transcriptional activities of the nuclear receptors such as GR (glucocorticoid receptor) and TR (thyroid hormone receptor) in a hormonedependent manner [88]. In addition to these functions, DBC1 is also known to induce high-fat 
diet-induced liver steatosis through inhibiting SIRT1 activity in a mouse model [89]. Lastly, DBC1 is important for DNA damage signaling pathways by stabilizing Chk1, which is a critical effector molecule in the DNA damage signaling pathway. Thus, DBC1 may be an important regulator of a wide variety of cellular processes including gene expression, chromatin remodeling, splicing, apoptosis and metabolism.

\section{Role of DBC1 in cancer}

\section{DBC1 overexpression in cancer}

Recent studies have shown through DNA microarray and protein analysis that DBC1 is upregulated in esophageal, prostate, colorectal, lung, and breast cancers [90-94]. Moreover, overexpression of DBC1 correlates with a poorer prognosis of gastric, colorectal, and esophageal cancers [90, 91, 95]. Likewise, breast carcinomas that over-express DBC1 showed a more frequent DMR (distant metastatic relapse rate) and significantly lower OS (Overall Survival) and RFS (Relapse free survival) among patients receiving endocrine therapy [96]. Therefore, DBC1 would be a critical poor prognostic marker for breast cancer patients. Expression of DBC1 was also higher in metastatic breast carcinoma than at the primary site and lung cancer cells show higher DBC1 expression than in normal lung fibroblasts. Interestingly, the level of DBC1 protein in normal cells differs from that found in lung and breast cancer cells [78]. This aberrant expression of $\mathrm{DBC} 1$ in cancer suggests that $\mathrm{DBC} 1$ may serve as a potential diagnostic marker.

\section{Interactions of $\mathrm{DBC1}$ with cancer relevant proteins}

DBC1 binds to several nuclear receptors and enzymes, including the estrogen receptors $\alpha$ and $\beta$, androgen receptors, the transcription factor BRCA1, and the deacetylase HDAC3. Through 
interacting with these molecules, DBC1 regulates proliferation, apoptosis and histone modification that are important processes for tumorigenesis in SIRT1 dependent or SIRT1 independent manners. Interestingly, depending on the type of cancer, interacting partner, and cancer-inducing stress type, DBC1 can function either as a tumor promoter or suppressor.

\section{DBC1 functions as a tumor suppressor}

Several studies have shown that DBC1 can function as a tumor suppressor in certain types of cancer cells mainly through inhibiting SIRT1 activity. For instance, through inhibiting SIRT1 activity, DBC1 induces acetylation of p53, FOXO, and BRCA1 transcriptional factors, promoting apoptosis [79]. In addition, DBC1 directly interacts with HDAC3, which is known to be overexpressed in many different cancers and to inhibit its deacetylase activity, leading to an increase in cell-cycle arrest and apoptosis of the cancer cells [97-99]. Therefore, these studies suggest a tumor suppressive activity of DBC1. However, SIRT1 itself can function either as a tumor promoter or a tumor suppressor. For instance, knock down of SIRT1 in colon cancer induces tumor progression in xenograft models [100] while SIRT1 expression is elevated in some prostate tumor cells [101]. In addition, in liver cancers, DBC1 does not act as a SIRT1 regulator, further illustrating that the tumor suppressive effect of DBC1 is cancer type-dependent [102].

\section{DBC1 functions as a tumor promoter}

DBC1 function as a tumor promoter through interacting with different nuclear receptors in SIRT1 independent manner. For instance, DBC1 interacts with estrogen receptor alpha (ER $\alpha)$ to stabilize its expression and promotes proliferation and cell cycle progression dependent upon 
estrogen [88] . In addition, in a ligand-dependent manner, DBC1 interacts with ER- $\beta$ to repress its transcriptional activity and enhances the expression of cell survival genes such as Bcl2 [103]. DBC1 interacts with and induces Androgen receptor transcriptional activity and enhances prostate specific antigen (PSA) expression in a hormone-dependent manner [104]. DBC1 interacts with SUV39H1 to inhibit this tumor suppressor effect in lung cancer cells [105]. SUV39H1 methyltransferase functions as a tumor suppressor by enhancing Ras induced spontaneous senescence. It also interacts with $\mathrm{pRb}$ to inhibit E2F1 target promoters through methylation, inducing cell cycle arrest. DBC1 can also function as a tumor promoter in a SIRT1dependent manner. For instance, through inhibiting SIRT1, DBC1 enhances survival against UV irradiation, protecting against genotoxic-stress induced cell death in breast cancer cell line [106]. Lastly, through inhibiting SIRT1 activity, DBC1 interacts with cell cycle and apoptotic response 1 (CCAR1) and enhances ER $\alpha$ DNA binding to increase target gene expression such as PgR, CTSD, and GREB1 that are known to promote tumor cell survival and metastasis of breast cancer cells [88]. Taken together, these findings clearly demonstrate that DBC1 functions as a tumor promoter in both SIRT1 dependent and independent manners.

\section{Regulation by AMPK and PKA-potential link between metabolism and cancer}

Impaired glycolysis or aerobic respiration has been suggested as a metabolic hallmark of cancer development $[107,108]$. Protein kinase A (PKA) and AMP-activated protein kinase (AMPK) are kinases that are involved in metabolic regulation [109], whose overexpression is frequently detected in some cancers. In addition, these proteins also confer anoikis-resistance $[110,111]$. Determining the molecular mechanism of how these metabolic proteins regulate oncogenic molecules will be critical, but it is largely unknown. Nevertheless, recently, Veronica et al. 
show how PKA and AMPK regulate the activity of SIRT1 deacetylase, which is known to function in tumorigenesis. Under a fasting condition, the level of cellular cAMP increases, resulting in activation of PKA and AMPK [109, 112]. The study shows that activated AMPK increases the activity of SIRT1 through dissociation of DBC1 from the SIRT1-DBC1 complex [113]. This result provides the possible link between metabolic signals and oncogenic pathways that are regulated by SIRT and/or DBC1, linking metabolism and cancer.

\section{Other DBC1 interacting proteins relevant to cancer}

Overexpressed c-Myc sequesters DBC1 to induce SIRT1 activity, which stabilizes c-Myc through a positive feedback loop to regulate proliferation and survival in cancer cells [114]. Interestingly, SIRT1 and c-Myc also has been shown to suppress transformation, cell growth, and metabolism through negative feedback $[114,115]$. These studies suggest that DBC1 might be critical in regulating the functions of c-Myc in cancer. 


\section{PART II}

\section{Anoikis}

\section{Definition of anoikis and significance of anoikis resistance in metastasis}

Extracellular matrix (ECM) is critical to the development and stabilization of tissue structure. Anoikis is form of apoptosis that occurs when normal epithelial cells lose their contact with the ECM, or when cells are misplaced onto an inappropriate matrix [116]. Carcinoma cells are known to be resistant to anoikis, which allows the tumor cells to survive upon detachment and travel through lymphatic and circulatory systems resulting in metastasis. Anoikis resistance therefore represents a critical stage of metastasis [117] and understanding the mechanisms regulating anoikis sensitivity will prove an important first step towards targeting metastatic malignancies.

\section{Regulation of Anoikis}

Survival signals are induced by attachment of epithelial cells to ECM through the integrin and other growth factor receptors. When these signals are disrupted, anoikis will be induced. Several key factors and pathways that regulate anoikis are summarized below, but more detailed information is reviewed in Frisch et al. [118].

\section{Integrin and growth factor Receptors}

Integrins are transmembrane receptors activated upon attachment of ligands such as fibronectin, collagen, laminin, and thrombospodin, which compose the ECM. Integrins exist as heterodimers including different alpha and beta subunits, resulting in about 24 unique integrins made through various subunit combinations [119]. In addition to functioning as a bridge between ECM and 
cytoskeletal proteins, integrins also regulate cell migration, survival, differentiation, cell cycle progression and apoptosis [119]. Moreover, integrins have been shown to regulate anoikis through different survival molecules and pathways [120]. For instance, integrins suppress anoikis through activating either Shc/MAPK and/or ILK/PI3K/Akt survival signaling pathways [121]. In addition, integrins can partly regulate anoikis through control of metabolic pathways including the pentose phosphate pathway and molecules that are important for survival such as NADPH and reactive oxygen species (ROS) whose level is induced by depletion of ATP upon detachment $[122,123]$.

Integrins also are known to crosstalk with growth factors to regulate anoikis through activating survival signaling pathways. Resistance to anoikis in tumor cells may be caused by a loss of integrin- growth factor coupling, allowing inappropriate survival signals to be maintained upon detachment. In colon cancer, for example, increased expression of EGF induces Src-Fak association through EGFR and leads to anoikis resistance[124]. Through crosstalk with growth factor receptors such as EGFR, integrins also regulate Bim (pro-apoptotic, BH3-only protein) expression and anoikis via the MEK/Erk pathway [125]. In addition, Insulin and Insulin-like growth factor receptors (IGFRs) are also known to induce anoikis resistance through PI3K/Akt signaling pathway [126] .

\section{Pro-/anti-apoptotic molecules}

Upon loss of association of integrin with ECM through detachment, expression of pro-apoptotic BH3-only Bcl-2 family members such as Bax, Bim, and Bid is increased which inactivates antiapoptotic Bcl-2 family proteins, such as Bcl-2 and Bcl-xL, resulting in stimulation of intrinsic apoptotic pathways to induce anoikis [125]. Upon detachment, Bax and Bid localize to the 
cytoplasm to induce permeablization of mitochondria and the release of cytochrome c and apoptotic molecules while Bim translocates to the mitochondria, where it interacts with Bcl-xL, neutralizing the pro-survival function of Bcl-xL [125]. Downregulation of an anti-apoptotic, endogenous caspase-8 inhibitor c-FLIP, leads to activation of extrinsic apoptotic pathway, which involves Fas ligand (FasL)-Fas-Associated protein with Death Domain (FADD) complex formation and activation of caspase-8 [119]. In fact, some cancer cells that overexpress Bcl-2, cFLIP, and/or Bcl-xL protect the cells from anoikis through blocking the transmission of death signaling to the mitochondria upon detachment $[127,128]$.

\section{Rho family GTPase signaling}

Small GTPase proteins like Rac and cdc42 are also important for adhesion-dependent signaling pathways and migration of cells through regulating actin cytoskeletons. In MDCK cells, it has been shown that Rac and cdc42 suppress anoikis in the PI3K/Akt signaling dependent manner. In addition, cdc42 can regulate anoikis through a positive feedback loop involving Rac and PI3K [129-131].

In addition to these pathways and molecules, epithelial-to-mesenchymal transition (EMT) has been recognized as a critical factor in regulation of anoikis sensitivity.

\section{Epithelial-to-mesenchymal transition (EMT)}

Intracellular adhesion proteins like E-cadherin (adherent), occludins (tight), claudins (tight), desmogleins (desmosome) and desmocollins (desmosome) promote and maintain the integrity of epithelial layers by regulating cell polarity [115]. In addition, epithelial-specific cytosolic 
proteins such as Ankyrin-G and Rab25 maintain the appropriate localization of these junction proteins $[116,117]$. Several molecules that regulate epithelial gene expression program have been identified, such as GATA3 [132], GRHL2 [133, 134], mir200 family of micro-RNAs [135], ESRP1 and ESRP2 [136]. The detailed mechanism of these molecules is illustrated in Frisch et al. 2013 [118].

During EMT, epithelial cells lose their polarized structure and cell-cell junctions, undergo cytoskeletal re-organization and gain mesenchymal characteristics, such as fibroblast-like cell morphology and increased cell migration and invasion [137]. The EMT process is important for many different cellular processes such as embryonic development, wound healing, inflammation and cell motility in normal epithelial cells [137]. However, when epithelial tumor cells undergo EMT, they can convert into migratory mesenchymal cancer cells that endure anchorageindependent survival, which leads to cancer metastasis. Therefore, anoikis resistance has been recognized as a hallmark of oncogenic EMT [138].

\section{Mechanisms that link EMT and anoikis}

Several key mechanisms that link EMT and anoikis-resistance are described here. More detailed information is also reviewed in Frisch et al.[118].

\section{Polarity proteins through TGF- $\beta$, Wnt, and hippo pathways}

Loss of cell polarity proteins such as Scribble, Crumbs, and Par, or translocation of these proteins to wrong places during EMT, can lead to activation of signaling pathways causing 
anoikis resistance. These polarity molecules regulate anoikis through association with different signaling molecules involved in EMT, mainly the Wnt, TGF- $\beta$, and Hippo pathways.

Two co-activators in Hippo-pathway, Yes-associated protein (YAP) and Transcriptional coactivator with PDZ-binding motif (TAZ) are key oncogenic transcriptional cofactors that bind to Scalloped (Sd) transcriptional factor in the active/un-phosphorylated form to induce expression of genes promoting cell growth, proliferation and inhibition of apoptosis [139]. In normal epithelial cells, YAP/TAZ is in a phosphorylated/inactive state interacting with Smad in the nucleus. Upon stimulation, phosphorylated YAP/TAZ localizes to the cytoplasm and binds to the polarity proteins Crumbs and Scribble in the membrane, sequestering Smad protein thus inactivating both TGF- $\beta$ and Hippo signaling pathways [140]. Inactivation of these signals would result in an increase in anoikis sensitivity and this might be a mechanism by which normal epithelial cells maintain anoikis sensitivity. During EMT, mislocalized Scribble protects against anoikis through activating TAZ [141, 142] or by inhibiting c-Myc induced Rac-JNK-cJun-Bim apoptotic pathway in breast cancers [143]. Lastly, Dvl (Dishevelled homolog), a segment polarity protein, regulates anterior and posterior polarities by affecting the transmission of Wnt and Hedgehog pathways. During EMT, YAP and TAZ proteins activate the Wnt signaling pathway through inhibiting Dvl protein, which results in an increase in anoikis resistance [144]. 


\section{EMT inducing transcriptional factors}

\section{$\underline{\text { Snail, Slug, Twist, and ZEB }}$}

Several different bHLH and Zn-Finger transcription factors such as Snail, Slug, Twist and ZEB [137] mediate oncogenic EMT and anoikis resistance through transcription repression of genes involved in apoptotic pathways and genes maintaining epithelial phenotype [118].

A number of studies show that Snail, Slug, Twist and ZEB transcription factors induce EMT and anoikis resistance through downregulation of E-cadherin in response to various stimuli, such as TGF- $\beta$ [145]. In addition, these molecules can regulate EMT and anoikis through other mechanisms. For instance, ZEB1 regulate EMT and anoikis through repressing expression of p73, a member of p53 family protein involved in maintaining mammary epithelial cell polarity by up-regulation of E-cadherin [146, 147]. In addition, a study utilizing human adenoid cystic carcinoma (ACC) shows that Slug induces EMT and anoikis resistance through affecting EGFR/PI3K/Akt pathway [148]. Twist cooperates with c-Myc to induce hyper-proliferation and transformation while inhibiting the c-Myc-ARF mediated apoptotic pathway [149]. c-Myc induces apoptosis upon cell-cell contact inhibition, which suggests that Twist induces EMT and anoikis resistance through inactivating the c-Myc mediated apoptotic pathway while activating c-Myc mediated proliferation [143]. Snail has been known to induce EMT and enhance the metastatic potential of noninvasive breast epithelial cells such as MCF7 in response to overexpression of the transcription/translation regulatory protein Y-box binding protein-1 (YB-1) through downregulation of epithelial and growth-related genes and activation of mesenchymal genes [150]. 


\section{CtBP}

C-terminal binding protein (CtBP) was found as a co-repressor whose activity is inhibited by E1a, which is known to induce anoikis sensitivity, through direct interaction. CtBP confers anoikis resistance through repressing expression of p53-target genes such as p21, PERP, Bax and Noxa [151]. In addition, CtBP interacts with EMT inducting transcriptional factors such as ZEB1 and ZEB2 to co-repress the promoter of epithelial phenotype related genes such as E-cadherin, desmoglein-2, and gap junction- $\beta 3$ in some tumor cells [152]. These studies suggest that CtBP co-represses epithelial and pro-apoptotic gene expression programs, potentially contributing to EMT, anoikis resistance and tumor metastasis [153]. Moreover, CtBP1/2 are known to be the targets in p14ARF-mediated p53-independent apoptosis in colon cancer. Interaction with p14ARF mediates proteasomal degradation of $\mathrm{CtBP}$, which allows the induction of apoptosis [154].

\section{$\underline{\mathrm{NF}-\kappa \mathrm{B}}$}

There are several studies showing the significance of $\mathrm{NF}-\kappa \mathrm{B}$ in EMT and anoikis resistance. Especially in intestinal epithelial cells, NF- $\mathrm{NB}$ activity is induced upon detachment and it happens through inducing expression of downstream target genes regulating survival signaling pathways such as the IAP family proteins, XIAP, survivin, c-FLIP, osteoprotegerin, and Bcl-xL $[155,156]$. In addition to these targets, NF- $\kappa \mathrm{B}$ also regulates genes such as TNF $\alpha$ and IL-6 which are involved in inflammatory pathways that further activate NF- $\kappa$ B signaling to induce EMT and metastatic progression $[157,158]$. In addition, survivin and XIAP complex is known to activate NF- $\mathrm{KB}$, which leads to increased expression of fibronectin, a mesenchymal marker. This 
in turn establishes integrin clustering under detached conditions and results in rescue from anoikis [159].

\section{$\underline{\text { FAK, ILK, and trkB }}$}

The anoikis suppressing effect of focal adhesion kinase (FAK) and integrin linked kinase (ILK) is well established [118]. FAK and ILK are intracellular adaptor kinases that link the celladhesion receptors, integrins and growth factors to the actin cytoskeleton and with a range of signaling pathways [121]. FAK and ILK colocalize with integrins at the site of cell attachment to ECM $[160,161]$. Therefore, upon ligand (collagen)-integrin interaction or growth factor (TGF$\beta)$-receptor binding, FAK and ILK are activated to regulate EMT. Several studies suggest that FAK induces EMT through PI3K-MAPK pathway by either up-regulation of KLF8, which is known to repress E-cadherin promoter [162-164], or EMT-inducing transcription factors like Snail1, ZEB1, and Twist2 [165] . In addition, FAK has been shown to induce EMT through either downregulation or internalization of E-cadherin in fibroblasts both in vitro and in vivo $[166,167]$. ILK is also known to regulate EMT through up-regulation of EMT inducing factors like Snail and Slug upon TGF- $\beta$ stimulation and down-regulation of E-cadherin $[168,169]$. TrkB is a neurotrophic tyrosine kinase receptor known to be overexpressed in many different cancers such as pancreatic and ovarian cancers $[170,171]$. TrkB has been known to contribute to disease progression by inducing EMT and inhibiting anoikis. Overexpression of TrkB induced EMT [172, 173], while inhibiting anoikis through PI3K/Akt pathway [171, 174]. 


\section{REFERENCES}

1. Mantovani A, Allavena P, Sica A and Balkwill F (2008) Cancer-related inflammation. Nature 454:436-44. doi: 10.1038/nature07205

2. Reuter S, Gupta SC, Chaturvedi MM and Aggarwal BB (2010) Oxidative stress, inflammation, and cancer: how are they linked? Free Radic Biol Med 49:1603-16. doi: 10.1016/j.freeradbiomed.2010.09.006

3. Kundu JK and Surh YJ (2012) Emerging avenues linking inflammation and cancer. Free Radic Biol Med 52:2013-37. doi: 10.1016/j.freeradbiomed.2012.02.035

4. Lin WW and Karin M (2007) A cytokine-mediated link between innate immunity, inflammation, and cancer. J Clin Invest 117:1175-83. doi: 10.1172/JCI31537

5. Sarkar D and Fisher PB (2006) Molecular mechanisms of aging-associated inflammation. Cancer Lett 236:13-23. doi: 10.1016/j.canlet.2005.04.009

6. Maggio M, Guralnik JM, Longo DL and Ferrucci L (2006) Interleukin-6 in aging and chronic disease: a magnificent pathway. J Gerontol A Biol Sci Med Sci 61:575-84.

7. Dandona P, Aljada A and Bandyopadhyay A (2004) Inflammation: the link between insulin resistance, obesity and diabetes. Trends Immunol 25:4-7.

8. Firestein GS (2003) Evolving concepts of rheumatoid arthritis. Nature 423:356-61. doi: 10.1038/nature01661

9. Naugler WE and Karin M (2008) The wolf in sheep's clothing: the role of interleukin-6 in immunity, inflammation and cancer. Trends Mol Med 14:109-19. doi: 10.1016/j.molmed.2007.12.007

10. Lee J (2013) Adipose tissue macrophages in the development of obesity-induced inflammation, insulin resistance and type 2 Diabetes. Arch Pharm Res 36:208-22. doi: 10.1007/s12272-013-0023-8

11. van Kruijsdijk RC, van der Wall E and Visseren FL (2009) Obesity and cancer: the role of dysfunctional adipose tissue. Cancer Epidemiol Biomarkers Prev 18:2569-78. doi: 10.1158/1055-9965.EPI-09-0372

12. Wan F and Lenardo MJ (2010) The nuclear signaling of NF-kappaB: current knowledge, new insights, and future perspectives. Cell Res 20:24-33. doi: 10.1038/cr.2009.137

13. Muller CW, Rey FA, Sodeoka M, Verdine GL and Harrison SC (1995) Structure of the NF-kappa B p50 homodimer bound to DNA. Nature 373:311-7. doi: 10.1038/373311a0

14. Ahn KS and Aggarwal BB (2005) Transcription factor NF-kappaB: a sensor for smoke and stress signals. Ann N Y Acad Sci 1056:218-33. doi: 10.1196/annals.1352.026

15. Sethi G, Sung B and Aggarwal BB (2008) Nuclear factor-kappaB activation: from bench to bedside. Exp Biol Med (Maywood) 233:21-31. doi: 10.3181/0707-MR-196

16. Sun SC and Ley SC (2008) New insights into NF-kappaB regulation and function. Trends Immunol 29:469-78. doi: 10.1016/j.it.2008.07.003

17. Shih VF, Tsui R, Caldwell A and Hoffmann A (2011) A single NFkappaB system for both canonical and non-canonical signaling. Cell Res 21:86-102. doi: 10.1038/cr.2010.161

18. Sun SC (2011) Non-canonical NF-kappaB signaling pathway. Cell Res 21:71-85. doi: 10.1038/cr.2010.177

19. Dejardin E (2006) The alternative NF-kappaB pathway from biochemistry to biology: pitfalls and promises for future drug development. Biochem Pharmacol 72:1161-79. doi: 10.1016/j.bcp.2006.08.007 
20. Hatada EN, Krappmann D and Scheidereit C (2000) NF-kappaB and the innate immune response. Curr Opin Immunol 12:52-8.

21. Bonizzi G and Karin M (2004) The two NF-kappaB activation pathways and their role in innate and adaptive immunity. Trends Immunol 25:280-8. doi: 10.1016/j.it.2004.03.008

22. Ghosh S, May MJ and Kopp EB (1998) NF-kappa B and Rel proteins: evolutionarily conserved mediators of immune responses. Annu Rev Immunol 16:225-60. doi: 10.1146/annurev.immunol.16.1.225

23. Grossmann M, O'Reilly LA, Gugasyan R, Strasser A, Adams JM and Gerondakis S (2000) The anti-apoptotic activities of Rel and RelA required during B-cell maturation involve the regulation of Bcl-2 expression. EMBO J 19:6351-60. doi: 10.1093/emboj/19.23.6351

24. Dejardin E, Droin NM, Delhase M, Haas E, Cao Y, Makris C, Li ZW, Karin M, Ware CF and Green DR (2002) The lymphotoxin-beta receptor induces different patterns of gene expression via two NF-kappaB pathways. Immunity 17:525-35.

25. Muppidi JR, Tschopp J and Siegel RM (2004) Life and death decisions: secondary complexes and lipid rafts in TNF receptor family signal transduction. Immunity 21:461-5. doi: 10.1016/j.immuni.2004.10.001

26. O'Neill L (2000) The Toll/interleukin-1 receptor domain: a molecular switch for inflammation and host defence. Biochem Soc Trans 28:557-63.

27. Medzhitov R (2001) Toll-like receptors and innate immunity. Nat Rev Immunol 1:13545. doi: $10.1038 / 35100529$

28. Ghosh S and Karin M (2002) Missing pieces in the NF-kappaB puzzle. Cell 109 Suppl:S81-96.

29. Rothwarf DM and Karin M (1999) The NF-kappa B activation pathway: a paradigm in information transfer from membrane to nucleus. Sci STKE 1999:RE1. doi: 10.1126/stke.1999.5.re1

30. Makris C, Roberts JL and Karin M (2002) The carboxyl-terminal region of IkappaB kinase gamma (IKKgamma) is required for full IKK activation. Mol Cell Biol 22:6573-81.

31. Yamaoka S, Courtois G, Bessia C, Whiteside ST, Weil R, Agou F, Kirk HE, Kay RJ and Israel A (1998) Complementation cloning of NEMO, a component of the IkappaB kinase complex essential for NF-kappaB activation. Cell 93:1231-40.

32. Rothwarf DM, Zandi E, Natoli G and Karin M (1998) IKK-gamma is an essential regulatory subunit of the IkappaB kinase complex. Nature 395:297-300. doi: 10.1038/26261

33. Li ZW, Chu W, Hu Y, Delhase M, Deerinck T, Ellisman M, Johnson R and Karin M (1999) The IKKbeta subunit of IkappaB kinase (IKK) is essential for nuclear factor kappaB activation and prevention of apoptosis. J Exp Med 189:1839-45.

34. Hu Y, Baud V, Delhase M, Zhang P, Deerinck T, Ellisman M, Johnson R and Karin M (1999) Abnormal morphogenesis but intact IKK activation in mice lacking the IKKalpha subunit of IkappaB kinase. Science 284:316-20.

35. Lawrence T, Bebien M, Liu GY, Nizet V and Karin M (2005) IKKalpha limits macrophage NF-kappaB activation and contributes to the resolution of inflammation. Nature 434:1138-43. doi: 10.1038/nature03491

36. Sil AK, Maeda S, Sano Y, Roop DR and Karin M (2004) IkappaB kinase-alpha acts in the epidermis to control skeletal and craniofacial morphogenesis. Nature 428:660-4. doi: $10.1038 /$ nature 02421 
37. Hu Y, Baud V, Oga T, Kim KI, Yoshida K and Karin M (2001) IKKalpha controls formation of the epidermis independently of NF-kappaB. Nature 410:710-4. doi: $10.1038 / 35070605$

38. Senftleben U, Li ZW, Baud V and Karin M (2001) IKKbeta is essential for protecting T cells from TNFalpha-induced apoptosis. Immunity 14:217-30.

39. Ruland J, Duncan GS, Elia A, del Barco Barrantes I, Nguyen L, Plyte S, Millar DG, Bouchard D, Wakeham A, Ohashi PS and Mak TW (2001) Bcl10 is a positive regulator of antigen receptor-induced activation of NF-kappaB and neural tube closure. Cell 104:33-42.

40. Hsu LC, Park JM, Zhang K, Luo JL, Maeda S, Kaufman RJ, Eckmann L, Guiney DG and Karin M (2004) The protein kinase PKR is required for macrophage apoptosis after activation of Toll-like receptor 4. Nature 428:341-5. doi: 10.1038/nature02405

41. Voll RE, Jimi E, Phillips RJ, Barber DF, Rincon M, Hayday AC, Flavell RA and Ghosh S (2000) NF-kappa B activation by the pre-T cell receptor serves as a selective survival signal in T lymphocyte development. Immunity 13:677-89.

42. Sakurai H, Chiba H, Miyoshi H, Sugita T and Toriumi W (1999) IkappaB kinases phosphorylate NF-kappaB p65 subunit on serine 536 in the transactivation domain. J Biol Chem 274:30353-6.

43. Yang F, Tang E, Guan K and Wang CY (2003) IKK beta plays an essential role in the phosphorylation of RelA/p65 on serine 536 induced by lipopolysaccharide. J Immunol 170:56305 .

44. Sakurai H, Suzuki S, Kawasaki N, Nakano H, Okazaki T, Chino A, Doi T and Saiki I (2003) Tumor necrosis factor-alpha-induced IKK phosphorylation of NF-kappaB p65 on serine 536 is mediated through the TRAF2, TRAF5, and TAK1 signaling pathway. J Biol Chem 278:36916-23. doi: 10.1074/jbc.M301598200

45. Lewander A, Gao J, Carstensen J, Arbman G, Zhang H and Sun XF (2012) NF-kappaB p65 phosphorylated at serine-536 is an independent prognostic factor in Swedish colorectal cancer patients. Int J Colorectal Dis 27:447-52. doi: 10.1007/s00384-011-1356-8

46. Lewander A, Gao J, Adell G, Zhang H and Sun XF (2011) Expression of NF-kappaB p65 phosphorylated at serine-536 in rectal cancer with or without preoperative radiotherapy. Radiol Oncol 45:279-84. doi: 10.2478/v10019-011-0030-7

47. Guan H, Zhang H, Cai J, Wu J, Yuan J, Li J, Huang Z and Li M (2011) IKBKE is overexpressed in glioma and contributes to resistance of glioma cells to apoptosis via activating NFkappaB. J Pathol 223:436-45. doi: 10.1002/path.2815

48. Adli M and Baldwin AS (2006) IKK-i/IKKepsilon controls constitutive, cancer cellassociated NF-kappaB activity via regulation of Ser-536 p65/RelA phosphorylation. J Biol Chem 281:26976-84. doi: M603133200 [pii]

10.1074/jbc.M603133200

49. Kravchenko VV, Mathison JC, Schwamborn K, Mercurio F and Ulevitch RJ (2003) IKKi/IKKepsilon plays a key role in integrating signals induced by pro-inflammatory stimuli. J Biol Chem 278:26612-9. doi: 10.1074/jbc.M303001200

50. Verhelst K, Verstrepen L, Carpentier I and Beyaert R (2013) IkappaB kinase epsilon (IKKepsilon): a therapeutic target in inflammation and cancer. Biochem Pharmacol 85:873-80. doi: 10.1016/j.bcp.2013.01.007

51. Qin B and Cheng K (2010) Silencing of the IKKepsilon gene by siRNA inhibits invasiveness and growth of breast cancer cells. Breast Cancer Res 12:R74. doi: 10.1186/bcr2644 
52. Dolcet X, Llobet D, Pallares J and Matias-Guiu X (2005) NF-kB in development and progression of human cancer. Virchows Arch 446:475-82. doi: 10.1007/s00428-005-1264-9

53. Candido J and Hagemann T (2013) Cancer-related inflammation. J Clin Immunol 33 Suppl 1:S79-84. doi: 10.1007/s10875-012-9847-0

54. Sovak MA, Bellas RE, Kim DW, Zanieski GJ, Rogers AE, Traish AM and Sonenshein GE (1997) Aberrant nuclear factor-kappaB/Rel expression and the pathogenesis of breast cancer. J Clin Invest 100:2952-60. doi: 10.1172/JCI119848

55. Dejardin E, Deregowski V, Chapelier M, Jacobs N, Gielen J, Merville MP and Bours V (1999) Regulation of NF-kappaB activity by I kappaB-related proteins in adenocarcinoma cells. Oncogene 18:2567-77. doi: 10.1038/sj.onc.1202599

56. Wang W, Abbruzzese JL, Evans DB, Larry L, Cleary KR and Chiao PJ (1999) The nuclear factor-kappa B RelA transcription factor is constitutively activated in human pancreatic adenocarcinoma cells. Clin Cancer Res 5:119-27.

57. Visconti R, Cerutti J, Battista S, Fedele M, Trapasso F, Zeki K, Miano MP, de Nigris F, Casalino L, Curcio F, Santoro M and Fusco A (1997) Expression of the neoplastic phenotype by human thyroid carcinoma cell lines requires NFkappaB p65 protein expression. Oncogene 15:1987-94. doi: 10.1038/sj.onc.1201373

58. Devalaraja MN, Wang DZ, Ballard DW and Richmond A (1999) Elevated constitutive IkappaB kinase activity and IkappaB-alpha phosphorylation in Hs294T melanoma cells lead to increased basal MGSA/GRO-alpha transcription. Cancer Res 59:1372-7.

59. Gilmore TD and Gerondakis S (2011) The c-Rel Transcription Factor in Development and Disease. Genes Cancer 2:695-711. doi: 10.1177/1947601911421925

60. Cabannes E, Khan G, Aillet F, Jarrett RF and Hay RT (1999) Mutations in the IkBa gene in Hodgkin's disease suggest a tumour suppressor role for IkappaBalpha. Oncogene 18:3063-70. doi: 10.1038/sj.onc. 1202893

61. Krappmann D, Emmerich F, Kordes U, Scharschmidt E, Dorken B and Scheidereit C (1999) Molecular mechanisms of constitutive NF-kappaB/Rel activation in Hodgkin/ReedSternberg cells. Oncogene 18:943-53. doi: 10.1038/sj.onc.1202351

62. Emmerich F, Theurich S, Hummel M, Haeffker A, Vry MS, Dohner K, Bommert K, Stein H and Dorken B (2003) Inactivating I kappa B epsilon mutations in Hodgkin/ReedSternberg cells. J Pathol 201:413-20. doi: 10.1002/path.1454

63. Finco TS, Westwick JK, Norris JL, Beg AA, Der CJ and Baldwin AS, Jr. (1997) Oncogenic Ha-Ras-induced signaling activates NF-kappaB transcriptional activity, which is required for cellular transformation. J Biol Chem 272:24113-6.

64. Baumann B, Weber CK, Troppmair J, Whiteside S, Israel A, Rapp UR and Wirth T (2000) Raf induces NF-kappaB by membrane shuttle kinase MEKK1, a signaling pathway critical for transformation. Proc Natl Acad Sci U S A 97:4615-20. doi: 10.1073/pnas.080583397

65. Pianetti S, Arsura M, Romieu-Mourez R, Coffey RJ and Sonenshein GE (2001) Her2/neu overexpression induces NF-kappaB via a PI3-kinase/Akt pathway involving calpainmediated degradation of IkappaB-alpha that can be inhibited by the tumor suppressor PTEN. Oncogene 20:1287-99. doi: 10.1038/sj.onc.1204257

66. Biswas DK and Iglehart JD (2006) Linkage between EGFR family receptors and nuclear factor kappaB (NF-kappaB) signaling in breast cancer. J Cell Physiol 209:645-52. doi: 10.1002/jcp.20785

67. Singh S, Shi Q, Bailey ST, Palczewski MJ, Pardee AB, Iglehart JD and Biswas DK (2007) Nuclear factor-kappaB activation: a molecular therapeutic target for estrogen receptor- 
negative and epidermal growth factor receptor family receptor-positive human breast cancer. Mol Cancer Ther 6:1973-82. doi: 10.1158/1535-7163.MCT-07-0063

68. Biswas DK, Cruz AP, Gansberger E and Pardee AB (2000) Epidermal growth factorinduced nuclear factor kappa B activation: A major pathway of cell-cycle progression in estrogen-receptor negative breast cancer cells. Proc Natl Acad Sci U S A 97:8542-7.

69. Micheau O, Lens S, Gaide O, Alevizopoulos K and Tschopp J (2001) NF-kappaB signals induce the expression of c-FLIP. Mol Cell Biol 21:5299-305. doi: 10.1128/MCB.21.16.52995305.2001

70. Chen C, Edelstein LC and Gelinas C (2000) The Rel/NF-kappaB family directly activates expression of the apoptosis inhibitor Bcl-x(L). Mol Cell Biol 20:2687-95.

71. Karin M (2006) Nuclear factor-kappaB in cancer development and progression. Nature 441:431-6. doi: 10.1038/nature04870

72. Karin M and Greten FR (2005) NF-kappaB: linking inflammation and immunity to cancer development and progression. Nat Rev Immunol 5:749-59. doi: 10.1038/nri1703

73. Dong R, Wang Q, He XL, Chu YK, Lu JG and Ma QJ (2007) Role of nuclear factor kappa $\mathrm{B}$ and reactive oxygen species in the tumor necrosis factor-alpha-induced epithelialmesenchymal transition of MCF-7 cells. Braz J Med Biol Res 40:1071-8.

74. Wang Z, Li Y and Sarkar FH (2010) Signaling mechanism(s) of reactive oxygen species in Epithelial-Mesenchymal Transition reminiscent of cancer stem cells in tumor progression. Curr Stem Cell Res Ther 5:74-80.

75. Hamaguchi M, Meth JL, von Klitzing C, Wei W, Esposito D, Rodgers L, Walsh T, Welcsh P, King MC and Wigler MH (2002) DBC2, a candidate for a tumor suppressor gene involved in breast cancer. Proc Natl Acad Sci U S A 99:13647-52. doi: 10.1073/pnas.212516099

76. Lopez-Beltran A, Alvarez-Kindelan J, Luque RJ, Blanca A, Quintero A, Montironi R, Cheng L, Gonzalez-Campora R and Requena MJ (2008) Loss of heterozygosity at 9q32-33 (DBC1 locus) in primary non-invasive papillary urothelial neoplasm of low malignant potential and low-grade urothelial carcinoma of the bladder and their associated normal urothelium. $\mathbf{J}$ Pathol 215:263-72. doi: 10.1002/path.2353

77. Kim JE, Chen J and Lou Z (2009) p30 DBC is a potential regulator of tumorigenesis. Cell Cycle 8. doi: 9473 [pii]

78. Kim JE and Sung S (2010) Deleted in breast cancer 1 (DBC1) is a dynamically regulated protein. Neoplasma 57:365-8.

79. Kim JE, Chen $\mathrm{J}$ and Lou Z (2008) DBC1 is a negative regulator of SIRT1. Nature 451:583-6. doi: 10.1038/nature06500

80. Anantharaman V and Aravind L (2008) Analysis of DBC1 and its homologs suggests a potential mechanism for regulation of sirtuin domain deacetylases by NAD metabolites. Cell Cycle 7:1467-72.

81. Rahman S and Islam R (2011) Mammalian Sirt1: insights on its biological functions. Cell Commun Signal 9:11. doi: 10.1186/1478-811X-9-11

82. Sundararajan R, Chen G, Mukherjee C and White E (2005) Caspase-dependent processing activates the proapoptotic activity of deleted in breast cancer-1 during tumor necrosis factor-alpha-mediated death signaling. Oncogene 24:4908-20. doi: 10.1038/sj.onc. 1208681

83. Zannini L, Buscemi G, Kim JE, Fontanella E and Delia D DBC1 phosphorylation by ATM/ATR inhibits SIRT1 deacetylase in response to DNA damage. J Mol Cell Biol 4:294-303. doi: mjs035 [pii]

10.1093/jmcb/mjs035 
84. Zhao W, Kruse JP, Tang Y, Jung SY, Qin J and Gu W (2008) Negative regulation of the deacetylase SIRT1 by DBC1. Nature 451:587-90. doi: 10.1038/nature06515

85. Raynes R, Pombier KM, Nguyen K, Brunquell J, Mendez JE and Westerheide SD (2013) The SIRT1 modulators AROS and DBC1 regulate HSF1 activity and the heat shock response. PLoS One 8:e54364. doi: 10.1371/journal.pone.0054364

86. Close P, East P, Dirac-Svejstrup AB, Hartmann H, Heron M, Maslen S, Chariot A, Soding J, Skehel M and Svejstrup JQ DBIRD complex integrates alternative mRNA splicing with RNA polymerase II transcript elongation. Nature 484:386-9. doi: nature10925 [pii] 10.1038/nature10925

87. Zhang LJ, Liu X, Gafken PR, Kioussi C and Leid M (2009) A chicken ovalbumin upstream promoter transcription factor I (COUP-TFI) complex represses expression of the gene encoding tumor necrosis factor alpha-induced protein 8 (TNFAIP8). J Biol Chem 284:6156-68. doi: 10.1074/jbc.M807713200

88. Yu EJ, Kim SH, Heo K, Ou CY, Stallcup MR and Kim JH Reciprocal roles of DBC1 and SIRT1 in regulating estrogen receptor alpha activity and co-activator synergy. Nucleic Acids Res 39:6932-43. doi: gkr347 [pii]

10.1093/nar/gkr347

89. Escande C, Chini CC, Nin V, Dykhouse KM, Novak CM, Levine J, van Deursen J, Gores GJ, Chen J, Lou Z and Chini EN Deleted in breast cancer-1 regulates SIRT1 activity and contributes to high-fat diet-induced liver steatosis in mice. J Clin Invest 120:545-58. doi: 39319 [pii]

10.1172/JCI39319

90. Kim SH, Kim JH, Yu EJ, Lee KW and Park CK (2012) The overexpression of DBC1 in esophageal squamous cell carcinoma correlates with poor prognosis. Histol Histopathol 27:4958.

91. Cha EJ, Noh SJ, Kwon KS, Kim CY, Park BH, Park HS, Lee H, Chung MJ, Kang MJ, Lee DG, Moon WS and Jang KY (2009) Expression of DBC1 and SIRT1 is associated with poor prognosis of gastric carcinoma. Clin Cancer Res 15:4453-9. doi: 1078-0432.CCR-08-3329 [pii] 10.1158/1078-0432.CCR-08-3329

92. Zhang Y, Gu Y, Sha S, Kong X, Zhu H, Xu B, Li Y and Wu K DBC1 is over-expressed and associated with poor prognosis in colorectal cancer. Int J Clin Oncol. doi: 10.1007/s10147012-0506-5

93. Lee H, Kim KR, Noh SJ, Park HS, Kwon KS, Park BH, Jung SH, Youn HJ, Lee BK, Chung MJ, Koh DH, Moon WS and Jang KY Expression of DBC1 and SIRT1 is associated with poor prognosis for breast carcinoma. Hum Pathol 42:204-13. doi: S0046-8177(10)00248-0 [pii] 10.1016/j.humpath.2010.05.023

94. Hiraike H, Wada-Hiraike O, Nakagawa S, Saji S, Maeda D, Miyamoto Y, Sone K, Tanikawa M, Oda K, Nakagawa K, Yano T, Fukayama M and Taketani Y (2011) Expression of DBC1 is associated with nuclear grade and HER2 expression in breast cancer. Exp Ther Med 2:1105-1109. doi: 10.3892/etm.2011.333

95. Zhang Y, Gu Y, Sha S, Kong X, Zhu H, Xu B, Li Y and Wu K (2013) DBC1 is overexpressed and associated with poor prognosis in colorectal cancer. Int $\mathrm{J}$ Clin Oncol. doi: 10.1007/s10147-012-0506-5

96. Lee H, Kim KR, Noh SJ, Park HS, Kwon KS, Park BH, Jung SH, Youn HJ, Lee BK, Chung MJ, Koh DH, Moon WS and Jang KY (2011) Expression of DBC1 and SIRT1 is 
associated with poor prognosis for breast carcinoma. Hum Pathol 42:204-13. doi: 10.1016/j.humpath.2010.05.023

97. Chini CC, Escande C, Nin V and Chini EN (2010) HDAC3 is negatively regulated by the nuclear protein DBC1. J Biol Chem 285:40830-7. doi: 10.1074/jbc.M110.153270

98. Glaser KB, Li J, Staver MJ, Wei RQ, Albert DH and Davidsen SK (2003) Role of class I and class II histone deacetylases in carcinoma cells using siRNA. Biochem Biophys Res Commun 310:529-36.

99. Bolden JE, Shi W, Jankowski K, Kan CY, Cluse L, Martin BP, MacKenzie KL, Smyth GK and Johnstone RW (2013) HDAC inhibitors induce tumor-cell-selective pro-apoptotic transcriptional responses. Cell Death Dis 4:e519. doi: 10.1038/cddis.2013.9

100. Kabra N, Li Z, Chen L, Li B, Zhang X, Wang C, Yeatman T, Coppola D and Chen J (2009) SirT1 is an inhibitor of proliferation and tumor formation in colon cancer. J Biol Chem 284:18210-7. doi: 10.1074/jbc.M109.000034

101. Huffman DM, Grizzle WE, Bamman MM, Kim JS, Eltoum IA, Elgavish A and Nagy TR (2007) SIRT1 is significantly elevated in mouse and human prostate cancer. Cancer Res 67:6612-8. doi: 10.1158/0008-5472.CAN-07-0085

102. Bae HJ, Chang YG, Noh JH, Kim JK, Eun JW, Jung KH, Kim MG, Shen Q, Ahn YM, Kwon SH, Park WS, Lee JY and Nam SW (2012) DBC1 does not function as a negative regulator of SIRT1 in liver cancer. Oncol Lett 4:873-877. doi: 10.3892/ol.2012.875

103. Koyama S, Wada-Hiraike O, Nakagawa S, Tanikawa M, Hiraike H, Miyamoto Y, Sone K, Oda K, Fukuhara H, Nakagawa K, Kato S, Yano T and Taketani Y (2010) Repression of estrogen receptor beta function by putative tumor suppressor DBC1. Biochem Biophys Res Commun 392:357-62. doi: 10.1016/j.bbrc.2010.01.025

104. Fu J, Jiang J, Li J, Wang S, Shi G, Feng Q, White E, Qin J and Wong J (2009) Deleted in breast cancer 1, a novel androgen receptor (AR) coactivator that promotes AR DNA-binding activity. J Biol Chem 284:6832-40. doi: M808988200 [pii]

10.1074/jbc.M808988200

105. Li Z, Chen L, Kabra N, Wang C, Fang J and Chen J (2009) Inhibition of SUV39H1 methyltransferase activity by DBC1. J Biol Chem 284:10361-6. doi: 10.1074/jbc.M900956200

106. Kim W and Kim JE (2013) Deleted in breast cancer 1 (DBC1) deficiency results in apoptosis of breast cancer cells through impaired responses to UV-induced DNA damage. Cancer Lett 333:180-6. doi: 10.1016/j.canlet.2013.01.026

107. Seyfried TN and Mukherjee P (2005) Targeting energy metabolism in brain cancer: review and hypothesis. Nutr Metab (Lond) 2:30. doi: 10.1186/1743-7075-2-30

108. Seyfried TN and Shelton LM (2010) Cancer as a metabolic disease. Nutr Metab (Lond) 7:7. doi: 10.1186/1743-7075-7-7

109. Hardie DG, Ross FA and Hawley SA (2012) AMPK: a nutrient and energy sensor that maintains energy homeostasis. Nat Rev Mol Cell Biol 13:251-62. doi: 10.1038/nrm3311

110. Ng TL, Leprivier G, Robertson MD, Chow C, Martin MJ, Laderoute KR, Davicioni E, Triche TJ and Sorensen PH (2012) The AMPK stress response pathway mediates anoikis resistance through inhibition of mTOR and suppression of protein synthesis. Cell Death Differ 19:501-10. doi: 10.1038/cdd.2011.119

111. Joseph RR, Yazer E, Hanakawa Y and Stadnyk AW (2005) Prostaglandins and activation of AC/cAMP prevents anoikis in IEC-18. Apoptosis 10:1221-33. doi: 10.1007/s10495-005-2049$\mathrm{y}$ 
112. Jiang G and Zhang BB (2003) Glucagon and regulation of glucose metabolism. Am J Physiol Endocrinol Metab 284:E671-8. doi: 10.1152/ajpendo.00492.2002

113. Nin V, Escande C, Chini CC, Giri S, Camacho-Pereira J, Matalonga J, Lou Z and Chini EN Role of deleted in breast cancer 1 (DBC1) protein in SIRT1 deacetylase activation induced by protein kinase A and AMP-activated protein kinase. J Biol Chem 287:23489-501. doi: M112.365874 [pii] 10.1074/jbc.M112.365874

114. Menssen A, Hydbring P, Kapelle K, Vervoorts J, Diebold J, Luscher B, Larsson LG and Hermeking H (2012) The c-MYC oncoprotein, the NAMPT enzyme, the SIRT1-inhibitor DBC1, and the SIRT1 deacetylase form a positive feedback loop. Proc Natl Acad Sci U S A 109:E18796. doi: 10.1073/pnas.1105304109

115. Yuan J, Minter-Dykhouse K and Lou Z (2009) A c-Myc-SIRT1 feedback loop regulates cell growth and transformation. J Cell Biol 185:203-11. doi: 10.1083/jcb.200809167

116. Frisch SM and Screaton RA (2001) Anoikis mechanisms. Curr Opin Cell Biol 13:555-62. doi: S0955-0674(00)00251-9 [pii]

117. Simpson CD, Anyiwe K and Schimmer AD (2008) Anoikis resistance and tumor metastasis. Cancer Lett 272:177-85. doi: S0304-3835(08)00394-7 [pii]

10.1016/j.canlet.2008.05.029

118. Frisch SM, Schaller M and Cieply B (2013) Mechanisms that link the oncogenic epithelial-mesenchymal transition

to suppression of anoikis. J Cell Sci xxx:xxx.

119. Zhong $X$ and Rescorla FJ Cell surface adhesion molecules and adhesion-initiated signaling: understanding of anoikis resistance mechanisms and therapeutic opportunities. Cell Signal 24:393-401. doi: S0898-6568(11)00333-0 [pii]

10.1016/j.cellsig.2011.10.005

120. Frisch SM and Ruoslahti E (1997) Integrins and anoikis. Curr Opin Cell Biol 9:701-6. doi: S0955-0674(97)80124-X [pii]

121. Persad S, Attwell S, Gray V, Mawji N, Deng JT, Leung D, Yan J, Sanghera J, Walsh MP and Dedhar S (2001) Regulation of protein kinase B/Akt-serine 473 phosphorylation by integrinlinked kinase: critical roles for kinase activity and amino acids arginine 211 and serine 343. J Biol Chem 276:27462-9. doi: 10.1074/jbc.M102940200

122. Giannoni E, Buricchi F, Grimaldi G, Parri M, Cialdai F, Taddei ML, Raugei G, Ramponi $\mathrm{G}$ and Chiarugi P (2008) Redox regulation of anoikis: reactive oxygen species as essential mediators of cell survival. Cell Death Differ 15:867-78. doi: 10.1038/cdd.2008.3

123. Schafer ZT, Grassian AR, Song L, Jiang Z, Gerhart-Hines Z, Irie HY, Gao S, Puigserver $P$ and Brugge JS (2009) Antioxidant and oncogene rescue of metabolic defects caused by loss of matrix attachment. Nature 461:109-13. doi: nature08268 [pii]

10.1038 /nature 08268

124. Zhan M, Zhao H and Han ZC (2004) Signalling mechanisms of anoikis. Histol Histopathol 19:973-83.

125. Kim YN, Koo KH, Sung JY, Yun UJ and Kim H (2012) Anoikis resistance: an essential prerequisite for tumor metastasis. Int J Cell Biol 2012:306879. doi: 10.1155/2012/306879

126. Wary KK, Mainiero F, Isakoff SJ, Marcantonio EE and Giancotti FG (1996) The adaptor protein Shc couples a class of integrins to the control of cell cycle progression. Cell 87:733-43. 
127. Rosen K, Coll ML, Li A and Filmus J (2001) Transforming growth factor-alpha prevents detachment-induced inhibition of c-Src kinase activity, Bcl-XL down-regulation, and apoptosis of intestinal epithelial cells. J Biol Chem 276:37273-9. doi: 10.1074/jbc.M106424200

128. Rosen K, Rak J, Leung T, Dean NM, Kerbel RS and Filmus J (2000) Activated Ras prevents downregulation of $\mathrm{Bcl}-\mathrm{X}(\mathrm{L})$ triggered by detachment from the extracellular matrix. A mechanism of Ras-induced resistance to anoikis in intestinal epithelial cells. J Cell Biol 149:44756.

129. Cheng TL, Symons M and Jou TS (2004) Regulation of anoikis by Cdc42 and Rac1. Exp Cell Res 295:497-511. doi: 10.1016/j.yexcr.2004.02.002

130. Coniglio SJ, Jou TS and Symons M (2001) Rac1 protects epithelial cells against anoikis. J Biol Chem 276:28113-20. doi: 10.1074/jbc.M102299200

131. Zugasti O, Rul W, Roux P, Peyssonnaux C, Eychene A, Franke TF, Fort P and Hibner U (2001) Raf-MEK-Erk cascade in anoikis is controlled by Rac1 and Cdc42 via Akt. Mol Cell Biol 21:6706-17.

132. Kouros-Mehr H, Kim JW, Bechis SK and Werb Z (2008) GATA-3 and the regulation of the mammary luminal cell fate. Curr Opin Cell Biol 20:164-70. doi: S0955-0674(08)00028-8 [pii]

10.1016/j.ceb.2008.02.003

133. Cieply B, Riley Pt, Pifer PM, Widmeyer J, Addison JB, Ivanov AV, Denvir J and Frisch SM Suppression of the Epithelial-Mesenchymal Transition by Grainyhead-like-2. Cancer Res 72:2440-53. doi: 0008-5472.CAN-11-4038 [pii]

10.1158/0008-5472.CAN-11-4038

134. Werth M, Walentin K, Aue A, Schonheit J, Wuebken A, Pode-Shakked N, Vilianovitch L, Erdmann B, Dekel B, Bader M, Barasch J, Rosenbauer F, Luft FC and Schmidt-Ott KM The transcription factor grainyhead-like 2 regulates the molecular composition of the epithelial apical junctional complex. Development 137:3835-45. doi: 137/22/3835 [pii]

10.1242/dev.055483

135. Gregory PA, Bert AG, Paterson EL, Barry SC, Tsykin A, Farshid G, Vadas MA, KhewGoodall Y and Goodall GJ (2008) The miR-200 family and miR-205 regulate epithelial to mesenchymal transition by targeting ZEB1 and SIP1. Nat Cell Biol 10:593-601.

136. Warzecha CC, Jiang P, Amirikian K, Dittmar KA, Lu H, Shen S, Guo W, Xing Y and Carstens RP An ESRP-regulated splicing programme is abrogated during the epithelialmesenchymal transition. EMBO J 29:3286-300. doi: emboj2010195 [pii]

10.1038/emboj.2010.195

137. Thiery JP, Acloque H, Huang RY and Nieto MA (2009) Epithelial-mesenchymal transitions in development and disease. Cell 139:871-90. doi: S0092-8674(09)01419-6 [pii]

10.1016/j.cell.2009.11.007

138. Guadamillas MC, Cerezo A and Del Pozo MA Overcoming anoikis--pathways to anchorage-independent growth in cancer. J Cell Sci 124:3189-97. doi: 124/19/3189 [pii]

$10.1242 /$ jcs. 072165

139. Huang J, Wu S, Barrera J, Matthews K and Pan D (2005) The Hippo signaling pathway coordinately regulates cell proliferation and apoptosis by inactivating Yorkie, the Drosophila Homolog of YAP. Cell 122:421-34. doi: 10.1016/j.cell.2005.06.007

140. Varelas X, Samavarchi-Tehrani P, Narimatsu M, Weiss A, Cockburn K, Larsen BG, Rossant J and Wrana JL The Crumbs complex couples cell density sensing to Hippo-dependent control of the TGF-beta-SMAD pathway. Dev Cell 19:831-44. doi: S1534-5807(10)00539-3 [pii] 
10.1016/j.devcel.2010.11.012

141. Humbert PO, Grzeschik NA, Brumby AM, Galea R, Elsum I and Richardson HE (2008) Control of tumourigenesis by the Scribble/Dlg/Lgl polarity module. Oncogene 27:6888-907. doi: onc2008341 [pii]

10.1038/onc.2008.341

142. Cordenonsi M, Zanconato F, Azzolin L, Forcato M, Rosato A, Frasson C, Inui M, Montagner M, Parenti AR, Poletti A, Daidone MG, Dupont S, Basso G, Bicciato S and Piccolo S The Hippo transducer TAZ confers cancer stem cell-related traits on breast cancer cells. Cell 147:759-72. doi: S0092-8674(11)01218-9 [pii]

10.1016/j.cell.2011.09.048

143. Zhan L, Rosenberg A, Bergami KC, Yu M, Xuan Z, Jaffe AB, Allred C and Muthuswamy SK (2008) Deregulation of scribble promotes mammary tumorigenesis and reveals a role for cell polarity in carcinoma. Cell 135:865-78. doi: S0092-8674(08)01238-5 [pii]

10.1016/j.cell.2008.09.045

144. Varelas X, Miller BW, Sopko R, Song S, Gregorieff A, Fellouse FA, Sakuma R, Pawson T, Hunziker W, McNeill H, Wrana JL and Attisano L The Hippo pathway regulates Wnt/betacatenin signaling. Dev Cell 18:579-91. doi: S1534-5807(10)00113-9 [pii]

10.1016/j.devcel.2010.03.007

145. Barrallo-Gimeno A and Nieto MA (2005) The Snail genes as inducers of cell movement and survival: implications in development and cancer. Development 132:3151-61. doi: 132/14/3151 [pii]

10.1242/dev.01907

146. Fontemaggi G, Gurtner A, Strano S, Higashi Y, Sacchi A, Piaggio G and Blandino G (2001) The transcriptional repressor ZEB regulates p73 expression at the crossroad between proliferation and differentiation. Mol Cell Biol 21:8461-70. doi: 10.1128/MCB.21.24.84618470.2001

147. Zhang Y, Yan W, Jung YS and Chen X (2012) Mammary epithelial cell polarity is regulated differentially by p73 isoforms via epithelial-to-mesenchymal transition. J Biol Chem 287:17746-53. doi: 10.1074/jbc.M112.358143

148. Jia J, Zhang W, Liu JY, Chen G, Liu H, Zhong HY, Liu B, Cai Y, Zhang JL and Zhao YF (2012) Epithelial mesenchymal transition is required for acquisition of anoikis resistance and metastatic potential in adenoid cystic carcinoma. PLoS One 7:e51549. doi: 10.1371/journal.pone.0051549

149. Valsesia-Wittmann S, Magdeleine M, Dupasquier S, Garin E, Jallas AC, Combaret V, Krause A, Leissner P and Puisieux A (2004) Oncogenic cooperation between H-Twist and NMyc overrides failsafe programs in cancer cells. Cancer Cell 6:625-30. doi: S1535610804003083 [pii]

10.1016/j.ccr.2004.09.033

150. Evdokimova V, Tognon C, Ng T, Ruzanov P, Melnyk N, Fink D, Sorokin A, Ovchinnikov LP, Davicioni E, Triche TJ and Sorensen PH (2009) Translational activation of snail1 and other developmentally regulated transcription factors by YB-1 promotes an epithelialmesenchymal transition. Cancer Cell 15:402-15. doi: 10.1016/j.ccr.2009.03.017

151. Grooteclaes M, Deveraux Q, Hildebrand J, Zhang Q, Goodman RH and Frisch SM (2003) C-terminal-binding protein corepresses epithelial and proapoptotic gene expression programs. Proc Natl Acad Sci U S A 100:4568-73. 
152. Postigo AA and Dean DC (1999) ZEB represses transcription through interaction with the corepressor CtBP. Proc Natl Acad Sci U S A 96:6683-8.

153. Grooteclaes ML and Frisch SM (2000) Evidence for a function of CtBP in epithelial gene regulation and anoikis. Oncogene 19:3823-8.

154. Paliwal S, Pande S, Kovi RC, Sharpless NE, Bardeesy N and Grossman SR (2006) Targeting of C-terminal binding protein (CtBP) by ARF results in p53-independent apoptosis. Mol Cell Biol 26:2360-72. doi: 26/6/2360 [pii]

10.1128/MCB.26.6.2360-2372.2006

155. Yan SR, Joseph RR, Rosen K, Reginato MJ, Jackson A, Allaire N, Brugge JS, Jobin C and Stadnyk AW (2005) Activation of NF-kappaB following detachment delays apoptosis in intestinal epithelial cells. Oncogene 24:6482-91. doi: 10.1038/sj.onc.1208810

156. Toruner M, Fernandez-Zapico M, Sha JJ, Pham L, Urrutia R and Egan LJ (2006) Antianoikis effect of nuclear factor-kappaB through up-regulated expression of osteoprotegerin, BCL-2, and IAP-1. J Biol Chem 281:8686-96. doi: 10.1074/jbc.M512178200

157. Grivennikov SI, Greten FR and Karin M (2010) Immunity, inflammation, and cancer. Cell 140:883-99. doi: 10.1016/j.cell.2010.01.025

158. Li CW, Xia W, Huo L, Lim SO, Wu Y, Hsu JL, Chao CH, Yamaguchi H, Yang NK, Ding Q, Wang Y, Lai YJ, LaBaff AM, Wu TJ, Lin BR, Yang MH, Hortobagyi GN and Hung MC (2012) Epithelial-mesenchymal transition induced by TNF-alpha requires NF-kappaBmediated transcriptional upregulation of Twist1. Cancer Res 72:1290-300. doi: 10.1158/00085472.CAN-11-3123

159. Mehrotra S, Languino LR, Raskett CM, Mercurio AM, Dohi T and Altieri DC IAP regulation of metastasis. Cancer Cell 17:53-64. doi: S1535-6108(09)00422-X [pii]

10.1016/j.ccr.2009.11.021

160. Shintani Y, Fukumoto Y, Chaika N, Svoboda R, Wheelock MJ and Johnson KR (2008) Collagen I-mediated up-regulation of $\mathrm{N}$-cadherin requires cooperative signals from integrins and discoidin domain receptor 1. J Cell Biol 180:1277-89. doi: jcb.200708137 [pii]

10.1083/jcb.200708137

161. Medici D and Nawshad A (2010) Type I collagen promotes epithelial-mesenchymal transition through ILK-dependent activation of NF-kappaB and LEF-1. Matrix Biol 29:161-5. doi: 10.1016/j.matbio.2009.12.003

162. Wang X, Zheng M, Liu G, Xia W, McKeown-Longo PJ, Hung MC and Zhao J (2007) Kruppel-like factor 8 induces epithelial to mesenchymal transition and epithelial cell invasion. Cancer Res 67:7184-93. doi: 67/15/7184 [pii]

10.1158/0008-5472.CAN-06-4729

163. Wang X, Urvalek AM, Liu J and Zhao J (2008) Activation of KLF8 transcription by focal adhesion kinase in human ovarian epithelial and cancer cells. J Biol Chem 283:13934-42. doi: M709300200 [pii]

10.1074/jbc.M709300200

164. Zhao J, Bian ZC, Yee K, Chen BP, Chien S and Guan JL (2003) Identification of transcription factor KLF8 as a downstream target of focal adhesion kinase in its regulation of cyclin D1 and cell cycle progression. Mol Cell 11:1503-15. doi: S1097276503001795 [pii] 165. Li XY, Zhou X, Rowe RG, Hu Y, Schlaepfer DD, Ilic D, Dressler G, Park A, Guan JL and Weiss SJ (2011) Snaill controls epithelial-mesenchymal lineage commitment in focal adhesion kinase-null embryonic cells. J Cell Biol 195:729-38. doi: 10.1083/jcb.201105103 
166. Cicchini C, Laudadio I, Citarella F, Corazzari M, Steindler C, Conigliaro A, Fantoni A, Amicone L and Tripodi M (2008) TGFbeta-induced EMT requires focal adhesion kinase (FAK) signaling. Exp Cell Res 314:143-52. doi: 10.1016/j.yexcr.2007.09.005

167. Canel M, Serrels A, Miller D, Timpson P, Serrels B, Frame MC and Brunton VG (2010) Quantitative in vivo imaging of the effects of inhibiting integrin signaling via Src and FAK on cancer cell movement: effects on E-cadherin dynamics. Cancer Res 70:9413-22. doi: 10.1158/0008-5472.CAN-10-1454

168. Serrano I, McDonald PC, Lock FE and Dedhar S Role of the integrin-linked kinase (ILK)/Rictor complex in TGFbeta-1-induced epithelial-mesenchymal transition (EMT). Oncogene. doi: onc201230 [pii]

10.1038/onc.2012.30

169. Chen D, Zhang Y, Zhang X, Li J, Han B, Liu S, Wang L, Ling Y, Mao S and Wang X Overexpression of integrin-linked kinase correlates with malignant phenotype in non-small cell lung cancer and promotes lung cancer cell invasion and migration via regulating epithelialmesenchymal transition (EMT)-related genes. Acta Histochem. doi: S0065-1281(12)00076-1 [pii]

10.1016/j.acthis.2012.05.004

170. Sclabas GM, Fujioka S, Schmidt C, Li Z, Frederick WA, Yang W, Yokoi K, Evans DB, Abbruzzese JL, Hess KR, Zhang W, Fidler IJ and Chiao PJ (2005) Overexpression of tropomysin-related kinase B in metastatic human pancreatic cancer cells. Clin Cancer Res 11:440-9.

171. Yu X, Liu L, Cai B, He Y and Wan X (2008) Suppression of anoikis by the neurotrophic receptor TrkB in human ovarian cancer. Cancer Sci 99:543-52. doi: 10.1111/j.13497006.2007.00722.x

172. Smit MA and Peeper DS Zeb1 is required for TrkB-induced epithelial-mesenchymal transition, anoikis resistance and metastasis. Oncogene 30:3735-44. doi: onc201196 [pii]

10.1038/onc.2011.96

173. Smit MA, Geiger TR, Song JY, Gitelman I and Peeper DS (2009) A Twist-Snail axis critical for TrkB-induced epithelial-mesenchymal transition-like transformation, anoikis resistance, and metastasis. Mol Cell Biol 29:3722-37. doi: MCB.01164-08 [pii]

10.1128/MCB.01164-08

174. Douma S, Van Laar T, Zevenhoven J, Meuwissen R, Van Garderen E and Peeper DS (2004) Suppression of anoikis and induction of metastasis by the neurotrophic receptor TrkB. Nature 430:1034-9. doi: 10.1038/nature02765 


\section{CHAPTER 2}

\section{Regulation of anoikis through a novel pathway induced by loss of E-cadherin and EMT}

\section{Part of this chapter was published in:}

Sanjeev Kumar*, Sun Hee Park*, Benjamin Cieply*, Jane Schupp, Elizabeth Killiam, Fan Zhang, David L.Rimm and Steven M. Frisch. (2011) A pathway for the control of anoikis sensitivity by Ecadherin and epithelial-to-mesenchymal transition. Mol Cell Biol. 19:4036-51.

*Co-First authors 


\section{INTRODUCTION}

Anoikis is apoptosis that is induced upon cell-matrix detachment or attachment to inappropriate matrix. While normal epithelial cells are sensitive to anoikis, tumor cells are known to be resistant due to genetic mutations or defects in the signaling pathways leading to constitutive activation of survival signaling and inactivation of the apoptotic pathway [1-5].

The oncogenic epithelial-to-mesenchymal transition (EMT) is critical for tumor development and metastasis $[6,7]$. Decrease in cell adhesion proteins like E-cadherin is the hallmark of EMT. Ecadherin loss induces multiple signaling pathways during EMT which makes cells resistant to anoikis [8]. In fact, downregulation of E-cadherin expression through specific up-regulation of EMT mediating transcriptional factors like ZEB results in induction of EMT, cancer progression, and metastasis $[9,10]$. In addition to ZEB, other oncogenic transcription factors such as Twist and Snail1/2 can also suppress anoikis both by regulating apoptosis control genes and by suppressing E-cadherin expression [11, 12].

Onder et al. showed that stable knock down of E-cadherin regulates anoikis through decreased phosphorylation of $\beta$-catenin, which results in activation of Wnt signaling [13]. In this study, a novel molecular mechanism in which E-cadherin regulates anoikis sensitivity through Ankyrin-GNRAGE-TBX2 pathway is investigated.

NRAGE (Neutrophin Receptor-interacting MAGE protein), also known as MAGE D-1, is a type II MAGE (melanoma antigen) protein which is broadly expressed in embryonic and adult somatic tissues [14]. NRAGE is known to function in various cellular process such as Dlx/Msx mediated 
transcription, cell cycle progression and myogenic differentiation $[14,15]$. MAGE family members share a highly conserved MAGE homology domain that interacts with various membrane proteins such as p75 neurotrophin receptor and Unc5 netrin receptor to facilitate apoptosis $[16$, 17]. The fact that NRAGE mediates p38 activation and neural progenitor apoptosis, and NRAGE knockout mice have a developmental defect in brain neuronal apoptosis, supports NRAGE as a pro-apoptotic factor $[18,19]$. Nevertheless, NRAGE is shown to be overexpressed in several cancers such as head and neck, lung, and kidney cancers [20-22]. In addition, quantitative RTPCR and quantitative immunofluorescence data showed that NRAGE is overexpressed in breast, lung, colorectal, and metastatic skin cancers [23]. Moreover, NRAGE expression was induced by EMT mediated by Twist and depletion of E-cadherin in Human mammary epithelial cells (HMLE) [23]. However, the molecular mechanism of NRAGE as a pro-tumorigenic factor has not been well studied. It has been shown that MAGE domain of NRAGE directly interacts with UPA (Unc5-PIDD-ankyrin) component of supermodule [23, 24]. NRAGE localization is regulated by Ankyrin-G: NRAGE is sequestered in cytoplasm in normal epithelial cells that express AnkyrinG whereas NRAGE mainly localizes in nucleus in cells that have undergone EMT, thus downregulating ankyrin-G, or cells that have depleted level of Ankyrin-G by siRNAs [23].

TBX2 is a member of the T-Box (TBX) family of transcriptional repressor proteins that are known to regulate embryonic development, cell cycle progression, senescence and apoptosis. In addition, TBX2 has been implicated in tumor development through downregulating the p14ARF (Alternative reading frame) tumor suppressor, which is frequently mutated in human carcinomas and promotes apoptosis through p53 dependent and independent, c-Myc and CtBP signaling pathways [25-28]. In fact, TBX2 is known to be overexpressed in melanomas, breast, bladder, 
and pancreatic cancers [25, 29-31]. TBX2 promoted anchorage independent survival which was independent of p53 in SW13 cells [32]. However, the role of TBX2 or p14ARF in anoikis regulation has not been previously studied.

In this chapter, we will demonstrate that during oncogenic EMT, cytoplasmic NRAGE localized to the nucleus and interacted with TBX2 to co-repress p14ARF conferring anoikis resistance.

\section{MATERIALS AND METHODS}

All materials and methods for this chapter have been published elsewhere [33].

\section{RESULTS}

The loss of the cell-cell adhesion protein E-cadherin through transduction with shRNA directed against this molecule has been associated with induction of the oncogenic epithelial to mesenchymal transition (EMT) in normal human mammary epithelial cells (HMLE) which are immortalized with SV40 T antigen and telomerase [34]. Likewise in these HMLE cells, ectopic expression of Twist, a known cellular repressor of E-cadherin, has been shown to promote this

\begin{abstract}
EMT process [34]. A significant resistance to the cell death phenomenon known as anoikis has been associated with this oncogenic
\end{abstract} EMT. We have confirmed these findings, both in the context

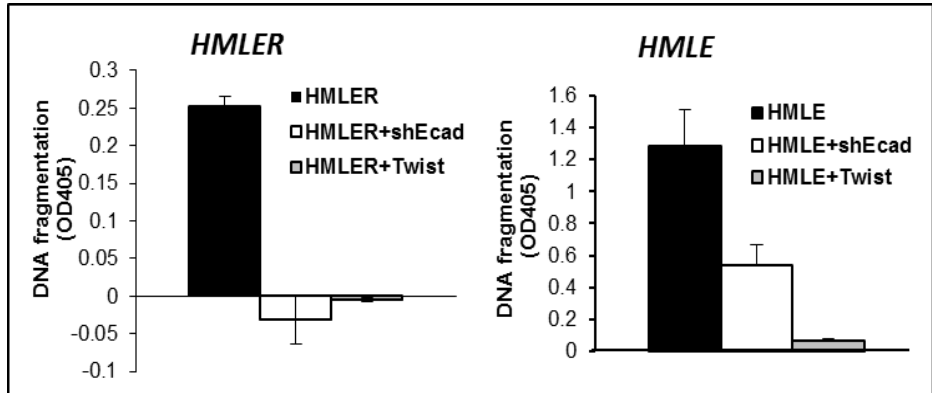

Figure 1. EMT protects cells against anoikis. HMLER or HMLE cell lines expressing either Twist or E-cadherin shRNA were assayed for anoikis at $6 \mathrm{hr}$ of suspension and cell lysates were analyzed for DNA fragmentation.

mentioned before as well as in both "HMLER cells," [13] a cell line expressing activated RAS, as well as in cell lines expressing other EMT associated genes (Fig. 1). Expression of a mouse 
"shRNA-resistant" form of E-cadherin (Fig. 2), was shown to ameliorate the effect that E-cadherin

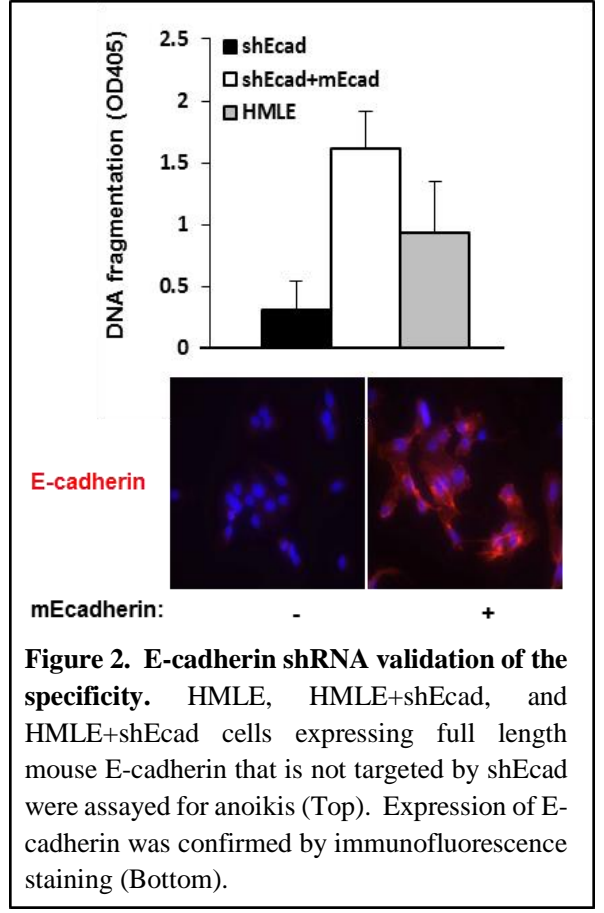

loss has on anoikis resistance, and in effect, confirming the specificity of the E-cadherin knockdown.

Ankyrin-G is known to co-localizes with E-cadherin [34], suggesting that ankyrin-G participates in E-cadherin signaling. Ankyrin-G expression is downregulated in claudinlow subclass of breast cancer tumors which suggest that Ankyrin-G is regulated with EMT [23, 35]. In fact, experimental induction of EMT suppressed Ankyrin-G expression [23]. Functionally, overexpression of Ank $\triangle \mathrm{MBD}-\mathrm{CAAX}$ (smaller version of ankyrin-G made by deleting $\mathrm{N}$-terminal membrane binding domain containing a C-terminal CAAX box that leads to membrane localization) resulted in sensitization of HMLE+shEcad cells to anoikis (Fig. 3 and 4). These results indicate that loss of Ankyrin$\mathrm{G}$ in context of human cancer and EMT may be understood in terms of

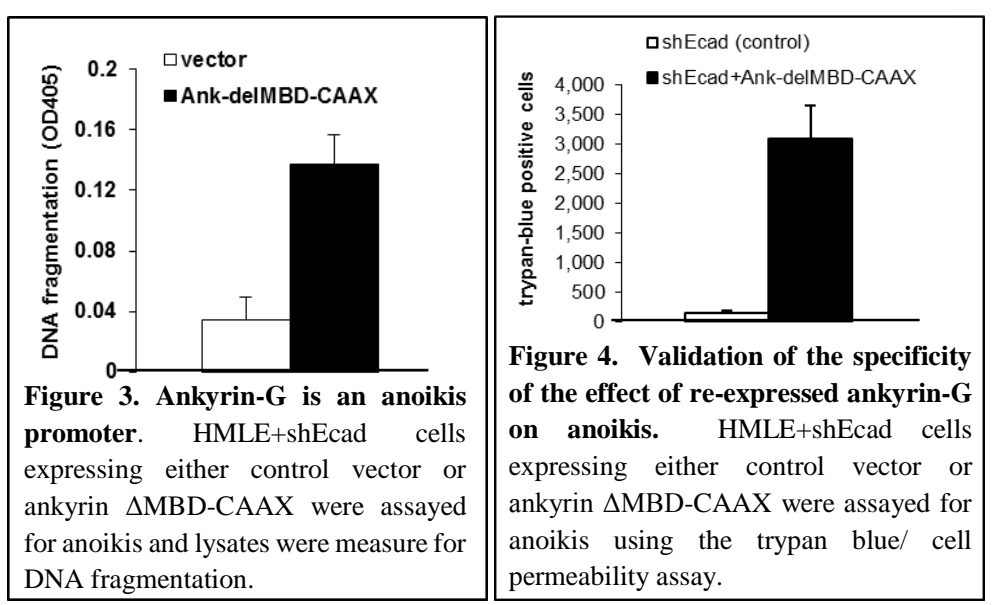
a cell survival effect.

Ankyrin-G regulated the localization of NRAGE through direct interaction, suggesting that the interaction between Ankyrin-G and NRAGE is functionally significant, because NRAGE interacts with both receptors and transcription factors. The potential role of NRAGE in anoikis was tested by depleting it in cells that had undergone EMT such as HMLE+shEcad and HMLE+Twist cells. 
The cell lines that have transiently transfected with NRAGE siRNAs became significantly more sensitive to anoikis (Fig. 5 and 6). Consistent effect of NRAGE on suppressing anoikis was also
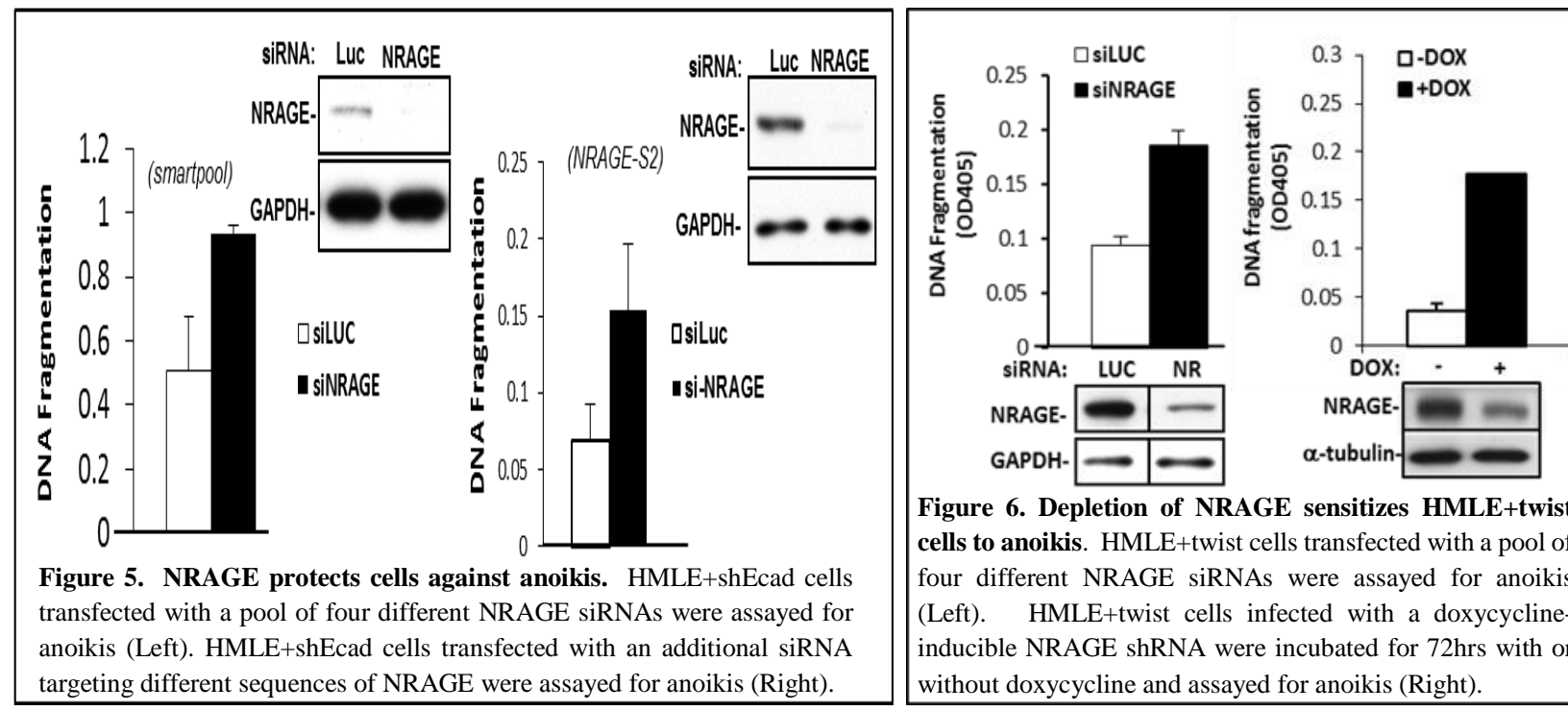

Figure 6. Depletion of NRAGE sensitizes HMLE+twist cells to anoikis. HMLE+twist cells transfected with a pool of four different NRAGE siRNAs were assayed for anoikis (Left). HMLE+twist cells infected with a doxycyclineinducible NRAGE shRNA were incubated for $72 \mathrm{hrs}$ with or without doxycycline and assayed for anoikis (Right).

shown both in the lung and breast carcinoma cells, NCI-H1299 and MDA-MB-435 respectively

(Fig. 7). In addition, depletion of NRAGE in MDA-MB-435 cells decreased formation of anchorage-independent colony formation (Fig. 7).

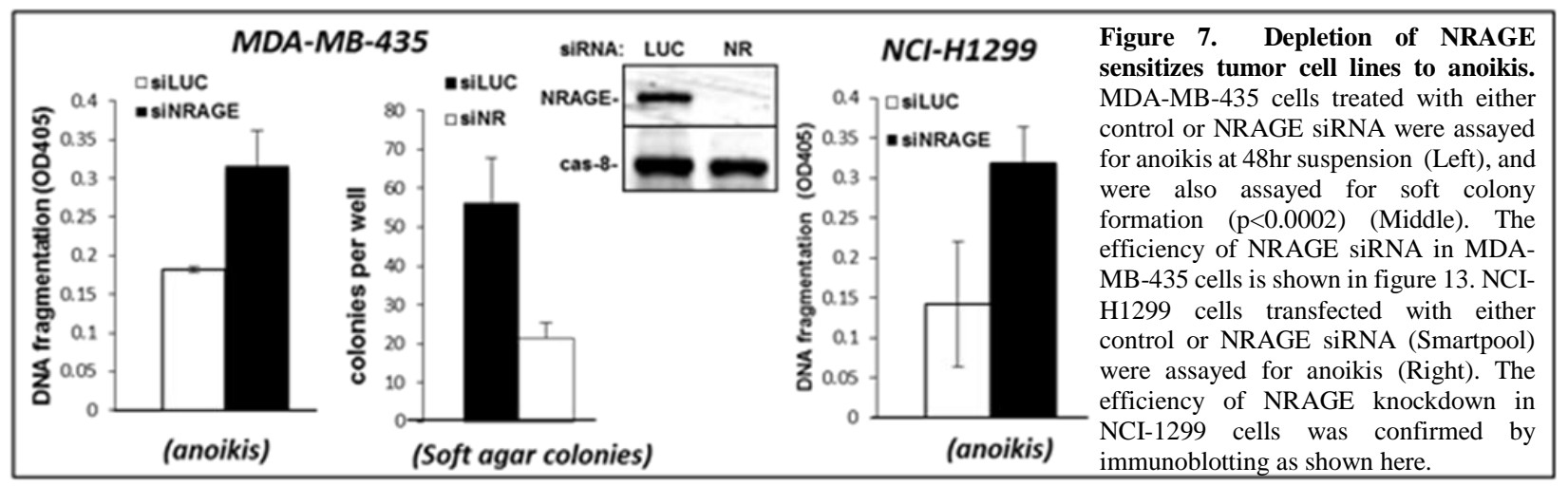

To investigate how NRAGE suppressed anoikis, a yeast two-hybrid interaction was performed

[23]. Among the several candidate proteins that were identified, TBX2, was investigated. The interaction between TBX2 and NRAGE was confirmed by immunoprecipitating endogenous NRAGE from HMLE+shEcad cell lysates (Fig. 8). 


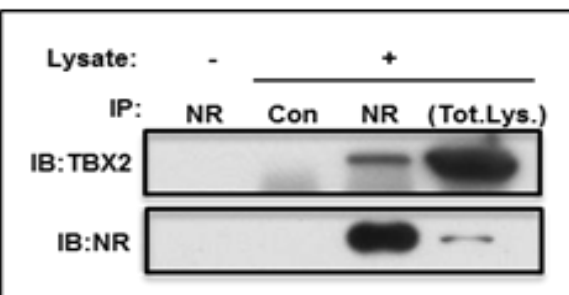

Figure 8. TBX2 and NRAGE endogenous interaction. HMLE+shEcad cells were immunoprecipitated with either NRAGE antibody or normal IgG antibody. The immunoprecipitates and total lysates were probed for both NRAGE and TBX2. NR: NRAGE, Con: Control.

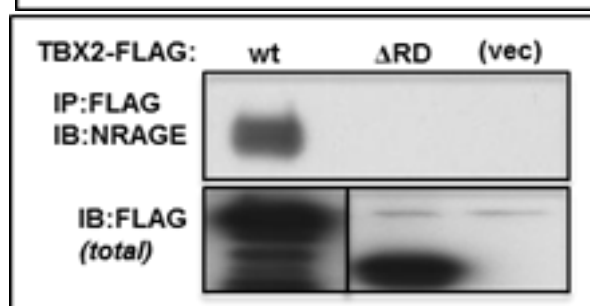

Figure 9. The repression domain of TBX2 is required for the interaction with NRAGE. 293T cells were co-transfected with either FLAG-TBX2, FLAG-TBX $\triangle \mathrm{RD}$, or control vector. The cell lysates were immunoprecipitated with FLAG beads and the precipitates were analyzed by western blotting.

repression by TBX2. Consistently, the rescued expression of wild-type NRAGE protected
The reverse co-IP was unreliable for technical reasons (data not shown). The repression domain of TBX2 was critical for the interaction with NRAGE (Fig. 9). These results suggested that NRAGE might regulate anoikis through interacting with the oncogenic transcriptional repressor TBX2, and that NRAGE might participate in gene

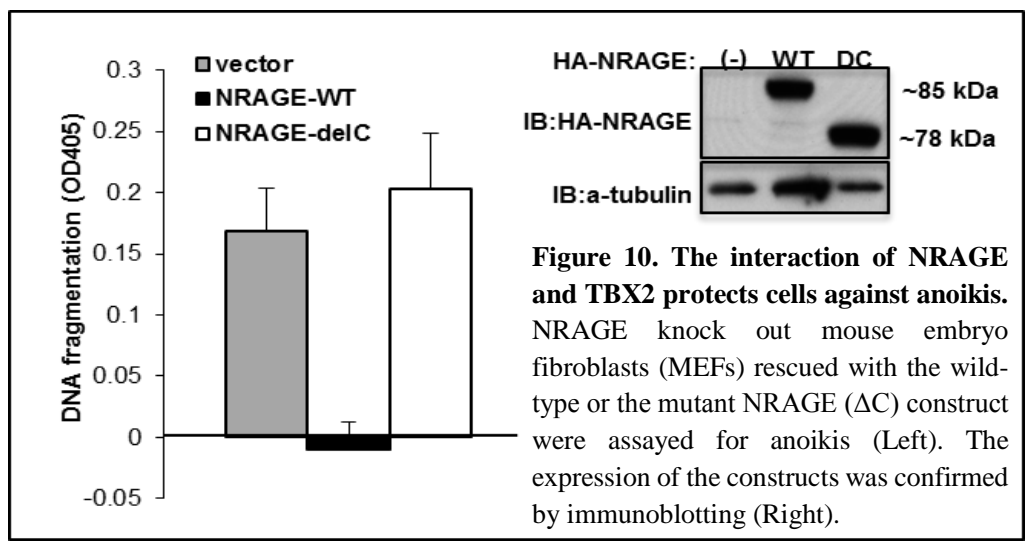

NRAGE-knockout mouse embryo fibroblasts (MEFs) against anoikis while a mutant NRAGE lacking the TBX2-interaction domain had no effect on anoikis (Fig. 10). Moreover, depletion of TBX2 using multiple siRNAs sensitized both HMLE+shEcad and HMLE+Twist cells to anoikis, suggesting that TBX2 was an anoikis suppressor (Fig. 11 and 12).

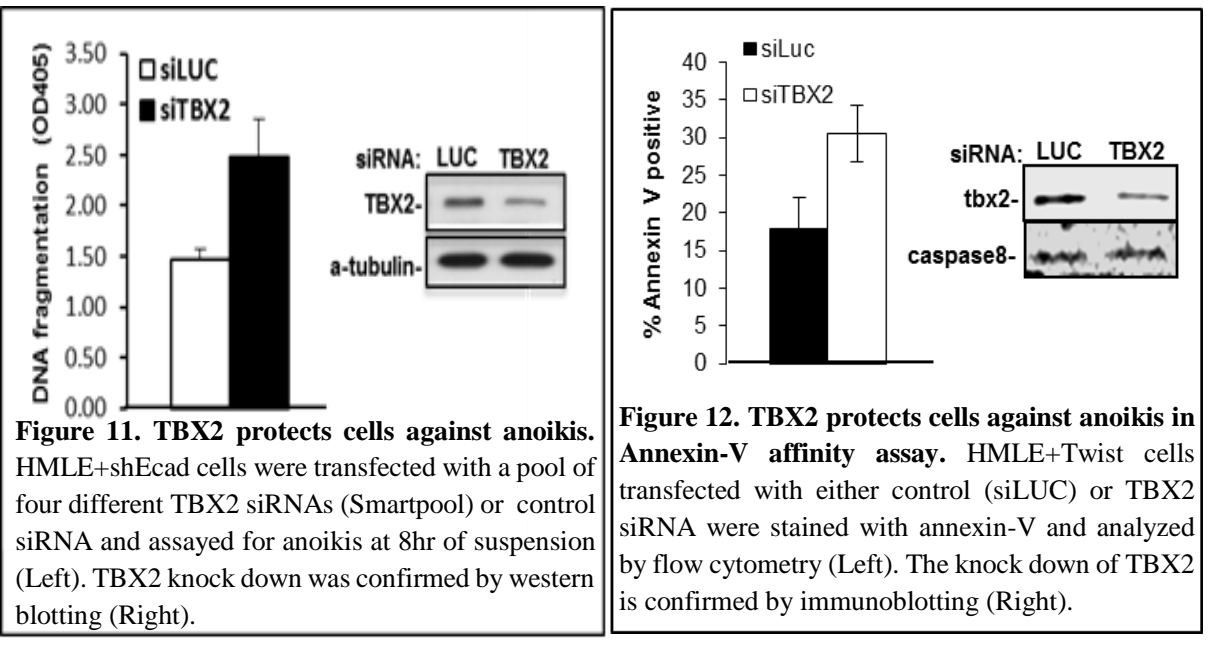


The effect of NRAGE in TBX2-mediated transcriptional repression was tested. TBX2 is known to

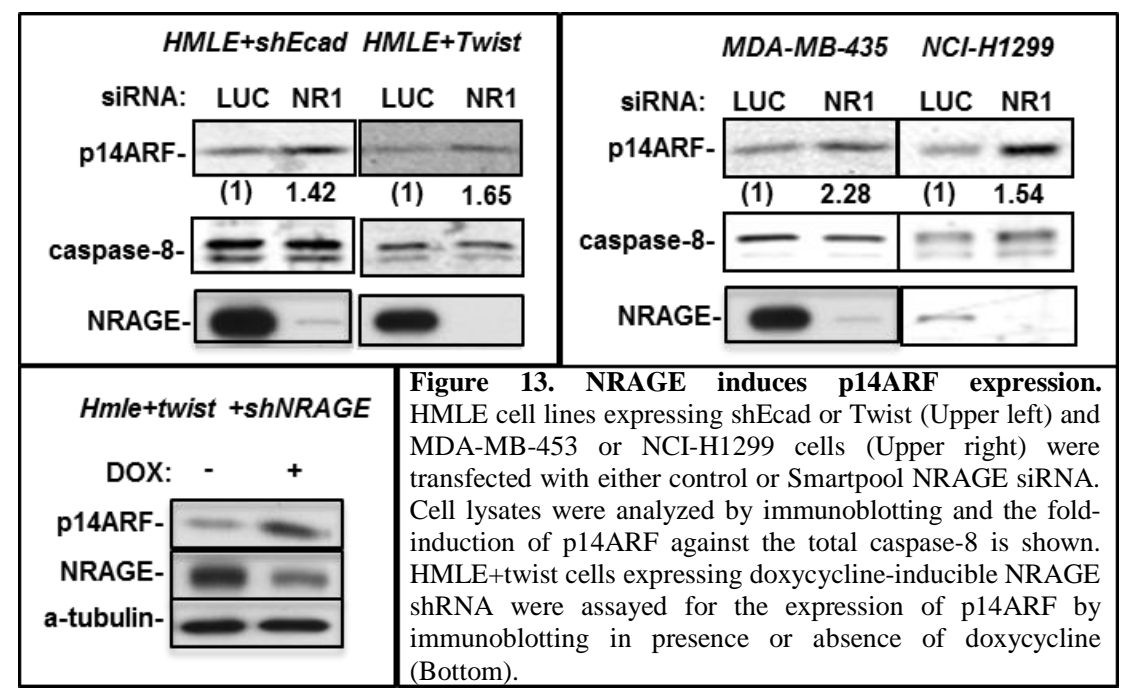

repress p14ARF. The level

of P14ARF protein was

increased by the depletion of

NRAGE protein both in

HMLE+shEcad and

HMLE+Twist (Fig 13).

Similar effect was observed

in tumor cells such as MDA-MB-435 (breast carcinoma) and NCI-H1299 (lung carcinoma) (Fig.

13). In addition, to eliminate off-target effects, and to show that the mechanism of p14ARF

induction is transcriptionally mediated, RT-PCR and western blotting were performed using

different siRNAs and cell lines. The results

showed that p14ARF protein (Fig. 14) and

also mRNA [23] were found to be

inducible by NRAGE siRNA, suggesting

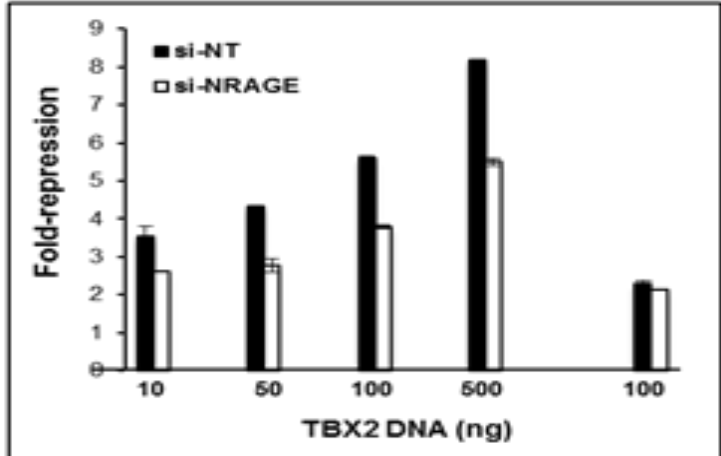

Figure 15. TBX2 requires NRAGE to repress the promoter activity of p14ARF. 293T cells pre-transfected with either a non-targetting (NT) or NRAGE siRNA (Smartpool) were cotransfected with different amounts of a TBX2 vector and a p14ARF promoter-luciferase vector containing either wildtype (first four pairs) or mutant TBX2 binding sites (last pair).

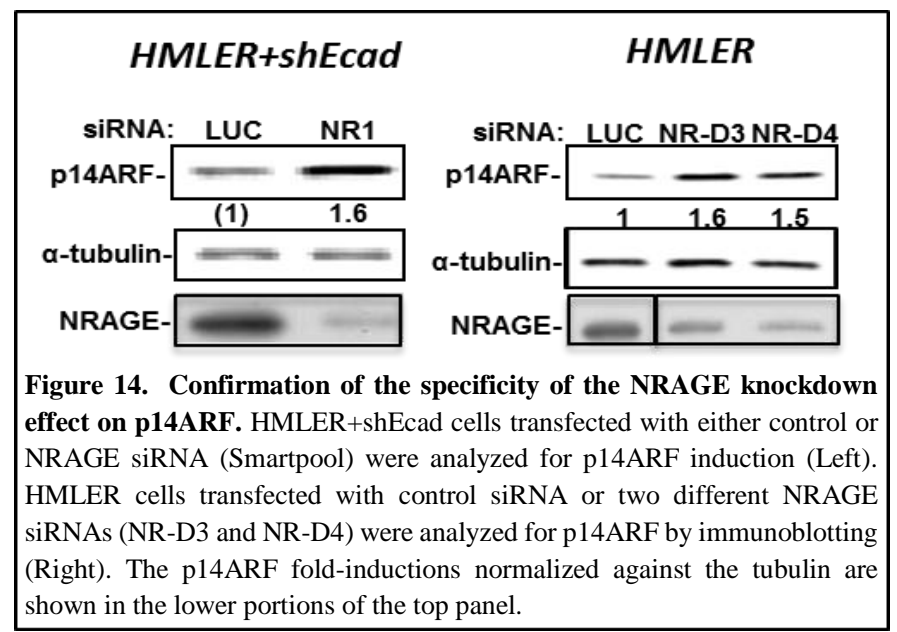

that NRAGE function as a co-repressor for TBX2.

To further show that NRAGE is the co-repressor of TBX2 on regulating p14ARF expression, reporter assays were performed to measure the effect of NRAGE on TBX2 repressor activity. Depletion of 
endogenous NRAGE in the TBX2-deficient cell line 293T impaired the ability of co-transfected TBX2 to repress the p14ARF promoter (Fig. 15).

The effect of EMT on interaction of NRAGE with the p14ARF promoter was tested. ChIP with FLAG antibody (on chromatin from cells that stably expressed 3XFlag-NRAGE) showed that significantly more NRAGE was bound to the ARF promoter in cells that had undergone EMT due to Twist expression than in the control HMLE cells (Fig. 16). Consistent with this, twist expression

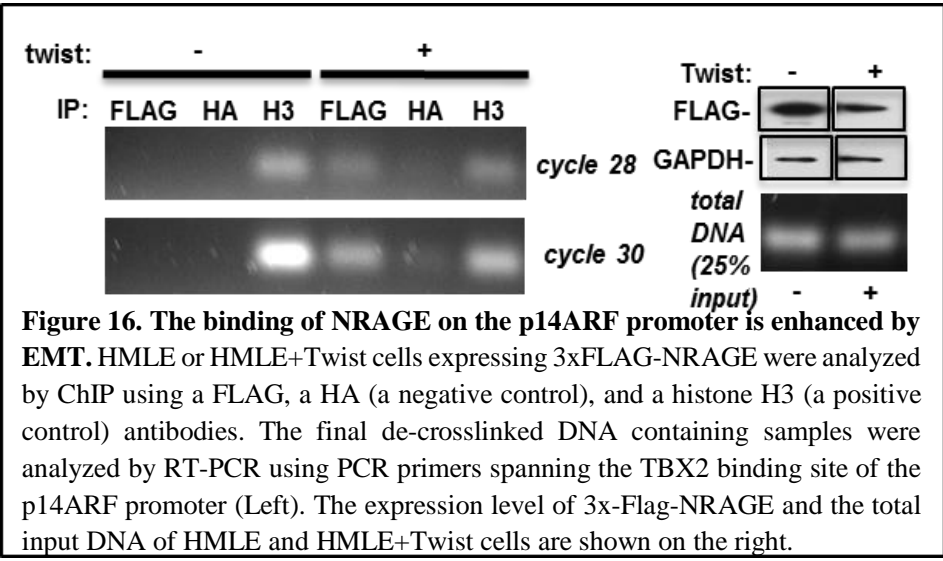
also promoted the nuclear localization of NRAGE and the repression of p14ARF [23]. These results suggested that ankyrin-G could regulate $\mathrm{p} 14 \mathrm{ARF}$, by binding NRAGE protein, thus regulating anoikis-sensitivity. Endogenous p14ARF expression was downregulated both in both HMLE+shEcad and HMLE+Twist cells compared to the parental HMLE cells (Fig. 17). However, when NRAGE was sequestered by the ectopic expression of ankyrin $\triangle$ MBD-CAAX protein [23], the expression of p14ARF was increased (Fig. 18), indicating that Ankyrin-G alleviated the repressive effect of NRAGE. Therefore, these results demonstrate that expression of $\mathrm{p} 14 \mathrm{ARF}$ is regulated by Ankyrin-G during EMT.

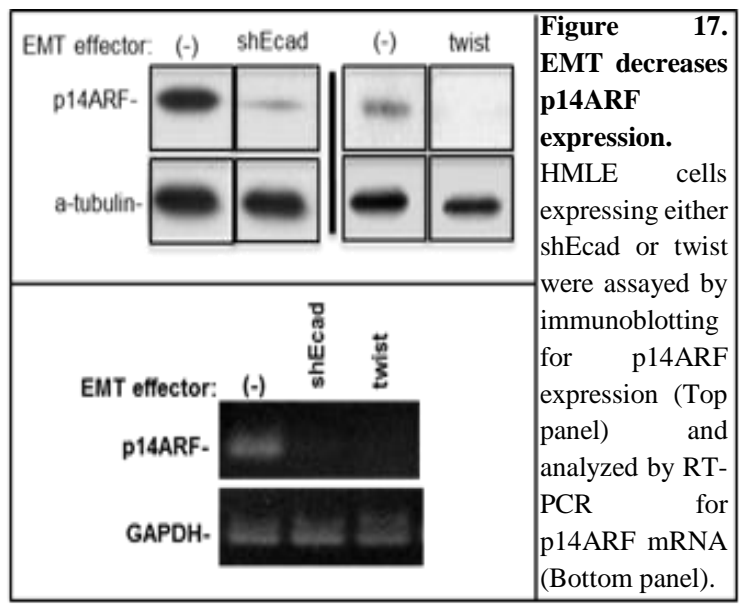




\section{HMLE+shEcad cells}

AnkDMBD+CAAX: (-) (+)

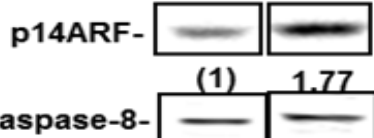

Figure 18. The expression of p14ARF is regulated by ankyrin-G. HMLE+shEcad cells expressing either control or ankyrin $\triangle \mathrm{MBD}$ CAAX construct were analyzed by immunoblotting for the expression of p14ARF protein. The fold-induction of p14ARF normalized against capase-8 is shown.
P14ARF promoted anoikis-sensitivity. Depletion of p14ARF at both mRNA and protein levels via siRNA transfection moderately protected against anoikis, suggesting that the p14ARF tumor suppressor gene is critical in the induction of anoikis (Fig. 19). These results led to a hypothesis that the NRAGE-TBX2 complex suppressed anoikis by suppressing

expression of p14ARF. To further explore this possibility, HMLER+Twist cells were transfected

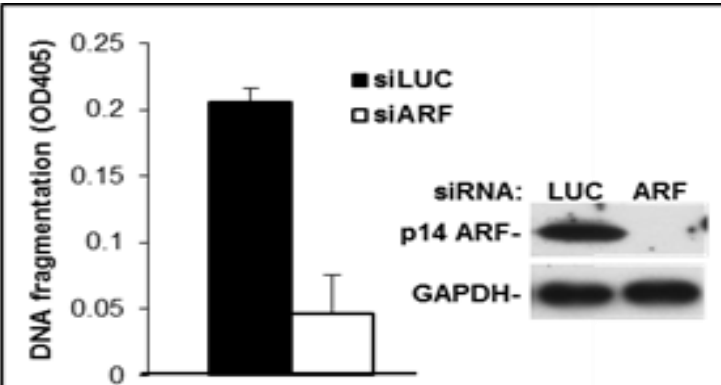

Figure 19. p14ARF promotes anoikis. HMLER cells transfected with either control or p14ARF siRNA (exon1 betaspecific) were suspended for $24 \mathrm{hrs}$ and assayed for anoikis (Left). The knock down of p14ARF is confirmed by western blotting (Right). with either NRAGE siRNA, p14ARF siRNA or both (Fig. 20). The depletion of NRAGE led to an increase in anoikis sensitivity and up-regulation of p14ARF. However, the effect of NRAGE depletion was abolished when cells were pretreated with p14ARF siRNA, confirming that the mechanism of NRAGE regulation of anoikis-

sensitivity is through p14ARF.

Furthermore, when p14ARF was

overexpressed in HMLE+Twist cells, sensitivity to anoikis was increased.

These results demonstrate that regulation of p14ARF by NRAGE is critical for mediation of anoikis

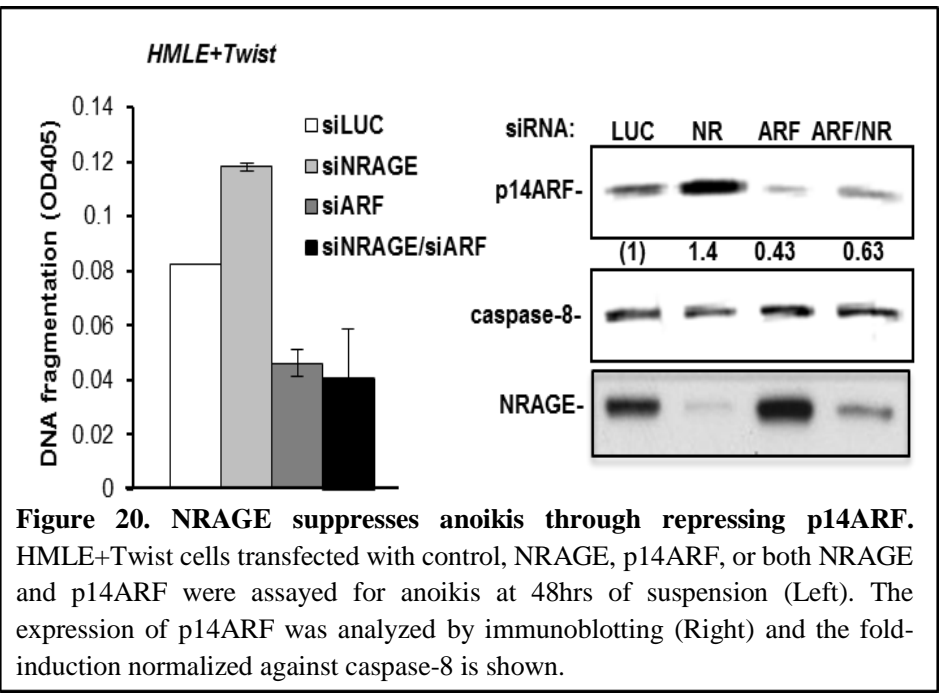
sensitivity (Fig. 21). 


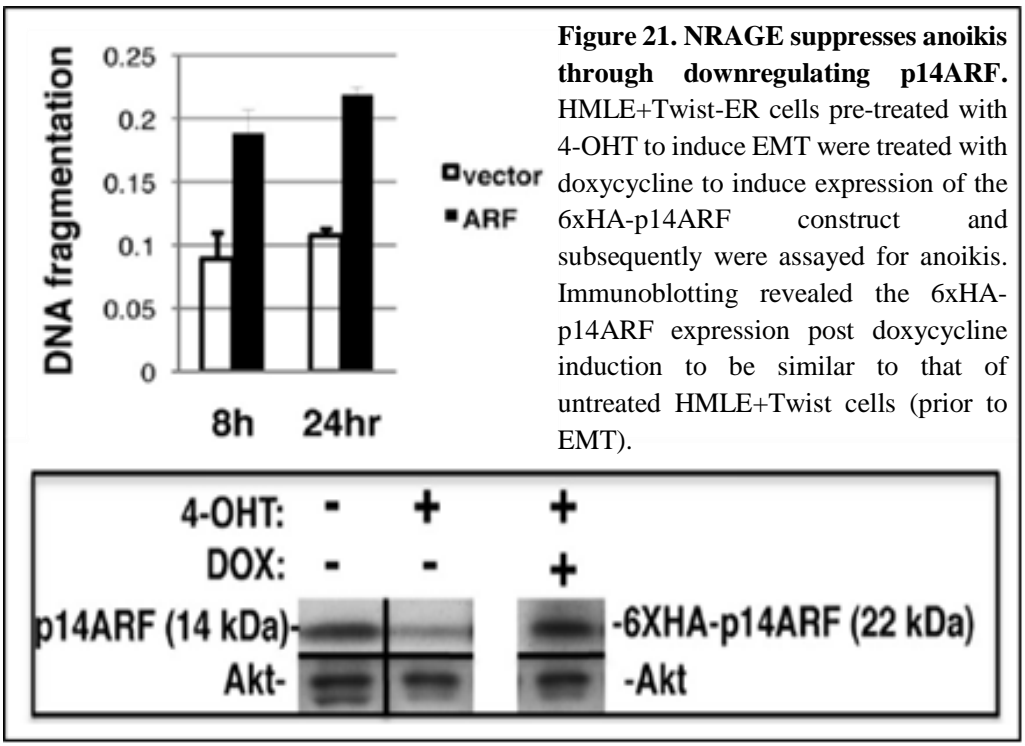




\section{DISCUSSION}

Loss of E-cadherin is critical for induction of EMT, leading to anoikis resistance, and metastasis $[13,36]$. In fact, several oncogenic transcription factors such as Twist, Snail, and ZEB1/2, are known to induce EMT, and they confer anoikis resistance through downregulation of E-cadherin $[12,37,38]$. E-cadherin loss resulted in transcriptional change of various molecules, mediated by EMT [13]. Therefore, E-cadherin can act as a critical modulator of the cell biological phenotypes and the molecular factors that lead to anoikis resistance and metastatic dissemination of carcinomas. In light of its well-established function in maintaining adherent junctions, E-cadherin loss ostensibly promotes metastasis by enabling the first step of the metastatic cascade: the disaggregation of cancer cells from one another and the induction of anoikis resistance.

In this study, we demonstrated that depletion of Ankyrin-G, which has shown to interact with NRAGE, allowed the fraction of NRAGE to localize to nucleus where it interacted with TBX2 to repress the p14ARF promoter in cells that have undergone EMT. Repression of p14ARF promotes anoikis resistance allowing the cells to survive upon detachment from the extracellular matrix.

We observed that NRAGE is an anoikis suppressor. This data has been supported by the fact that NRAGE is overexpressed in lung, kidney, and head and neck cancers as well as colon, melanoma, and prostate tumors $[20,22,23]$. On the other hand, NRAGE has been shown to inhibit metastasis in melanoma and pancreatic cancer cell lines. In addition, overexpression of NRAGE inhibited malignant phenotypes, such as proliferation, migration, and invasion in breast cancer cell lines [39, 40]. This contradicting function of NRAGE could be due to its differential function based on its localization. MAGE-D1/NRAGE induces apoptosis through interacting with receptors such as 
Unc5 and p75NTR [24, 41]. In fact, nuclear localization of NRAGE and interaction with TBX2 were increased in cells that have undergone EMT [23]. To further evaluate the function of NRAGE as an anoikis suppressor and a pro-tumorigenic factor, the use of a genetically engineered mouse model may provide valuable insight for future research.

TBX2 is frequently amplified in pancreatic and overexpressed in melanomas and breast cancers and plays an important role in tumorigenesis $[25,29,30]$. Consistently, we have demonstrated here that TBX2 suppresses anoikis and permits anchorage independent growth [23], which further supports TBX2 as a tumorigenic factor. TBX2 is known to interact with several co-repressors to promote metastasis such as KAP-1, Ajuba, and CtBP [42-45] . However, the mechanism of repression by TBX2 is not well understood. Our data showed that NRAGE is a novel co-repressor of TBX2. As with other co-repressors, NRAGE likely targets multiple genes for repression, which remain to be identified.

Our results demonstrated that p14ARF, which is frequently deleted in human cancers [27], is an anoikis promoter. This indicates a novel function of the tumor suppressor gene. P14ARF haploinsufficiency shows a pro-tumorigenic phenotype, consistent with the idea that even a twofold decrease of ARF expression (as observed here) has important biologic consequences.

These data demonstrated a novel pathway, ankyrin-G/NRAGE/TBX2/p14ARF, that confers anoikis-resistance in response to EMT (Figure 22). 


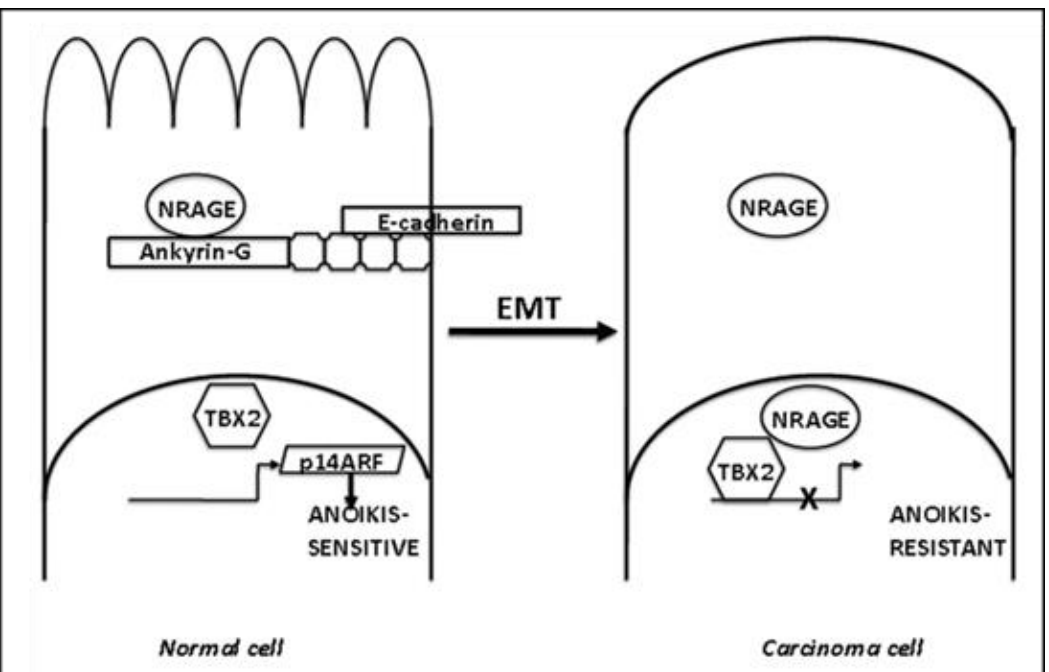

Figure 22. Molecular mechanism of anoikis regulation upon loss of E-cadherin and EMT. 


\section{REFERENCES}

1. Frisch SM and Francis H (1994) Disruption of epithelial cell-matrix interactions induces apoptosis. J Cell Biol 124:619-26.

2. $\quad$ Frisch SM and Ruoslahti E (1997) Integrins and anoikis. Curr Opin Cell Biol 9:701-6.

3. Frisch SM and Screaton RA (2001) Anoikis mechanisms. Curr Opin Cell Biol 13:555-62.

4. Gilmore AP (2005) Anoikis. Cell Death Differ 12 Suppl 2:1473-7.

5. Simpson CD, Anyiwe K and Schimmer AD (2008) Anoikis resistance and tumor metastasis.

Cancer Lett 272:177-85. doi: S0304-3835(08)00394-7 [pii]

10.1016/j.canlet.2008.05.029

6. Kalluri R (2009) EMT: when epithelial cells decide to become mesenchymal-like cells. J Clin Invest 119:1417-9. doi: 39675 [pii]

10.1172/JCI39675

7. Kalluri R and Weinberg RA (2009) The basics of epithelial-mesenchymal transition. J Clin Invest 119:1420-8. doi: 39104 [pii]

$10.1172 / \mathrm{JCI} 39104$

8. Zavadil J, Haley J, Kalluri R, Muthuswamy SK and Thompson E (2008) Epithelialmesenchymal transition. Cancer Res 68:9574-7. doi: 68/23/9574 [pii]

10.1158/0008-5472.CAN-08-2316

9. Smit MA and Peeper DS Zeb1 is required for TrkB-induced epithelial-mesenchymal transition, anoikis resistance and metastasis. Oncogene. doi: onc201196 [pii]

10.1038/onc.2011.96

10. Singh AB, Sharma A, Smith JJ, Krishnan M, Chen X, Eschrich S, Washington MK, Yeatman TJ, Beauchamp RD and Dhawan P (2011) Claudin-1 up-regulates the repressor ZEB-1 to inhibit E-cadherin expression in colon cancer cells. Gastroenterology 141:2140-53. doi: 10.1053/j.gastro.2011.08.038

11. Puisieux A, Valsesia-Wittmann S and Ansieau S (2006) A twist for survival and cancer progression. Br J Cancer 94:13-7. doi: 6602876 [pii]

$10.1038 /$ sj.bjc.6602876

12. Smit MA, Geiger TR, Song JY, Gitelman I and Peeper DS (2009) A Twist-Snail axis critical for TrkB-induced epithelial-mesenchymal transition-like transformation, anoikis resistance, and metastasis. Mol Cell Biol 29:3722-37. doi: MCB.01164-08 [pii]

10.1128/MCB.01164-08

13. Onder TT, Gupta PB, Mani SA, Yang J, Lander ES and Weinberg RA (2008) Loss of Ecadherin promotes metastasis via multiple downstream transcriptional pathways. Cancer Res 68:3645-54.

14. Sasaki A, Hinck L and Watanabe K (2005) RumMAGE-D the members: structure and function of a new adaptor family of MAGE-D proteins. J Recept Signal Transduct Res 25:181-98. doi: J781807071546500 [pii]

10.1080/10799890500210511

15. Masuda Y, Sasaki A, Shibuya H, Ueno N, Ikeda K and Watanabe K (2001) Dlxin-1, a novel protein that binds Dlx5 and regulates its transcriptional function. J Biol Chem 276:5331-8. doi: 10.1074/jbc.M008590200

16. Salehi AH, Roux PP, Kubu CJ, Zeindler C, Bhakar A, Tannis LL, Verdi JM and Barker PA (2000) NRAGE, a novel MAGE protein, interacts with the p75 neurotrophin receptor and 
facilitates nerve growth factor-dependent apoptosis. Neuron 27:279-88. doi: S08966273(00)00036-2 [pii]

17. Chomez P, De Backer O, Bertrand M, De Plaen E, Boon T and Lucas S (2001) An overview of the MAGE gene family with the identification of all human members of the family. Cancer Res 61:5544-51.

18. Kendall SE, Battelli C, Irwin S, Mitchell JG, Glackin CA and Verdi JM (2005) NRAGE mediates p38 activation and neural progenitor apoptosis via the bone morphogenetic protein signaling cascade. Mol Cell Biol 25:7711-24. doi: 25/17/7711 [pii]

10.1128/MCB.25.17.7711-7724.2005

19. Bertrand MJ, Kenchappa RS, Andrieu D, Leclercq-Smekens M, Nguyen HN, Carter BD, Muscatelli F, Barker PA and De Backer O (2008) NRAGE, a p75NTR adaptor protein, is required for developmental apoptosis in vivo. Cell Death Differ 15:1921-9. doi: cdd2008127 [pii] 10.1038/cdd.2008.127

20. Bhattacharjee A, Richards WG, Staunton J, Li C, Monti S, Vasa P, Ladd C, Beheshti J, Bueno R, Gillette M, Loda M, Weber G, Mark EJ, Lander ES, Wong W, Johnson BE, Golub TR, Sugarbaker DJ and Meyerson M (2001) Classification of human lung carcinomas by mRNA expression profiling reveals distinct adenocarcinoma subclasses. Proc Natl Acad Sci U S A 98:13790-5. doi: 10.1073/pnas.191502998

191502998 [pii]

21. Boer JM, Huber WK, Sultmann H, Wilmer F, von Heydebreck A, Haas S, Korn B, Gunawan B, Vente A, Fuzesi L, Vingron M and Poustka A (2001) Identification and classification of differentially expressed genes in renal cell carcinoma by expression profiling on a global human 31,500-element cDNA array. Genome Res 11:1861-70. doi: 10.1101/gr.184501

22. Ginos MA, Page GP, Michalowicz BS, Patel KJ, Volker SE, Pambuccian SE, Ondrey FG, Adams GL and Gaffney PM (2004) Identification of a gene expression signature associated with recurrent disease in squamous cell carcinoma of the head and neck. Cancer Res 64:55-63.

23. Kumar S, Park SH, Cieply B, Schupp J, Killiam E, Zhang F, Rimm DL and Frisch SM A pathway for the control of anoikis sensitivity by E-cadherin and epithelial-to-mesenchymal transition. Mol Cell Biol 31:4036-51. doi: MCB.01342-10 [pii]

10.1128/MCB.01342-10

24. Williams ME, Strickland P, Watanabe K and Hinck L (2003) UNC5H1 induces apoptosis via its juxtamembrane region through an interaction with NRAGE. J Biol Chem 278:17483-90. doi: $10.1074 /$ jbc.M300415200

M300415200 [pii]

25. Rowley M, Grothey E and Couch FJ (2004) The role of Tbx2 and Tbx3 in mammary development and tumorigenesis. J Mammary Gland Biol Neoplasia 9:109-18. doi: 10.1023/B:JOMG.0000037156.64331.3f

490060 [pii]

26. Jacobs JJ, Keblusek P, Robanus-Maandag E, Kristel P, Lingbeek M, Nederlof PM, van Welsem T, van de Vijver MJ, Koh EY, Daley GQ and van Lohuizen M (2000) Senescence bypass screen identifies TBX2, which represses Cdkn2a (p19(ARF)) and is amplified in a subset of human breast cancers. Nat Genet 26:291-9. doi: 10.1038/81583

27. Kamb A, Gruis NA, Weaver-Feldhaus J, Liu Q, Harshman K, Tavtigian SV, Stockert E, Day RS, 3rd, Johnson BE and Skolnick MH (1994) A cell cycle regulator potentially involved in genesis of many tumor types. Science 264:436-40. 
28. Sherr CJ, Bertwistle D, W DENB, Kuo ML, Sugimoto M, Tago K, Williams RT, Zindy F and Roussel MF (2005) p53-Dependent and -independent functions of the Arf tumor suppressor. Cold Spring Harb Symp Quant Biol 70:129-37. doi: 10.1101/sqb.2005.70.004

29. Mahlamaki EH, Barlund M, Tanner M, Gorunova L, Hoglund M, Karhu R and Kallioniemi A (2002) Frequent amplification of 8q24, 11q, 17q, and 20q-specific genes in pancreatic cancer. Genes Chromosomes Cancer 35:353-8. doi: 10.1002/gcc.10122

30. Vance KW, Carreira S, Brosch G and Goding CR (2005) Tbx2 is overexpressed and plays an important role in maintaining proliferation and suppression of senescence in melanomas. Cancer Res 65:2260-8. doi: 65/6/2260 [pii]

10.1158/0008-5472.CAN-04-3045

31. Abrahams A, Parker MI and Prince S (2010) The T-box transcription factor Tbx2: its role in development and possible implication in cancer. IUBMB Life 62:92-102. doi: 10.1002/iub.275 32. Ismail A and Bateman A (2009) Expression of TBX2 promotes anchorage-independent growth and survival in the p53-negative SW13 adrenocortical carcinoma. Cancer Lett 278:230-40. doi: S0304-3835(09)00031-7 [pii]

10.1016/j.canlet.2009.01.006

33. Liu J, Esmailpour T, Shang X, Gulsen G, Liu A and Huang T (2011) TBX3 over-expression causes mammary gland hyperplasia and increases mammary stem-like cells in an inducible transgenic mouse model. BMC Dev Biol 11:65. doi: 10.1186/1471-213X-11-65

34. Kizhatil K, Davis JQ, Davis L, Hoffman J, Hogan BL and Bennett V (2007) Ankyrin-G is a molecular partner of E-cadherin in epithelial cells and early embryos. J Biol Chem 282:2655261. doi: M703158200 [pii]

10.1074/jbc.M703158200

35. Hennessy BT, Gonzalez-Angulo AM, Stemke-Hale K, Gilcrease MZ, Krishnamurthy S, Lee JS, Fridlyand J, Sahin A, Agarwal R, Joy C, Liu W, Stivers D, Baggerly K, Carey M, Lluch A, Monteagudo C, He X, Weigman V, Fan C, Palazzo J, Hortobagyi GN, Nolden LK, Wang NJ, Valero V, Gray JW, Perou CM and Mills GB (2009) Characterization of a naturally occurring breast cancer subset enriched in epithelial-to-mesenchymal transition and stem cell characteristics. Cancer Res 69:4116-24. doi: 0008-5472.CAN-08-3441 [pii]

10.1158/0008-5472.CAN-08-3441

36. Derksen PW, Liu X, Saridin F, van der Gulden H, Zevenhoven J, Evers B, van Beijnum JR, Griffioen AW, Vink J, Krimpenfort P, Peterse JL, Cardiff RD, Berns A and Jonkers J (2006) Somatic inactivation of E-cadherin and p53 in mice leads to metastatic lobular mammary carcinoma through induction of anoikis resistance and angiogenesis. Cancer Cell 10:437-49.

37. Spaderna S, Schmalhofer O, Wahlbuhl M, Dimmler A, Bauer K, Sultan A, Hlubek F, Jung A, Strand D, Eger A, Kirchner T, Behrens J and Brabletz T (2008) The transcriptional repressor ZEB1 promotes metastasis and loss of cell polarity in cancer. Cancer Res 68:537-44. doi: 68/2/537 [pii]

10.1158/0008-5472.CAN-07-5682

38. Vandewalle C, Comijn J, De Craene B, Vermassen P, Bruyneel E, Andersen H, Tulchinsky E, Van Roy F and Berx G (2005) SIP1/ZEB2 induces EMT by repressing genes of different epithelial cell-cell junctions. Nucleic Acids Res 33:6566-78.

39. Chu CS, Xue B, Tu C, Feng ZH, Shi YH, Miao Y and Wen CJ (2007) NRAGE suppresses metastasis of melanoma and pancreatic cancer in vitro and in vivo. Cancer Lett 250:268-75. doi: S0304-3835(06)00570-2 [pii]

10.1016/j.canlet.2006.10.020 
40. Du Q, Zhang Y, Tian XX, Li Y and Fang WG (2009) MAGE-D1 inhibits proliferation, migration and invasion of human breast cancer cells. Oncol Rep 22:659-65.

41. Yang B, O'Herrin SM, Wu J, Reagan-Shaw S, Ma Y, Bhat KM, Gravekamp C, Setaluri V, Peters N, Hoffmann FM, Peng H, Ivanov AV, Simpson AJ and Longley BJ (2007) MAGE-A, mMage-b, and MAGE-C proteins form complexes with KAP1 and suppress p53-dependent apoptosis in MAGE-positive cell lines. Cancer Res 67:9954-62. doi: 67/20/9954 [pii] 10.1158/0008-5472.CAN-07-1478

42. Lin X, Sun B, Liang M, Liang YY, Gast A, Hildebrand J, Brunicardi FC, Melchior F and Feng XH (2003) Opposed regulation of corepressor CtBP by SUMOylation and PDZ binding. Mol Cell 11:1389-96.

43. Wang C, Ivanov A, Chen L, Fredericks WJ, Seto E, Rauscher FJ, 3rd and Chen J (2005) MDM2 interaction with nuclear corepressor KAP1 contributes to p53 inactivation. EMBO J 24:3279-90. doi: 7600791 [pii]

10.1038/sj.emboj.7600791

44. Wang C, Rauscher FJ, 3rd, Cress WD and Chen J (2007) Regulation of E2F1 function by the nuclear corepressor KAP1. J Biol Chem 282:29902-9. doi: M704757200 [pii]

10.1074/jbc.M704757200

45. Ayyanathan K, Peng H, Hou Z, Fredericks WJ, Goyal RK, Langer EM, Longmore GD and Rauscher FJ, 3rd (2007) The Ajuba LIM domain protein is a corepressor for SNAG domain mediated repression and participates in nucleocytoplasmic Shuttling. Cancer Res 67:9097-106. doi: 67/19/9097 [pii]

10.1158/0008-5472.CAN-07-2987 


\section{CHAPTER 3}

\section{Regulation of anoikis by Deleted in Breast Cancer-1 (DBC1) through NF-אB}

Sun Hee Park, Philip Riley IV, Steven M Frisch

Published in Apoptosis. 2013 Apr 16. [Epub ahead of print] Regulation of anoikis by deleted in breast cancer-1 (DBC1) through NF-kB.

Park SH, Riley P 4th, Frisch SM.

Apoptosis, 2013 


\begin{abstract}
Anoikis-resistance of tumor cells is critical for anchorage-independent growth and metastasis. The inflammatory-response transcription factor $\mathrm{NF}-\kappa \mathrm{B}$ contributes to anoikis-resistance and tumor progression through mechanisms that are understood incompletely. Deleted in Breast Cancer-1 protein (KIAA1967) is over-expressed in several tumor types, and correlates with a poorer prognosis in some cases. We report here that DBC1 suppressed anoikis in normal epithelial and breast cancer cell lines. DBC1 interacted with $\mathrm{IKK} \beta$, stimulating its kinase activity, promoting NF- $\kappa \mathrm{B}$ transcriptional activity through the phosphorylation of RelA serine-536 and enhancing the expression of the NF- $\mathrm{B}$ target genes, c-FLIP and Bcl-xL. Our results indicate that DBC1 is an important co-factor for the control of the IKK $\beta-N F-\kappa B$ signaling pathway that regulates anoikis.
\end{abstract}




\section{INTRODUCTION}

Anoikis is defined as apoptosis that is rescued by cellular interaction with an appropriate extracellular matrix [1]. Physiologically, it is critical for cellular homeostasis and development. Anoikis-resistance is a hallmark of metastasis, because it is required for anchorage-independent growth during tumor dissemination. Identification of the factors and mechanisms that control anoikis is a high priority in cancer cell biology and developmental therapeutics. Such factors may control either the set-point, i.e., the gene expression program controlling sensitivity vs. resistance of cells (which may exist prior to detachment from matrix) or the apoptosis-triggering mechanisms that occur in detached cells, or both. Indeed, oncogenes or tumor suppressor proteins affecting both functions have been identified [2-4].

Among the signaling and transcription factor pathways involved in regulating anoikis, NF- $\mathrm{KB}$ is notable because it links anoikis with inflammatory signaling between and within cells [5-7]. Consistent with this, several NF-kB target genes including, c-FLIP, survivin, Bcl-2, Bcl-xL, cIAP-2, xIAP, PLK1, and trkB

protect tumor cells against anoikis [8-14]. Accordingly, NF-kB signaling is widely up-regulated in diverse tumor types $[5,7]$. This up-regulation is attributed mainly to hyperactivation of upstream signaling pathways, except in a subclass of leukemias in which activating RelA mutations occur. These pathways include Akt, inflammatory cytokines, TNF and, interestingly, cell-matrix detachment of tumor cells, but not normal cells $[6,14]$.

Phosphorylation and acetylation regulate the NF- $\mathrm{KB}$ activation process in several respects, including nuclear translocation, DNA binding, and potency of transcriptional activation $[15,16]$. The kinase IKK $\beta$ plays a particularly significant role in that it both promotes the translocation of NF- $\mathrm{kB}$ to the nucleus through the phosphorylation of IкB- $\alpha$, as well as enhancing the ability of RelA to activate transcription 
by phosphorylation of sites within the RelA activation domain [17-20]. The mechanisms linking the regulation of NF- $\mathrm{NB}$ to the control of anoikis are understood incompletely, however.

Deleted in Breast Cancer (DBC1) is a nuclear protein encoded by a gene on 8p21 that was originally believed to reside within a deleted region in breast cancer, a deletion assignment that was later found to be inaccurate [21]. In fact, DBC1 over-expression has been observed in colorectal, esophageal and breast cancers, where its over-expression correlates, in some cases, with poor prognosis [22-25]. These observations suggest a potential role of $\mathrm{DBC} 1$ in tumor progression, although paradoxical roles as a tumor suppressor have been proposed as well [26].

In this study, we demonstrate that DBC1 suppresses anoikis by activating IKK $\beta$ through a direct interaction, increasing NF- $\kappa \mathrm{B}$ activity and enhancing the expression of key anoikis-relevant cell survival genes. 


\section{MATERIALS AND METHODS}

Antibodies

Antibodies used in this study were from the following sources: DBC1 (pAb, Bethyl laboratory and mAb Cell signaling); RelA (Santa cruz biotechnology); RelA acetyl-lys310 (Abcam); $\beta$-Actin (Sigma); IKK- $\beta$ (rabbit mAb, Cell signaling); p-RelA S536 (Cell signaling); $\beta$-Tubulin (Santa Cruz biotechnology); $\alpha$ Tubulin (Millipore Mab DM1A); human c-FLIP (NF-6, Enzo life sciences, Inc); mouse c-FLIP clone DAVE-2 (Axxora), HA (Covance HA. 11 mAb (Ascites)); FLAG (Sigma mAb M2); GADPH (SigmaAldrich pAb G9545); Bcl-xL (rabbit pAb, Cell Signaling); cleaved caspase 3 (Cell Signaling); p-IкB- $\alpha$ (mouse mAb, Cell Signaling); NRAGE (Santa Cruz pAb sc-28243); Normal rabbit IgG (Covance).

\section{Reagents}

Reagents were from the following sources: TNF $($ R\&D System); Bay 11-7082 (Sigma-Aldrich); recombinant GST-IкB $\alpha$ and active IKK- $\beta$ (Signalchem); S-protein HRP Conjugate (Novagen).

ShRNAs and siRNAs

DBC1 siRNA duplexes from Sigma Aldrich Sense: 5'-AAACGGAGCCUACUGAACAUU-3' AntiSense: 5'-AAUGUUCAGUAGGCUCCGUUU-3'. Non-targeting control siRNA (Dharmacon RNAi Technology). The siDBC1 sequences are adapted from [27]. DBC1 shRNAs in the vector pTRIPZ were from Open Biosystems: A6: 193-0178-A-6 GGTTCCACTTAACAACTA (in 5'UTR); B2: 193-0195B-2 CGGCTCTACCTAGAGAAC (in coding sequence).

Protein Expression and Purification

Human DBC1 was expressed in E.coli BL21 using a clone in the GST vector pGEX-6P3 (generated as 
described below). BL21 cells were grown in Luria broth supplemented with $50 \mu \mathrm{g} / \mathrm{mL}$ ampicilin at $37^{\circ} \mathrm{C}$ overnight. Protein expression was induced by adding $1 \mathrm{mM}$ isopropyl thio- $\beta$-D-galactopyranoside (IPTG) for $2 \mathrm{hrs}$. Cells were pelleted by centrifugation at 5,000 rpm and washed with 1x PBS once and resuspended in bufferA (50 mM sodium phosphate buffer $(\mathrm{pH}$ 7.4), $500 \mathrm{mM} \mathrm{KCl}, 1 \mathrm{mM}$ DTT and a protease inhibitor mixture (Pierce)). The cells were lysed by French Press (twice), and the lysate was centrifuged at 100,000 rpm for $1 \mathrm{hr}$ to obtain the soluble fraction of the cell extract. The supernatant was incubated with $0.3 \mathrm{ml}$ of $50 \%$ slurry of gluthione-sephorose (Pharmacia-pre-equilibrated with PBS) for 2 hours at 4 degrees on rotating wheel. Beads were washed once with wash buffer (50 mM Tris- $\mathrm{HCl}$, pH8, $300 \mathrm{mM} \mathrm{NaCl}, 1 \mathrm{mM}$ DTT/PBS+protease inhibitors ) and washed 3 times with cleavage buffer (50 mM Tris-HCl, pH8, $150 \mathrm{mM} \mathrm{NaCl}, 1 \mathrm{mM}$ EDTA, $1 \mathrm{mM}$ dithiothreitol $+0.01 \%$ Triton X-100). To elute protein, $160 \mathrm{uL}$ of cleavage buffer containing Protease (Pierce, 27-0843-01) mixture (12.8ul [80unit] of PreScission protease and 147.2ul of cleavage buffer) was added to $160 \mathrm{ul}$ of bead solution. The mixture was incubated for 5 hours at $4^{0} \mathrm{C}$ on rotating wheel, spun down for 15 seconds at full speed, and the supernatant was transferred to a new tube. The protein sample was dialyzed with kinase assay buffer (see below) overnight using Slide-A-Lyzer MINI Dialysis Units (Thermo Scientific).

\section{qRT-PCR}

The primers used for RT-PCR were as follows:

CIAP-1 (BIRC2) 5-TTGAGGTGTTGGGAATCTGG-3, 5-GGCCTTTCATTCGTATCAAGAAC-3; XIAP(BIRC4) 5-GCACGGATCTTTACTTTTGGG-3, 5-GGGTCTTCACTGGGCTTC-3; Survivin 5CAAGGAGCTGGAAGGCTG-3, 5-TTCTTGGCTCTTTCTCTGTCC-3; BCL2 5GTGGATGACTGAGTACCTGAAC-3, 5-GCCAGGAGAAATCAAACAGAGG-3; BCLXL 5GACATCCCAGCTCCACATC-3, 5-GTTCCCATAGAGTTCCACAAAAG-3; FLIP 5- 
CTTGGCCAATTTGCCTGTAT-3, 5-TCTTTGGCTTCCCTGCTAGA-3. Beta2M: 5GGCATTCCTGAAGCTGACAG-, 5-TGGATGACGTGAGTAAACCTG-3.

For real-time quantitative RT-PCR, RNA was purified from cell lines using RNeasy Plus mini kit (Qiagen, Germantown, MD) and cDNA was synthesized with invitrogen 18080-051 Superscript III First-strand Synthesis System for RT-PCR using 1-3 ug of RNA template with oligo-dT primers. Reactions were run in total $20 \mathrm{uL}$ utilizing 10ul of 2x Applied Biosystems (Foster City, CA) SYBR green PCR Master Mix, 8 uL of $10 \mathrm{uM}$ primer mix and $2 \mathrm{uL}$ of 50X diluted cDNA.

Expression constructs

3xHA-DBC1-pCDNA3.1: DBC1 coding sequence from pCMV-SPORT6 vector (obtained from Open Biosystems) was ligated into the BglII-EcoRI site of 3xHA-pRc/CMV2 vector (D. Anderson, University of Saskatchewan). The 3xHA-DBC1 fragment is then subcloned by PCR into the HindIII-EcoRI site of pCDNA3.1.

pCDNA-IKK- $\beta$-Flag WT expression construct was obtained from Addgene (plasmid 23298).

DBC1/pGEX: Full length DBC1 coding sequence (aa1-923) amplified from DBC1-pCMV-SPORT6 vector by PCR was subcloned into pGEX-6P3 vector (GE Healthcare) that was cut with EcoRI and XhoI. RelA-cFlag-pcDNA3 (mouse) vector was obtained from Addgene (Plasmid 20012).

RelAS536A-cFlag-pCDNA3 was generated by performing mutagenesis the Quick-change IIXL kit (Agilent).

HA-DBC1/pBabe-puro: DBC1 fragment was amplified by PCR from pCMV-Sport6 vector (Open Biosystems) using a forward primer that had an HA sequence. The fragment was ligated into the SalI site of pBabe-puro retroviral vector (addgene).

HA-FLIP-pMIG: c-FLIP coding sequence was amplified by PCR from the pcDNA3-Myc-FLIP vector 
(kindly provided by J. Tschopp, University of Lausanne) with inclusion of a single HA tag on the forward primers and ligated into the XhoI-EcoRI site of pMIG (Addgene).

$\underline{\text { IKK- } \beta \text {-S-mscv-puro: }}$ Synthetic double stranded oligonucleotides (S-tag-f: CTAGC CCACC ATG AAG GAG ACCGCC GCT GCC AAG TTC GAG AGA CAG CAC ATG GAC TCC GGC GGC A; S-tag-r: agcttGCCGCCGGAGTCCATGTGCTGTCTCTCGAACTTGGCAGCGGCGGTCTCCTTCATGGTGG

g) were annealed and ligated into the NheI-HindIII site of pcDNA3.1+ to generate the vector Stag/pcDNA3.1. The NheI-EcoRI fragment from this vector was ligated together with an EcoRI-NotI fragment generated by PCR from pcDNA-IKK- $\beta$-Flag-WT vector (Addgene plasmid 23298). The ligated product was then re-amplified with primers spanning the S-tag and the IKK- $\beta$ sequence, carrying XhoI and NotI sites respectively. This PCR product was subcloned into the XhoI-NotI site of pMSCVIRES-puro.

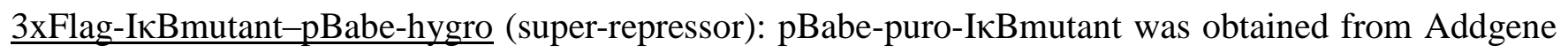
(plasmid 15291). Full length IKBmt fragment was amplified by PCR and ligated into 3xFlag-CMV-10 (Invitrogen) that was cut with NotI-BgIII. The 3xFlag-IKBmt from 3xFlag-IKBmt-CMV10 vector was amplified by PCR and ligated into pBabe-hygro (Addgene) that was cut with BamHI and EcoRI.

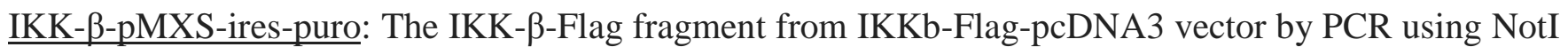
primers and subcloned into the Not I site of pMXS-ires-puro-FF (R. Carstens, University of Pennsylvania), creating three C-terminal Flag sequences.

NF-kB-luc reporter vector: pNF-kB-Luc contains five copies of a consensus NF-kB site in a pGL2 luciferase reporter vector (Promega).

TK-LacZ vector: constructed by A. Ivanov used as an internal control for luciferase assays. 


\section{Cell lines}

In this study, we used MCF10aPG2, a subclone of the human mammary epithelial cell line MCF10a developed in our lab that undergoes anoikis more rapidly than the parental line (S.H.-P. and S.M.F., unpublished data), except for acinar morphogenesis assays, where MCF10aneoT cells (F. Miller, Karmanos Cancer Center) were used. These cells were maintained in MCF10a medium (DME/F12+5\% horse serum $+1 \mathrm{x}$ penicillin-streptomycin-glutamine (PSG) $+10 \mathrm{ug} / \mathrm{ml}$ insulin, $10 \mathrm{ng} / \mathrm{ml}$ EGF, 0.5ug/ml hydrocortisone, and 0.1ug/ml cholera toxin). MDA-MB231 and MDA-MB-468 (provided by A. Ivanov) were maintained in DMEM $+10 \%$ fetal bovine serum +1 X PSG. All derivative cell lines were mixed populations generated by drug selection or flow sorting after viral infection (except the HA-DBC1expressing MCF10a cells, where high-expressing clones were selected). BT-549 cells were provided from E. Pugacheva (WVU) and maintained in RPMI $+10 \%$ fetal bovine serum $+1 \mathrm{X}$ PSG. Inducible DBC1 shRNA knockdown cell lines were generated by infection with the A6/pTRIPZ or B2/pTRIPZ lentiviruses (described above), followed by selection with $2 \mu \mathrm{g} / \mathrm{ml}$ puromycin, and after 24 hours induction with $1 \mu \mathrm{g} / \mathrm{ml}$ doxycycline, cells were then flow-sorted for RFP. Retroviruses were packaged by co-transfecting $60 \mathrm{~mm}$ dishes of $293 \mathrm{~T}+\mathrm{GP} 2$ cells (Clontech) using Mirus LT1 reagent, with $4.5 \mu \mathrm{g}$ of retroviral plasmid and $2.5 \mu \mathrm{g}$ of pCMV-VSV-G. Lentiviral constructs were packaged by co-transfecting $60 \mathrm{~mm}$ dishes of $293 \mathrm{~T}$ cells, using Mirus LT1, with $3.3 \mu \mathrm{g}$ of lentiviral vector, $2.2 \mu \mathrm{g}$ of sPAX2 and 1.2 $\mu \mathrm{g}$ of CMV-VSV-G. Viral supernatants were cleared about 48 hours post-transfection by filtration through 0.45 micron cellulose acetate filters (Whatman), aliquoted and stored at -80 degrees. To improve the transfection efficiency, cells were infected by spinning down the cells with virus stock at $1,400 \mathrm{rpm}$ for $1.5 \mathrm{hr}$ at room temperature followed by overnight incubation at $37^{0}$. After infection, and selection in puromycin $(2 \mu \mathrm{g} / \mathrm{ml})$, and/or flow-sorting for GFP or RFP expression, expression of the transgenes or knockdown was verified by western blotting. To induce shRNA expression, $1 \mu \mathrm{g} / \mathrm{ml}$ of 
doxycycline was added to growth media in cells with pTRIPZ-based shRNA and incubated for 48 hours before performing any experiment.

Derivative cell lines used in this study were generated as follows:

MCF10a with inducible DBC1 shRNA knockdown: MCF10a cells were infected with the A6/pTRIPZ or B2/pTRIPZ lentiviruses (described above), selected with puromycin $(2 \mu \mathrm{g} / \mathrm{ml})$, and after 24 hours induction with $1 \mu \mathrm{g} / \mathrm{ml}$ doxycycline, cells were flow-sorted for RFP.

Breast cancer cells with inducible DBC1 shRNA knockdown: MDA-MB-231 and BT-549 cells were infected with the A6/pTRIPZ lentiviruses, and selected for puromycin $(2 \mu \mathrm{g} / \mathrm{ml})$. After 24 hours induction with $1 \mu \mathrm{g} / \mathrm{ml}$ doxycycline, cells were flow-sorted for RFP.

MCF10a+DBC1 over-expression: MCF10a cells were infected with HA-DBC1/pBabe-puro and selected for puromycin $(2 \mu \mathrm{g} / \mathrm{ml})$. Empty vector control cells lines were generated by infecting with pBabe-puro and selecting for puromycin.

DBC1-KO MEFs with rescued DBC1 expression: DBC1-KO mouse embryo fibroblasts [27], kindly provided by Z. Lou (Mayo Clinic College of Medicine), were immortalized with SV40 T-antigen by infection with the ZipTer retrovirus (provided by P. Soriano, Hutchinson Cancer Center). Cells were then infected with HA-DBC1/pBabe-puro vector and selected for puromycin $(2 \mu \mathrm{g} / \mathrm{ml})$. Empty vector control cells lines were also generated by infecting immortalized DBC1-knock out MEFs with pBabepuro and selecting for puromycin $(2 \mu \mathrm{g} / \mathrm{ml})$.

MCF10a over-expressing IKK- $\beta$ : MCF10a cells were infected with $3 x$ Flag-IKK $\beta$-pMXS-puro and selected for puromycin $(2 \mu \mathrm{g} / \mathrm{ml})$. Empty vector control cells lines were also generated by infecting with pMXS-puro and selecting for puromycin. 
MCF10a with inducible DBC1 shRNA and c-FLIP over-expression: MCF10a cells expressing DBC1 shRNA (A6/TripZ) were infected with HA-FLIP/pMIG and selected for GFP-positive cells by flow cytometry. Empty vector control cells were also generated by infecting with empty pMIG vector and selecting for GFP-positive cells by flow cytometry.

Mouse embryo fibroblasts expressing IкBmt: Immortalized DBC1-KO and WT MEFs were infected

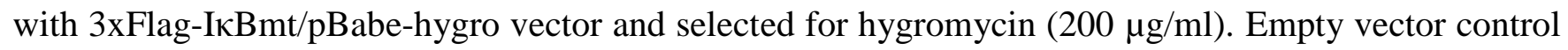
cells lines were also generated by infecting immortalized DBC1-KO and WT MEFs with pBabe-hygro and selecting for hygromycin.

MDA MB-231 cells overexpressing S-tag-IKK- $\beta$ : MDA-MB-231 cells were infected with S-tag-IKK$\beta / \mathrm{MSCV}$-IRES-Puro vector and selected for puromycin $(2 \mu \mathrm{g} / \mathrm{ml})$. Empty vector control cells lines were also generated by infecting MDA-MB231 cells with mscv-puro and selecting for puromycin.

Western blots

Novex/Invitrogen 4-12\% gradient gels were transferred under standard conditions in Tris-glycine/5\% methanol buffer and transfer was run overnight at $45 \mathrm{~V}$ or at $80 \mathrm{~V}$ for 3 hours with stirring. Secondary antibodies anti-mouse-hrp and anti-rabbit-hrp were from BioRad; Clean-Blot secondary antibody (Pierce/Thermo) was used to avoid detection of precipitated $\operatorname{IgG}$ on blots used for coimmunoprecipitation experiments. Blots were developed using either enzyme-linked chemiluminescence (ECL, West Pico, Pierce), or, for the more quantitative applications, using fluorescently tagged secondary antibodies, buffers and scanning instrument from LiCor; quantitation generated by the software was based on raw pixel integrations. 
siRNA transfection and anoikis assays

$1.5 \times 10^{5}$ cells were plated in wells of 6 -well collagen-coated dishes. Two duplicate wells with target siRNA and two duplicate wells with control siRNA, using $500 \mu \mathrm{L}$ of Opti-MEM containing $5 \mu \mathrm{l}$ of 20 $\mu \mathrm{M}$ siRNA (or $1 \mu \mathrm{l}$ of $100 \mu \mathrm{M}$ DBC1 siRNA) and $5 \mu \mathrm{l}$ of lipofectamine RNAi-max, added to a well containing 2.0 ml of Opti-MEM. After 4-6 hours, cells were re-fed with regular growth medium, and, 24 hours later, each well was split into one $60 \mathrm{~mm}$ dish. These were further incubated forty-eight hours, trypsinized, and resuspended in $3 \mathrm{ml}$ of growth medium. Cells were counted and 100,000 cells were plated in a 35mm Ultralow Attachment well and incubated for specified periods of time in presence of $0.5 \%$ of methylcellulose. At each time points, including time zero, cells were spun down at 4,000 rpm for 1.5 minutes in a microfuge tube, washed in ice-cold D-PBS once and lysed in $100 \mathrm{uL}$ of phosphate buffered saline (PBS) containing 0.5\% Triton-X100 and 10 mM EDTA. Lysates were incubated on ice for 15 minutes and cleared at 13,200 rpm for 12 minutes and, 5-15ul were assayed in a total of 100ul of Roche Cell Death ELISA Lysis/Incubation buffer in the Roche system and read in a Perkin-Elmer Envision/Excite. Values measured at a suspension time of zero (time-zero), which were generally unaffected by the siRNAs we transfected in this study, were subtracted from the final values shown in the figures. MCF10a cells that were pre-treated with either curcumin $(25 \mu \mathrm{M})$ for 4 hours were suspended for indicated time and collected to measure DNA fragmentation using Roche Cell Death ELISA lysis kit as described above.

Cell permeability-based cell death assays

DBC1-KO MEF ( 100,000 cells) expressing either vector or HA-DBC1 vector treated with BAY 11$7082(10 \mu \mathrm{M})$ for 1 hour were plated on low attachment 6-well plates containing $2 \mathrm{ml}$ of growth medium. Cells were collected at indicated time points, spun down at 3,200 rpm for 15 seconds, 
resuspended in $100 \mu \mathrm{L}$ of Accumax (Innovative Cell Technologies) and incubated ( 5-10 minutes) at room temperature to generate single cell suspensions. Equal volumes of trypan blue staining solution (Invitrogen) were added to the cell suspension and the percentage of dead cells was counted on a hemacytometer in duplicate; time-zero cell death values were subtracted.

\section{RelA acetylation assay}

MCF10a cells expressing control shRNA or DBC1 shRNA, or mouse embryo fibroblasts (DBC1 knocko ut or DBC1-rescued) were plated on 6 well plates. When cells were about $80 \%$ confluent, cells were trea ted with TNF (20ng/ml for MCF10a, 40ng/ml for MEF) for 30 or 120 minutes. Cells were lysed with 5 $\% \beta \mathrm{ME} / 1 \mathrm{xSDS}$ sample buffer, boiled and analyzed on western blots using acetyl-lys310 relA antibody.

\section{Reporter Assays}

50,000 MCF10ap+DBC1 shRNA cells were plated on 12 well plates coated with collagen in duplicates and shRNA was induced with $1 \mu \mathrm{g} / \mathrm{ml}$ of doxycyclin. Next day, cells were co-transfected with $600 \mathrm{ng}$ NF-kB- luciferase construct, $150 \mathrm{ng}$ TK-lacZ and either $250 \mathrm{ng}$ of HA-DBC1-pCDNA3.1 or pCDNA3.1 vector by using Lipofectamine 2000 reagent (Invitrogen) at a ratio of $1 \mu \mathrm{g}$ of DNA to $2 \mu \mathrm{L}$ of Lipofectamine reagent. MEF DBC1 WT and KO expressing 3xFlag-I $\mathrm{KB} \alpha$ mutant construct were plated on 6 well plates coated with collagen. Next day, cells were transfected with either DBC1 or control siRNA. After 24hrs, cells were re-plated on 12 well plates coated with collagen in duplicates. Following day, cells are co-transfected with ug of NF-kB-luciferase construct and TK-LacZ (1 $\mu \mathrm{g}$ of total DNA) by using Lipofectamine 2000 reagent. After 28hrs, cells were treated with TNF (20ng/ml) for 90mins and lysed with 200ul of $1 \mathrm{x}$ cell culture lysis buffer (Promega). The cell lysates were centrifuged at $4 \mathrm{C}$ for $12 \mathrm{mins}$ at $13,200 \mathrm{rpm}$ and assayed for luciferase and beta-galactosidase activity in 100ul of luciferase 
assay reagent or $150 \mathrm{ul}$ of $1 \mathrm{x}$ galactosidase assay buffer (both Promega), which were analyzed in a Perkin-Elmer Envision/Excite apparatus. Light units were normalized to b-galactosidase activity to control for transfection efficiency. For MDA-MB 231 cells, 60,000 cells plated on 6-well dishes were transfected with $750 \mathrm{ng} \mathrm{NF- \kappa B-luciferase} \mathrm{construct} \mathrm{and} 250 \mathrm{ng}$ TK-LacZ. After 24 hours, cells were replated on low- attachment 6-well plates. Cells were harvested at time points indicated and assayed for luciferase and $\beta$-galactosidase activity. MCF10a cells plated on 6 well plates coated with collagen were transfected with either control or DBC1 siRNA. After 24 hours, cells were split and plated onto 12 well

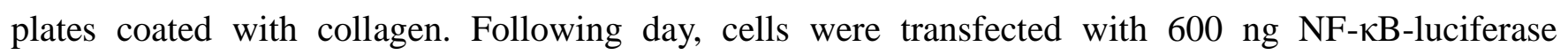
construct, $150 \mathrm{ng}$ TK-LacZ, and either $250 \mathrm{ng}$ of pCDNA3.1 or 3xFlag-IKK $\beta$-pCDNA3.1 vector by using Lipofectamine 2000 reagent. After 28 hours, cells were treated with TNF (20 ng/ml) for $1.5 \mathrm{hr}$ and assay assayed for luciferase and beta-galactosidase activity.

\section{Effect of Bay 11-7082 on RelA localization}

Cells grown on poly-L-lysine coated coverslips were treated with $10 \mathrm{ng} / \mathrm{ml}$ of Bay 11-7082 for 1 hour at $37^{0}$ followed by $20 \mathrm{ng} / \mathrm{ml}$ of TNF for various times. At each time point, cells were fixed in PBS containing $4 \%$ paraformaldehyde and permeabilized with PBS containing $0.2 \%$ Triton X-100. Cells were blocked in PBS containing 10\% normal goat serum, 0.1\% Tween-20, and 0.1\% BSA (blocking solution) for 60 minutes at room temperature. A 1:500 dilution of RelA antibody to blocking solution was then applied overnight at $4^{\circ} \mathrm{C}$. Slides were washed with $0.1 \%$ PBS/Tween-20 three times and incubated for 1.5 hour with Alexa 488-conjugated goat anti-rabbit reagent (Molecular Probes) diluted 1:1000 in blocking solution. Coverslips were mounted with ProLong Gold (Molecular Probes)

containing 4', 6-Diamidino-2-phenylindole. Target proteins were detected fluorescently using microscope (Zeiss Axiovert). 
Acinar Morphogenesis assay

MCF10aneoT cells expressing either control or DBC1 shRNA were assayed for morphogenesis following the protocol indicated in [28].

\section{RelA S536 phosphorylation assay}

MCF10a cells expressing either control or DBC1 shRNA were plated on 6 well plates. Cells were treated with TNF (20 ng/ml) for 1.5 hours or 3 hours and lysed with 1x SDS sample buffer $+5 \% \beta \mathrm{ME}$. Western blots were performed using relA phospho-S536 specific antibody or total relA antibody; buffer containing $1 \mathrm{X}$ TBS+0.1\% Tween+ 5\% BSA was used for phospho-specific antibody incubation and blocking. Three independent experiments were performed. Image $\mathbf{J}$ was used to measure the relative phosphorylation level against total RelA expression. The results from three different experiments were averaged and indicated in the bottom of the blots with standard deviation.

S-tag pulldown assay

MDA-MB-231 cells expressing either S-tag-IKK- $\beta$ or empty vector (one 100ml dish for each sample) were pre-treated with TNF $(20 \mathrm{ng} / \mathrm{ml})$ for $1.5 \mathrm{hr}$ or suspended for 24 hours on low attachment plates. Cells were lysed in IP buffer $(600 \mu \mathrm{L})$, followed by preclearing the lysates at 13,200 rpm for 10 minutes. Lysates were precipitated with $40 \mu \mathrm{L}$ of a $50 \%$ slurry of S-protein beads (Novagen/EMD Biosciences) that had been pre-equilibrated with IP buffer containing $10 \mathrm{mg} / \mathrm{ml}$ of bovine serum albumin and washed. After overnight incubation at $4^{\circ} \mathrm{C}$ with rotation, beads were washed three times with IP buffer. Samples were boiled in 2x SDS sample buffer for 5 minutes and analyzed by Western blotting. 
In vitro kinase assay

To each $20 \mu \mathrm{L}$ reaction, recombinant proteins GST-IKK- $\beta$, GST-I $\kappa \mathrm{B} \alpha$ and DBC1 protein was added at the indicated amounts. The final concentrations of components in the kinase assay buffer were: $25 \mathrm{mM}$ Tris-HCl, pH8, 50mM KCl, 10mM Mgcl2, 1mM Na3VO4, 1mM DTT and $500 \mu \mathrm{M}$ ATP. After 30 minute incubation at $30^{\circ}$, the reactions were stopped by the addition of $20 \mu \mathrm{L}$ of $2 \mathrm{X}$ SDS sample buffer $+\beta M E$ to the tube and boiling. Samples were analyzed on western blots for I $\mathrm{B} \alpha$ phospho-S32/36.

In vivo kinase assay

MDA-MB-231 cells that express either control or DBC1 shRNA were plated on 60mm dishes. Cells (Either attached or suspended for 24 hours in complete growth medium) were lysed in 600ul of standard IP buffer (25mM Tris pH8, 150mM NaCl, 0.5\% Triton-X100, 10\% glycerol, $1 \mathrm{mM}$ EDTA, $1 \mathrm{mM}$ betaglycerophosphate, and Pierce complete protease inhibitor). After centrifugation at 13,200 rpm for10 minutes at $4^{\circ} \mathrm{C}$, supernatants were incubated with either $1 \mu \mathrm{g}$ of IKK- $\beta$ or normal IgG antibodyovernight at $4{ }^{\circ} \mathrm{C}$ with rotation, followed by incubation with $40 \mu \mathrm{l}$ of pre-equilibrated protein Asepharose for another hour. Beads were washed three times with IP buffer and washed three times with kinase assay buffer (25mM Tris-HCl pH8, 50mM KCl, 10mM MgCl2, 1mM Na3VO4, and 1mM DTT). Kinase assay buffer $(40 \mu \mathrm{L})$ containing GST-IкB $\alpha(50 \mathrm{ng})$ fusion protein and ATP $(1 \mathrm{mM})$ was added to the beads, which were incubated at $30^{\circ} \mathrm{C}$ for 30 minutes. Following removal of the beads by centrifugation, the supernatant was diluted with 2S SDS sample buffer, heated and analyzed by western blotting and probed for phospho-IкB $\alpha$, IKK- $\beta$, and $\mathrm{DBC} 1$. 


\section{Endogenous co-IP}

The co-immunoprecipitation of DBC1 and NRAGE was performed in HMLE+Twist cells following the protocol described in [29].

Co-transfection and pull down assay

293T cells co-transfected with 3xHA-DBC1 and 3xFlag-NRAGE ([29]) were assayed for their interaction following the protocol described in [29]. 


\section{RESULTS}

\section{DBC1 suppresses anoikis}

To investigate the potential role of DBC1 in anoikis, full-length $\mathrm{DBC} 1$ was over-expressed in the human
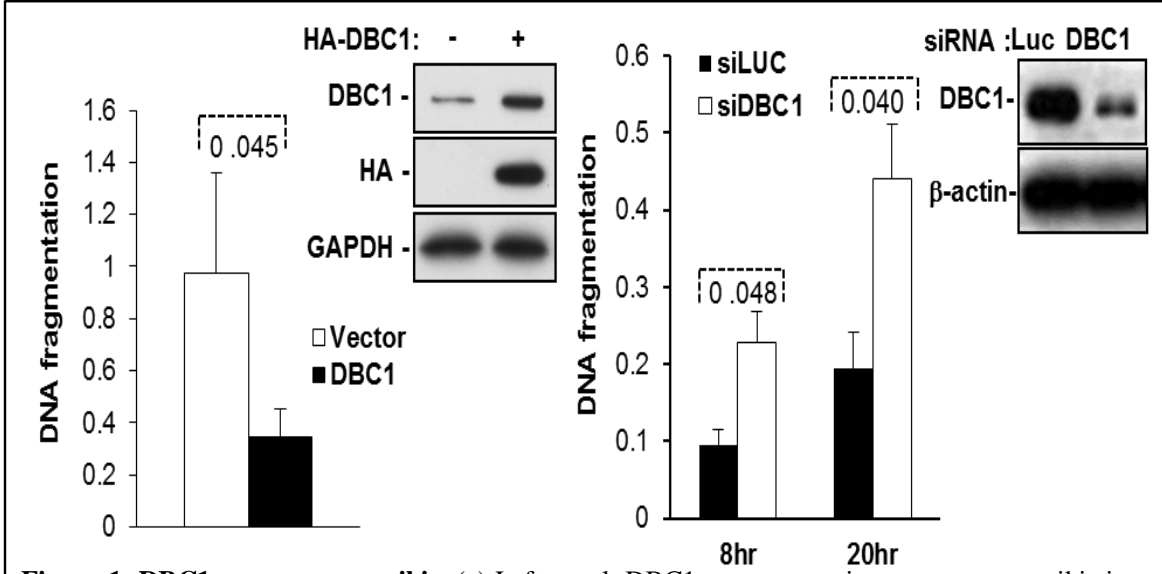

Figure 1. DBC1 suppresses anoikis. (a) Left panel. DBC1 over-expression suppresses anoikis in MCF10a cells. MCF10a infected with DBC1 retroviral expression vector or control vector were su spended for six hours and assayed for anoikis using a cell death ELISA assay. (b) Right panel. DBC 1 suppresses anoikis in MCF10a cells: DBC1 knockdown approach. MCF10a transfected with DB $\mathrm{C} 1$ siRNA were assayed for anoikis using DNA fragmentation ELISA. Western blotting confirmed $t$ he knock down of DBC1. mammary epithelial cell line

MCF10a. Over-expression ( 3-

fold) of DBC1 conferred significant $(\sim 3$-fold $)$ resistance to anoikis after six hours of suspension, although anoikis was not permanently suppressed (Fig.

1a). Conversely, the partial

depletion of DBC1 via siRNA transfection sensitized MCF10a cells to anoikis (Fig. 1b). Similar results were obtained using MCF10a cells stably transfected with DBC1 shRNA targeting a sequence distinct from the siRNA targets, ruling out off-target effects (Fig. S1). The effect of DBC1 siRNA on anoikis was further validated using a cell permeability assay for percent cell death as well as a three-dimensional acinar morphogenesis assay (Fig. S2, S3).

The generality of the protective effect of DBC1 on anoikis was then addressed in several diverse cell lines. First, mouse embryo fibroblasts (MEF) derived from $\mathrm{DBC1}^{-1-}$ mice [27] were found to be more sensitive to anoikis than $\mathrm{DBC}^{+/+}$MEF (Fig. 1c). To exclude potential artifacts due to spurious differences between

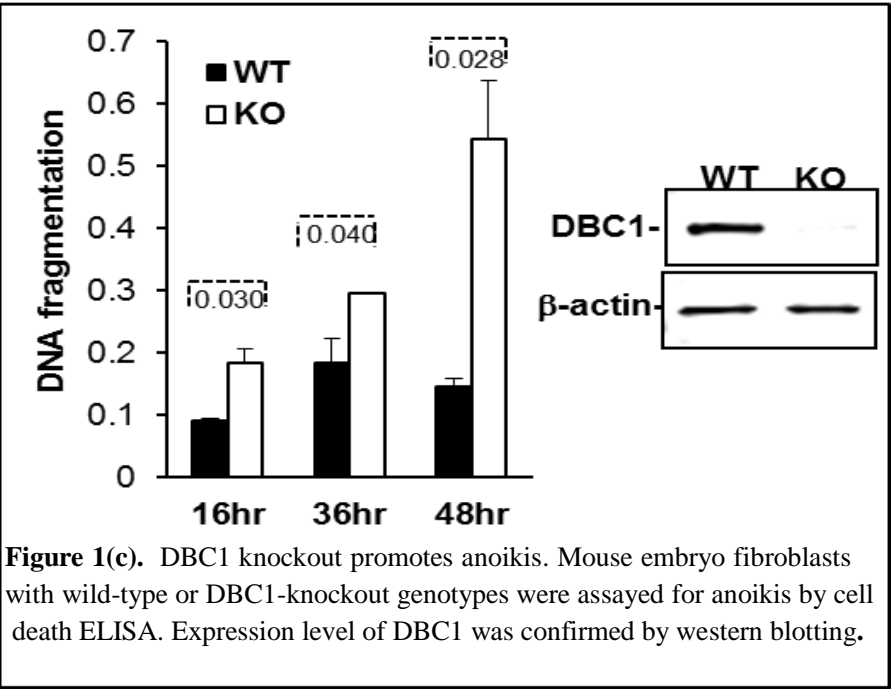


MEF cell lines, $\mathrm{DBC} 1^{-/-}$MEFs were rescued with DBC1 retroviral expression vector, which reverted

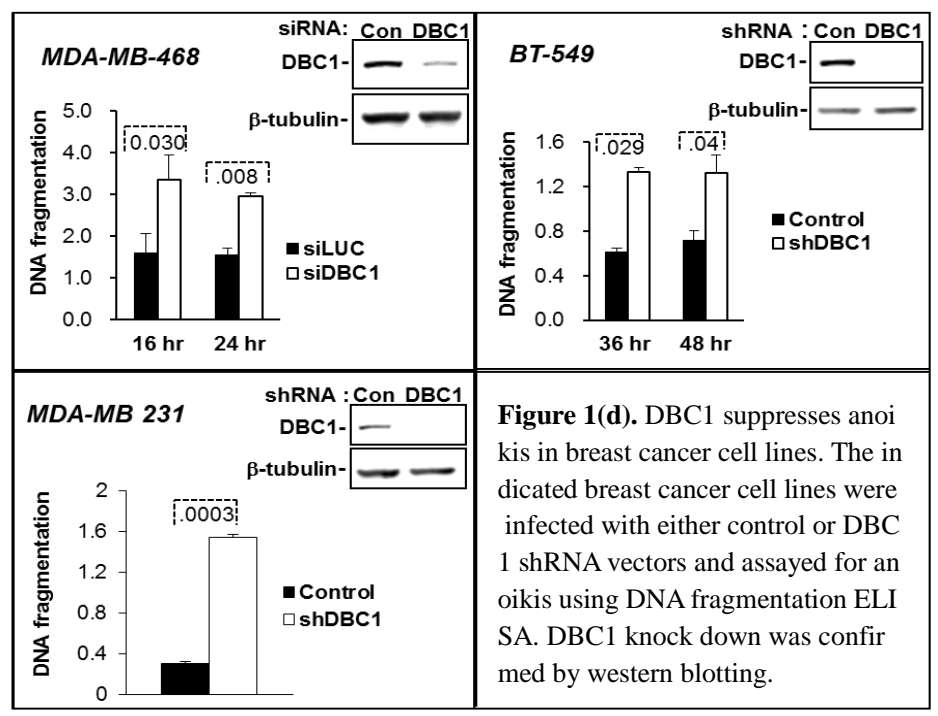

them to the wild-type level of anoikissensitivity (Fig. S4). The anoikis-sensitization effect of DBC1 depletion was also observed in three breast cancer cell lines: MDA-MB-231, BT-549 and MDA-MB-468 (Fig. 1d). These data indicate that DBC1 functions as a generalized anoikis suppressor.

\section{DBC1 affects the expression of NF-кB target genes}

We hypothesized that $\mathrm{DBC} 1$ might affect NF- $\mathrm{NB}$, in light of the documented importance of this factor for anoikis regulation $[8,12,14]$. To test this, we initially probed for several $\mathrm{NF}-\kappa \mathrm{B}$ target genes in cells with or

without DBC1

expression. MCF10a cells with DBC1
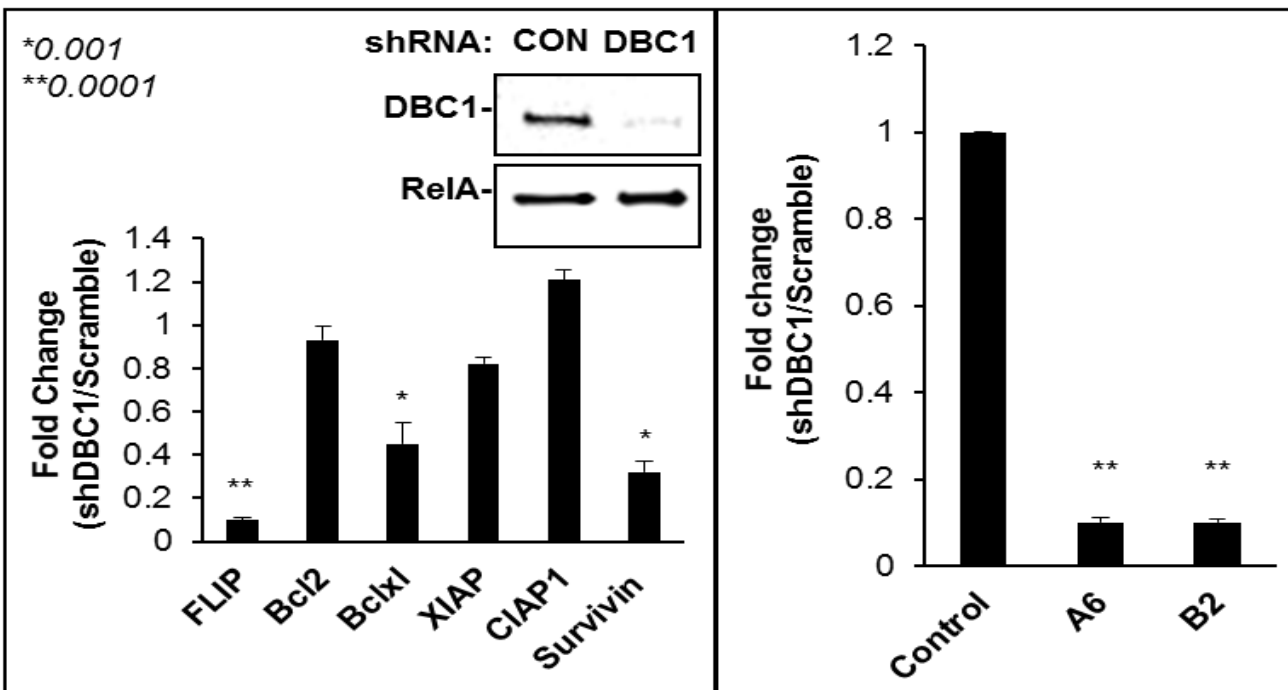

Figure 2 (a). DBC1 affects expression of NF-kB target genes. (Left panel): DBC1 induces expression level of NF-kB target genes in MCF10A cells. (Left panel): MCF10a cells expressing DBC1 or control shRNAs were analyzed by real time PCR for the expression level of the indicated NF-kB target genes; DBC1 knockdown was confirmed by western blotting; RelA was used as a loading control as DBC1 did not affect its level. (Right panel): MCF10a cells expressing two different DBC1 shRNAs were assayed for c-FLIP, to rule out off-target effects.

by qRT-PCR, showing

significant decreases in the levels of the NF- $\mathrm{B}$ target genes c-FLIP, Bcl-x-1, and survivin; other target genes, Bcl-2, xIAP, and cIAP, were unaffected (Fig. 2a). Positive regulation of both c-FLIP and bcl-xl 
proteins by DBC1 was observed in both attached and detached MCF10a cells (Fig. 2b), as well as in the comparison of wild-type vs. DBC1 knockout MEFs (Fig. S5).

These data indicated that DBC1 protein enhanced the expression of some NF- $\kappa \mathrm{B}$ target genes, under attached or detached conditions.

\section{DBC1 regulates anoikis through NF-kB}

Initially, the role of $\mathrm{NF}-\kappa \mathrm{B}$ in anoikis of MCF10a cells was

tested by the use of the dietary, non-specific inhibitor,

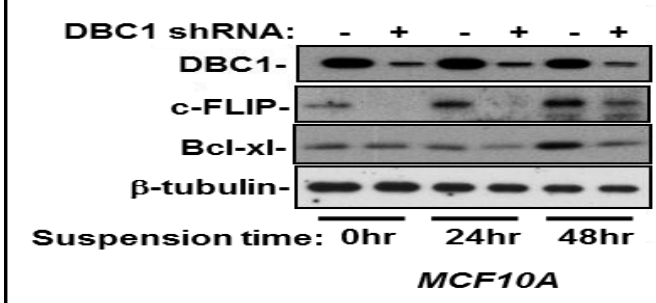

Figure 2(b). DBC1 knockdown reduces c-FLIP and Bcl-xl expression in MCF10A. Expression levels of cFLIP and Bcl-xl in attached or suspended MCF10A cells were assayed by western blotting. curcumin and a highly specific pharmacologic inhibitor of IKK- $\beta$ activity, Bay 11-7082 [30, 31]. Both compounds, used at similar concentrations to those previously reported for cell lines, sensitized MCF10a cells and mouse embryo fibroblasts to anoikis (Fig. 3a, b). The anoikis-hypersensitive state in BAY 117082-treated mouse embryo fibroblasts was not reversed by DBC1 expression, indicating that DBC1 protects primarily through the $\mathrm{NF}-\kappa \mathrm{B}$ pathway (Fig. 3b).

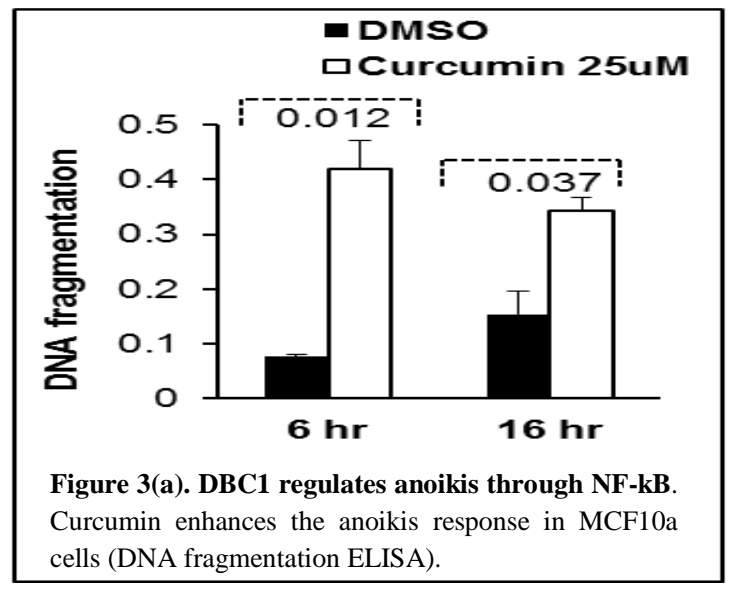

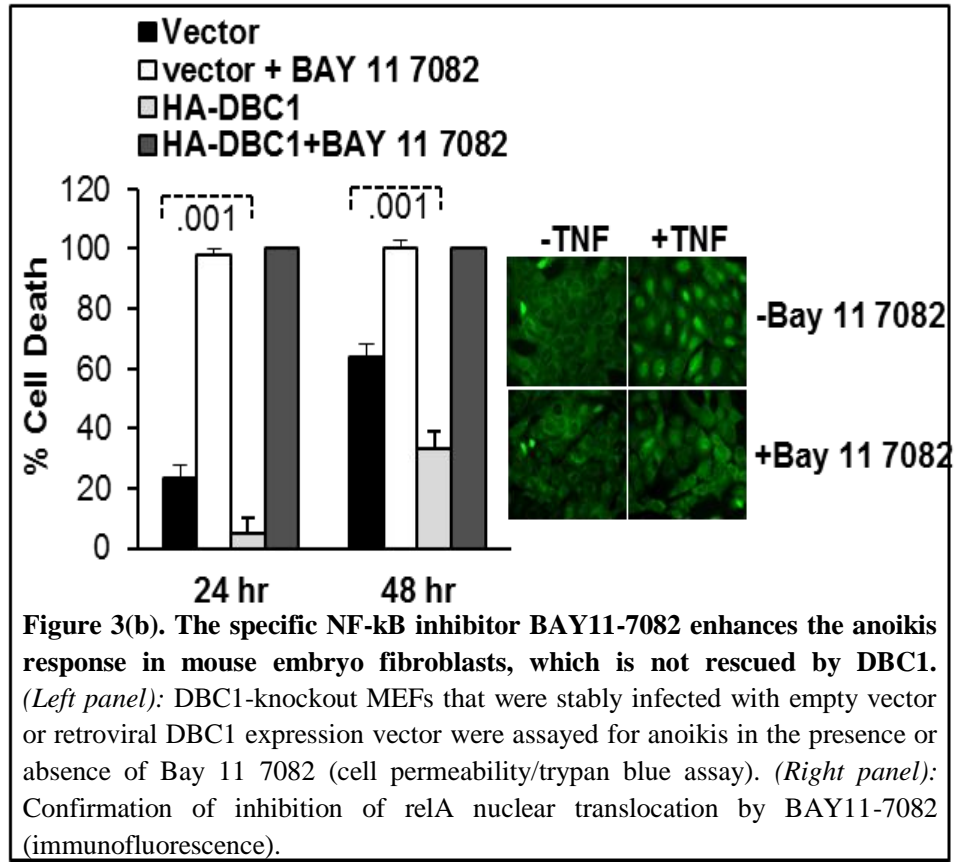


Further supporting the role of NF-kB in anoikis, over-expression of IKK- $\beta$, which has been shown previously to activate the NF-KB pathway [32], protected MCF10a against anoikis efficiently and induced higher levels of c-FLIP expression, both in attached and, especially, detached cells (Fig. 3c).

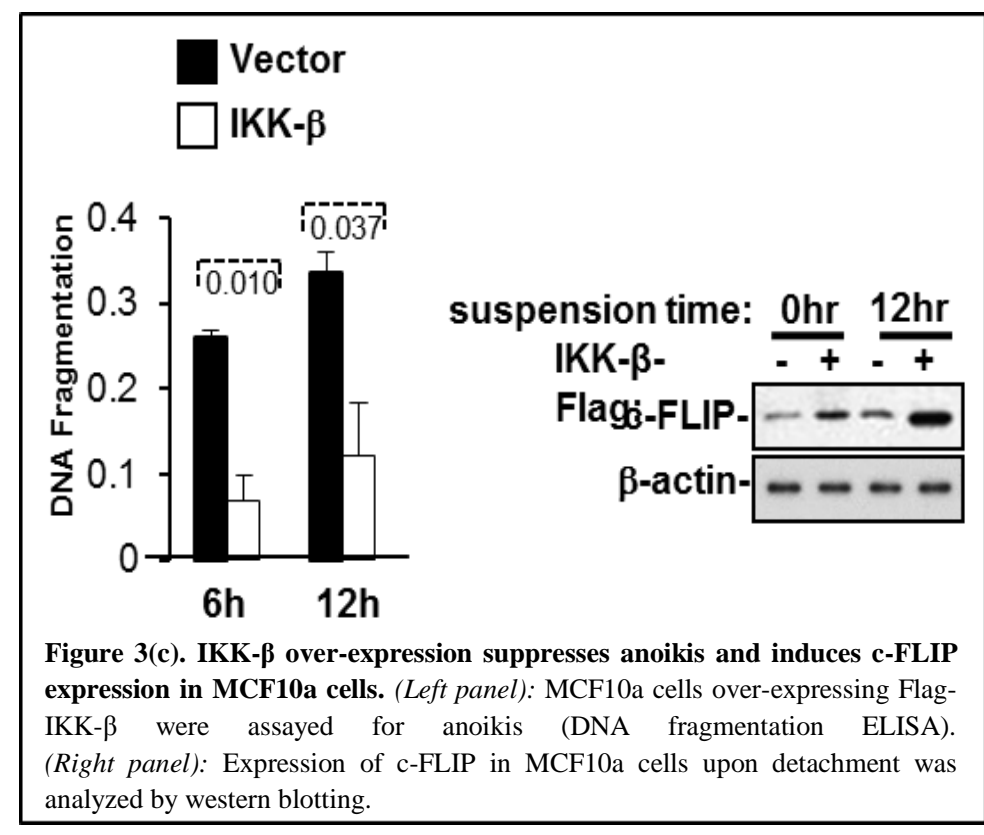

reverse the effect of DBC1 knockdown (i.e., confer resistance to anoikis; Fig. 3d). These data indicate that DBC1 promoted the expression of multiple NF- $\kappa$ B target genes, including c-FLIP, suppressing anoikis.
Among NF- $\kappa \mathrm{B}$ target genes, c-FLIP is particularly noted for its ability to regulate anoikis [11]. To test the role of c-FLIP in the suppression of anoikis by $\mathrm{DBC} 1$, MCF10a cells that express inducible DBC1 shRNA were infected with a constitutive cFLIP retroviral construct. This was found to

\begin{tabular}{|l|l}
\hline &
\end{tabular}

\section{DBC1 activates NF-kB-mediated transcription}

The results described above suggested that $\mathrm{DBC} 1$ activated the transcriptional activity of NF- $\mathrm{KB}$. To

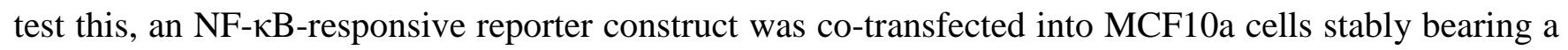
doxycycline-inducible DBC1 shRNA construct. The depletion of DBC1 inhibited NF- $\kappa$ B-driven luciferase expression significantly (Fig. 4a). As a control, cells were co-transfected with DBC1 cDNA expression vector to rescue DBC1 expression (because the shRNA was targeted to the 3' UTR), which rescued the $\mathrm{NF}-\kappa \mathrm{B}$ activity, ruling out off-target effects. The effect of $\mathrm{DBC} 1$ on $\mathrm{NF}-\kappa \mathrm{B}$ activity was 


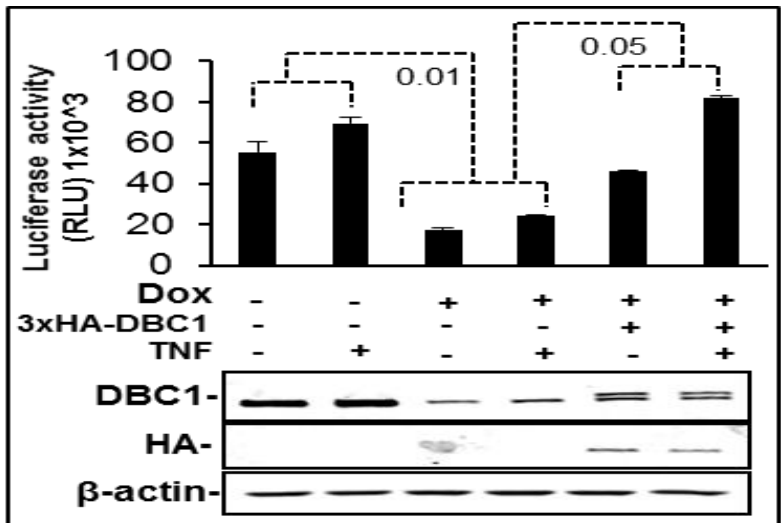

Figure 4(a). DBC1 promotes NF- $\mathrm{\kappa B}$ activation in MCF10a cells. MCF10a+shDBC1 cells were transfected with $3 \mathrm{X}-\mathrm{NF}-\mathrm{\kappa B}-\mathrm{luc}$, and either empty pCDNA3.1 or 3xHA-DBC1-pCDNA3.1. The cells were then assayed for luciferase activity following stimulation with TNF in the indicated samples. Knockdown and re-expression of (shRNA-resistant) DBC1 was confirmed by western blotting.

observed in cells with or without stimulation by TNF- $\alpha$.

The effect of DBC1 was confirmed by

additional experiments in DBC1 knockout vs. DBC1 wild-type MEFs, which were co-transfected with the $\mathrm{NF}-\mathrm{kB}-\mathrm{luc}$ reporter vector, in the presence or absence of

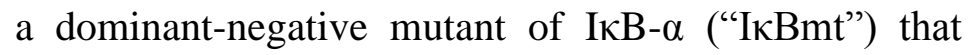
constitutively inhibits relA translocation regardless of stimulatory signals [33]. DBC1 enhanced NF- $\mathrm{BB}$

reporter activity in this system, which was inhibited to below baseline level by the I $\mathrm{K} B \mathrm{mt}$ construct, indicating the dependence of DBC1stimulated NF- $\kappa \mathrm{B}$ activity on the canonical kinase pathway (Fig. 4b).

Breast cancer cell lines, but not normal mammary epithelial cells, respond to detachment conditions

by activating NF- $\mathrm{kB}$ activity, contributing to anoikis-resistance [14]. To determine whether this

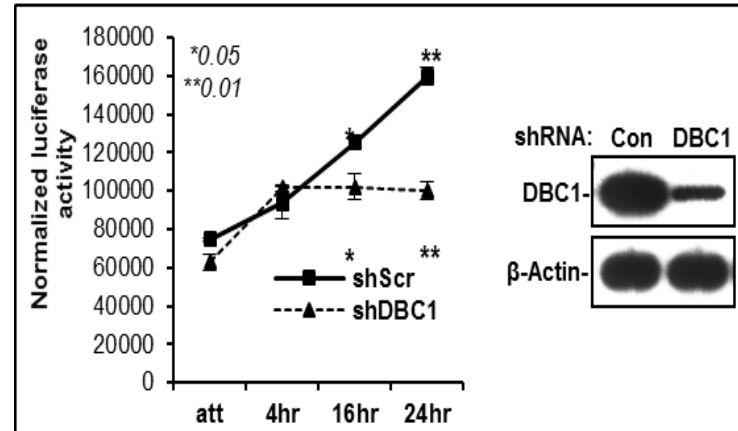

Figure 4(c). DBC1 suppresses NF-kB activity induced u pon detachment. MDA-MB-231 cells expressing either $\mathrm{c}$ ontrol or DBC1 shRNA were transfected with 3X-NF-kB-1 uc and assayed for luciferase activity following the indicat ed times of detachment. stimulation was DBC1-dependent, MDA-MB-231 cells with or without DBC1 shRNA expression were transfected with the NF- $\kappa \mathrm{B}$ reporter construct and assayed for $\mathrm{NF}-\kappa \mathrm{B}$ activity following detachment. Control cells activated NF$\kappa \mathrm{B}$ almost linearly over a 24-hour period, as reported previously [14]. By contrast, cells with DBC1 knockdown 
showed significantly reduced NF-אB activity, especially at time points after four hours (Fig. 4c). This indicated that the detachment-induced increase in $\mathrm{NF}-\kappa \mathrm{B}$ activity in a breast cancer cell line was partially dependent upon DBC1 protein.

\section{DBC1 interacts with IKK- $\beta$ and stimulates its activity}

By immunofluorescence, we confirmed previous reports that DBC1 was a nuclear protein [27], and, consistent with this, the translocation of relA to the nucleus upon stimulation with TNF was not affected by DBC1 (Fig. S6). This excluded mechanisms involving the canonical activity of the IKK complex in promoting relA translocation from cytoplasm to nucleus. We also addressed the possibility that DBC1 an endogenous inhibitor of SIRT1 deacetylase activity [34, 35] - activated the transcriptional activation domain of relA through acetylation, but relA K310 acetylation was not detectable in MCF10a cells (data

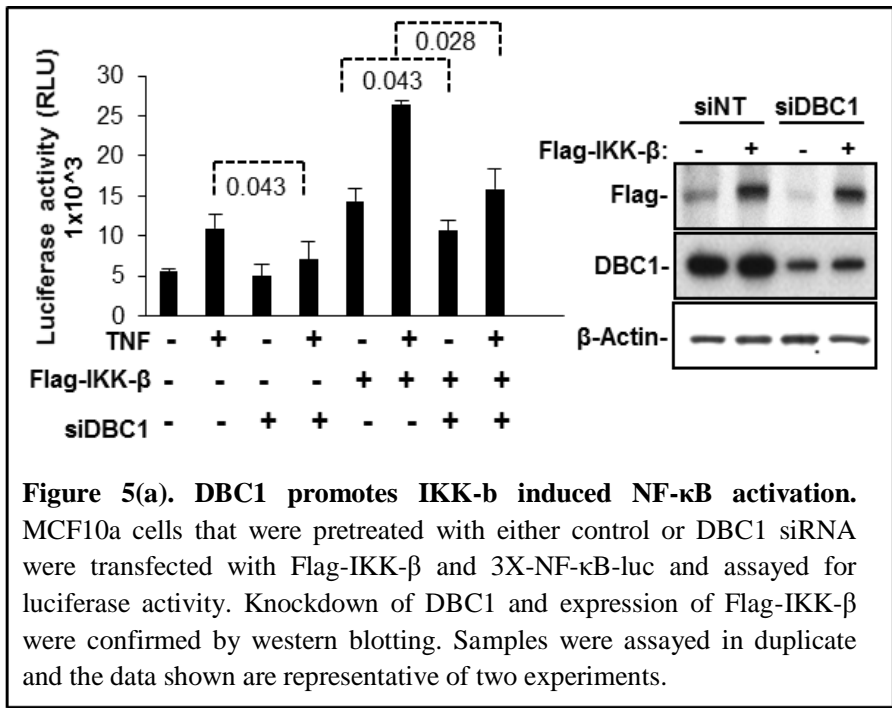

not shown), and there was no significant effect of DBC1 acetylation in mouse embryo fibroblasts (Fig. S7).

Interestingly, DBC1 stimulated the activation of $\mathrm{NF}-\kappa \mathrm{B}$ activity by co-transfected IKK- $\beta$ in reporter assays (Fig. 5a). Moreover, the major phosphorylation site for IKK- $\beta$ on relA, S536, potentiated transactivation by relA using a co-

transfection assay (Fig. S8), as reported previously in other systems [17-20]. We reasoned that perhaps DBC1 stimulated the kinase activity of IKK- $\beta$ on relA S536. Consistent with this, the phosphorylation of relA S536 was suppressed by shRNA-mediated depletion of DBC1 (Fig. 5b). 
By high-throughput proteomics analysis of the NF- $\mathrm{BB}$ pathway, DBC1 was identified previously as a candidate interactor of IKK- $\beta$ [36]. To demonstrate an interaction of DBC1 with IKK- $\beta$, S-tagged IKK- $\beta$ expressed in MDA-MB-231 cells was precipitated with S-protein agarose and probed for DBC1. Interactions clearly above a background control (i.e., a sample of MDA-MB-231 cells without the S-tagged construct)

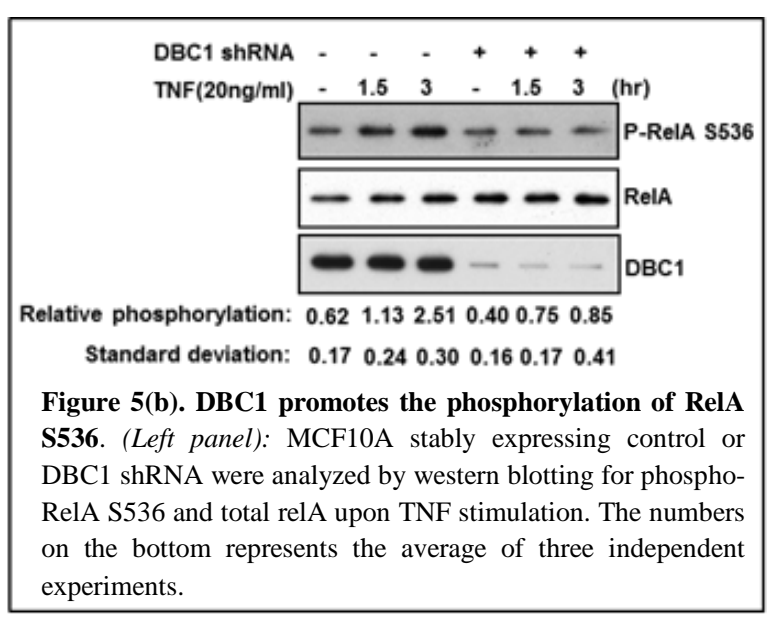

were observed, with highest efficiency in cells that were detached for twenty-four hours prior to lysis

A fully endogenous co-immunoprecipitation of IKK- $\beta$ with DBC1 was observed as well, but these

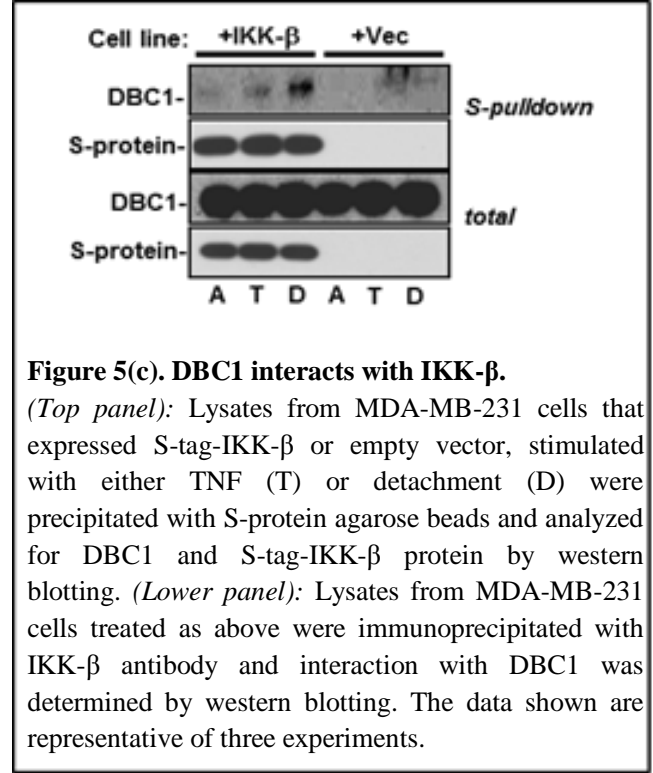
results were not as consistently reproducible as those using the S-tagged construct, perhaps reflecting the low abundance of nuclear IKK- $\beta$ expression [37](data not shown).

DBC1 stimulated NF- $\mathrm{NB}$ transcriptional activity and the phosphorylation of relA S536 and interacted with IKK- $\beta$ as well. To test the effect of DBC1 on IKK- $\beta$ kinase activity, recombinant proteins were assayed in vitro. The results showed a dose-dependent stimulation of IKK- $\beta$ activity by DBC1 protein (Fig. 5d), with maximal stimulation at a DBC1: IKK- $\beta$ molar ratio of approximately 1.0-1.5. Correspondingly, the knockdown of DBC1 decreased the enzymatic activity of IKK- $\beta$ that was immunoprecipitated from detached MDA-MB-231 cells and assayed (Fig. 5e). 
These observations confirmed that DBC1 interacted with and stimulated the activity of IKK- $\beta$, resulting in enhanced NF- $\kappa \mathrm{B}$ activity and protection from anoikis.

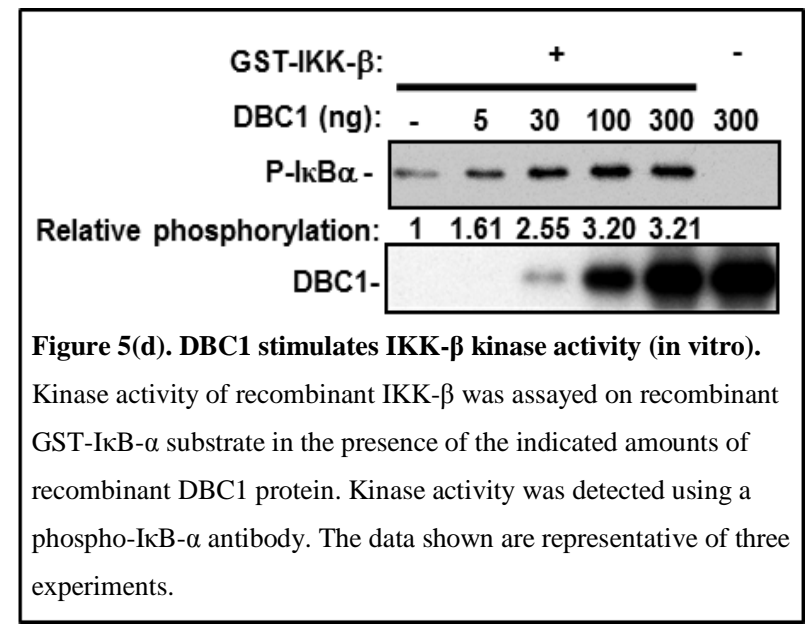

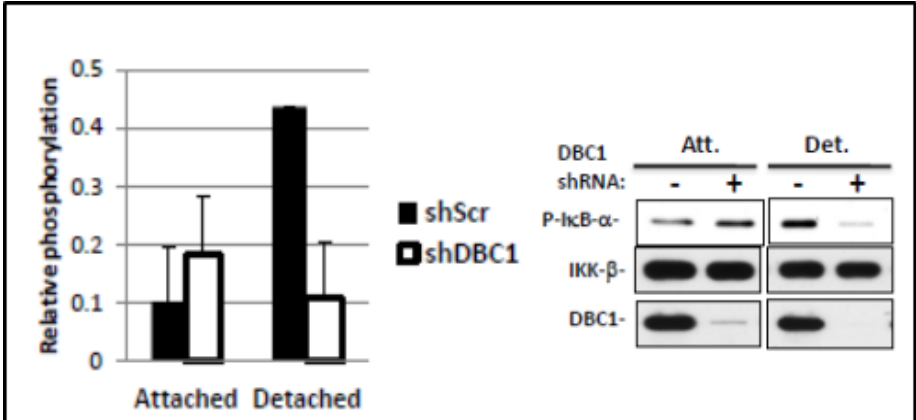

Figure 5(e). DBC1 stimulates IKK- $\beta$ kinase activity (in vivo). MDAMB-231 cells with control or DBC1 shRNAs (see figure 4c) were assayed for IKK- $\beta$ under attached or suspended conditions; phosphorylation of substrate was normalized to total IKK- $\beta$ to generate the values shown, which were averaged together over two experiments.

\section{DBC1 interacts with NRAGE}

Our yeast-two-hybrid study showed that DBC1 is a candidate interactor with NRAGE. To confirm their interaction, 293T co-transfection assay was performed using 3X-HA tagged DBC1 and 3X-Flag tagged NRAGE (Fig. 6). In addition, to further confirm their interaction, an endogenous co-IP using HMLE+T wist cells was performed (Fig.7). The results showed that DBC1 interacts with NRAGE.

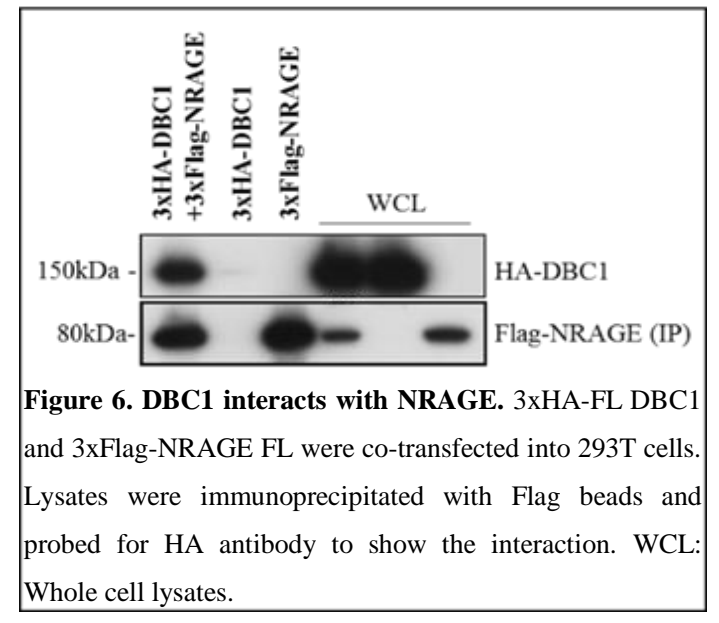

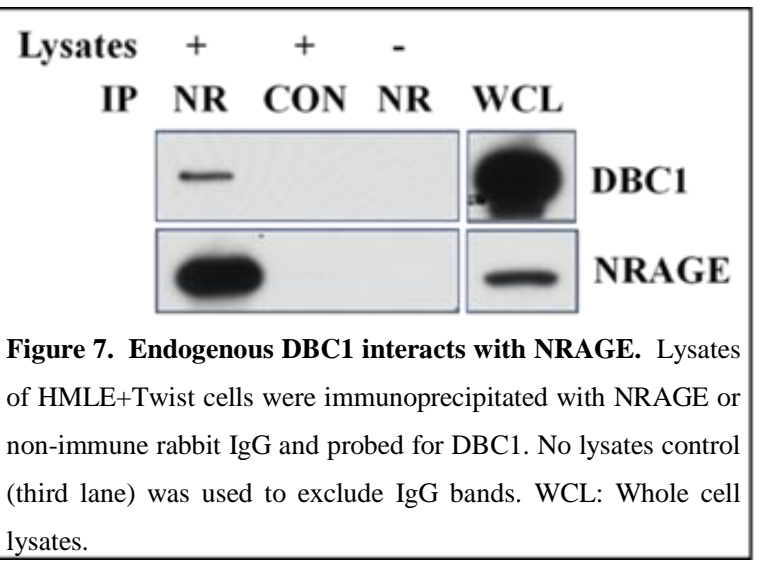

lysates. 


\section{DISCUSSION}

The key finding of this study is that DBC1 protein contributes to the protection of normal and transformed cells against anoikis. Notably, DBC1 is not invariably anti-apoptotic. For example, the interaction of DBC1 with SIRT1 is enhanced by genotoxic and/or oxidative stress, through ATMmediated DBC1 phosphorylation, enhancing p53 acetylation - a pro-apoptotic effect of DBC1 with respect to genotoxic/oxidative stress-induced apoptotic responses, in contrast with its role in anoikis [21].

The novel pathway by which $\mathrm{DBC} 1$ protein promotes $\mathrm{NF}-\mathrm{\kappa B}$ activity and anoikis-resistance is depicted in figure 8 . DBC1 may be conceptualized as a co-factor for IKK- $\beta$ that stimulates its kinase activity on relA (S536), promoting the transcriptional activation of $\mathrm{NF}-\kappa \mathrm{B}$ target genes that enhance anoikisresistance. Among the most robustly DBC1-sensitive genes were c-FLIP and Bcl-xl, both of which have significant roles in anoikis-resistance of tumor cells, documented both here and elsewhere [11, 38]. In this connection, novel drugs that act by destabilizing c-FLIP expression are

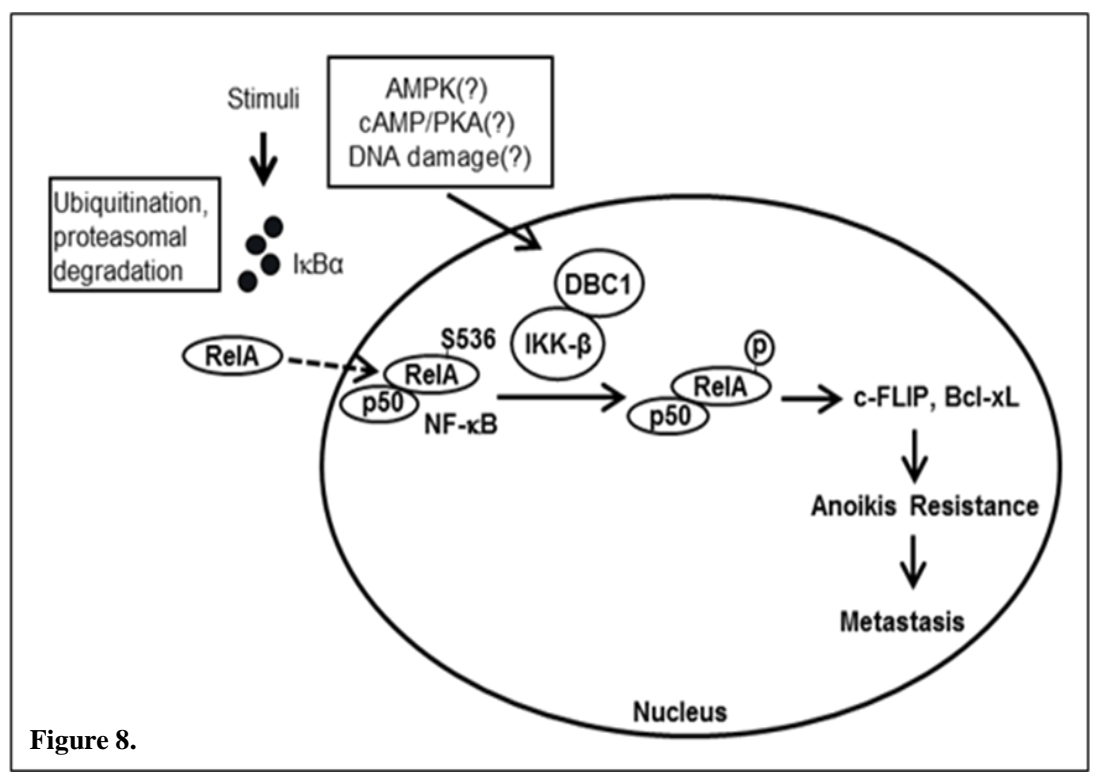
being developed with the goal of sensitizing tumor cells to anoikis [39].

Notably, IKK complexes can promote cell survival by additional, NF- $\mathrm{B}$-independent mechanisms as well, for example, through the phosphorylation of Foxo3A, p53, and mTORC (the latter resulting in survivin up-regulation) [5]. Although our data indicate a dominant role of $\mathrm{NF}-\kappa \mathrm{B}$ in the DBC1 cell 
survival effect, we cannot exclude that other IKK-dependent, NF-кB-independent effects might play additional roles. In this connection, IKK-I/IKK- $\varepsilon$ appear to be responsible for increased relA S536 phosphorylation in some tumor cells [40]; the potential of DBC1 to affect additional IKK complexes will be interesting to explore. Note also that while IKK- $\beta$ clearly is important also for the phosphorylation of IKB- $\alpha, \mathrm{DBC} 1$ did not affect the phosphorylation of this substrate in vivo, consistent with the primarily nuclear localization of $\mathrm{DBC} 1$, the stimulus-responsive nuclear and cytoplasmic localization of IKK- $\beta$ and the constitutive cytoplasmic localization of IкB- $\alpha[27,41]$.

Recent studies indicate that increased relA S536 phosphorylation and DBC1 over-expression each correlate with worse prognosis in colorectal cancer, a cancer type that is influenced dramatically by inflammatory stimuli that activate NF- $\mathrm{B}[25,42]$. Correlation of more aggressive disease with DBC1 over-expression has been reported in breast cancer also [22, 23], and our data here show that DBC1 is important for the detachment-induced NF- $\mathrm{KB}$ activation that is observed in breast cancer cell lines, reported by the Richer laboratory [14]. These observations suggest that DBC1 over-expression, which has been demonstrated in esophageal cancer as well [24], promotes tumor progression through the pathway that we have elucidated here.

Biochemically, DBC1 was previously shown to regulate several transcription factors or regulators of transcription factors. As an endogenous inhibitor of SIRT1 deacetylase activity [34, 35], DBC1 enhanced the acetylation and stability of the SIRT1 substrate p53, potentially enhancing apoptosis in certain contexts. However, a recent study in liver cancer cells showed an effect of DBC1 neither on SIRT1 activity nor p53 acetylation, complicating the interpretation of this phenomenon [43]. We did not observe an effect of $\mathrm{DBC} 1$ on the acetylation of relA in mouse embryo fibroblasts, and failed to detect 
significant relA acetylation in MCF10a cells, diminishing the relevance of this as a potential mechanism for DBC1 to regulate NF- $\mathrm{kB}$, at least in our cell lines. DBC1 regulates several other factors as well, including the SUV39H1 histone methyltransferase, histone deacetylase-3, BRCA1, estrogen receptor and androgen receptor, thus having multiple pleiotropic effects on transcription [44-49]. In fact, DBC1 may also modulate alternative splicing, as it is a component of the DBIRD complex that integrates mRNA splicing with RNA polymerase II-mediated transcription [50]. Thus, it is not only possible but likely that DBC1 affords anoikis-resistance by mechanisms additional to the NF- $\mathrm{kB}$ mediated one described here, which remain to be identified. In this connection, though, microarray analysis identified c-FLIP plus a surprisingly short list of other DBC1-regulated genes, suggesting that NF- $\mathrm{KB}$ and/or additional c-FLIP regulatory proteins may be the most significant DBC1 targets (data not shown).

The interaction of DBC1 with IKK- $\beta$ signifies that NF-KB is positioned for activation by novel mechanisms that have not yet been suggested. For example, the interaction between SIRT1 and DBC1 is dissociated by cAMP/PKA, acting through AMP-dependent protein kinase (AMPK), suggesting a novel mechanism for the metabolic control of SIRT1 [51]. Although it is not yet clear how this dissociation is achieved, it is intriguing to note that NF- $\mathrm{BB}$ is inhibited by AMPK. This raises the possibility that the interaction of DBC1 with IKK- $\beta$ may also be regulated by AMPK or other signal transducers, providing novel metabolic control mechanisms for NF-kB and anoikis.

The interaction between DBC1 and NRAGE suggests that crosstalk exists such that DBC1 and NRAGE affect each other's functions and signaling pathways. This potential crosstalk is discussed in chapter 4. 


\section{ACKNOWLEDGEMENTS}

S.M. Frisch was supported by NIH grant R01CA123359. The flow cytometry core facility (Mary Babb Randolph Cancer Center) was supported by NIH grants RR020866 and P20 RR16440 and we thank Kathy Brundage for performing the flow-sorting. We also wish to thank Zenkun Lou, Eduardo Chini for

the DBC1-knockout cells, Alexey Ivanov, Elena Pugacheva, Jurg Tschopp, Russ Carstens, Yon Rojanasakul and Sierra Talbott for constructs; we also thank the Biochemistry Protein Core for assistance with recombinant protein production.

\section{CONFLICT OF INTEREST}

The authors declare no conflict of interest. 


\section{REFERENCES}

1. Frisch SM and Francis H (1994) Disruption of epithelial cell-matrix interactions induces apoptosis. J Cell Biol 124:619-26.

2. Guadamillas MC, Cerezo A and Del Pozo MA Overcoming anoikis--pathways to anchorageindependent growth in cancer. J Cell Sci 124:3189-97. doi: 124/19/3189 [pii]

$10.1242 /$ jcs. 072165

3. Frisch SM, Schaller M and Cieply B (2013) Mechanisms that link the oncogenic epithelialmesenchymal transition to suppression of anoikis. J Cell Sci xxx:xxx.

4. Simpson CD, Anyiwe K and Schimmer AD (2008) Anoikis resistance and tumor metastasis. Cancer Lett 272:177-85. doi: S0304-3835(08)00394-7 [pii]

10.1016/j.canlet.2008.05.029

5. Baldwin AS Regulation of cell death and autophagy by IKK and NF-kappaB: critical mechanisms in immune function and cancer. Immunol Rev 246:327-45. doi: 10.1111/j.1600065X.2012.01095.X

6. Aggarwal BB and Sung B NF-kappaB in cancer: a matter of life and death. Cancer Discov 1:469-71. doi: $1 / 6 / 469$ [pii]

10.1158/2159-8290.CD-11-0260

7. DiDonato JA, Mercurio F and Karin M NF-kappaB and the link between inflammation and cancer. Immunol Rev 246:379-400. doi: 10.1111/j.1600-065X.2012.01099.x

8. Toruner M, Fernandez-Zapico M, Sha JJ, Pham L, Urrutia R and Egan LJ (2006) Antianoikis effect of nuclear factor-kappaB through up-regulated expression of osteoprotegerin, BCL-2, and IAP-1. J Biol Chem 281:8686-96. doi: M512178200 [pii]

10.1074/jbc.M512178200

9. Liu Z, Li H, Wu X, Yoo BH, Yan SR, Stadnyk AW, Sasazuki T, Shirasawa S, LaCasse EC, Korneluk RG and Rosen KV (2006) Detachment-induced upregulation of XIAP and cIAP2 delays anoikis of intestinal epithelial cells. Oncogene 25:7680-90. doi: 1209753 [pii]

10.1038/sj.onc. 1209753

10. Mehrotra S, Languino LR, Raskett CM, Mercurio AM, Dohi T and Altieri DC IAP regulation of metastasis. Cancer Cell 17:53-64. doi: S1535-6108(09)00422-X [pii]

10.1016/j.ccr.2009.11.021

11. Mawji IA, Simpson CD, Hurren R, Gronda M, Williams MA, Filmus J, Jonkman J, Da Costa RS, Wilson BC, Thomas MP, Reed JC, Glinsky GV and Schimmer AD (2007) Critical role for Fasassociated death domain-like interleukin-1-converting enzyme-like inhibitory protein in anoikis resistance and distant tumor formation. J Natl Cancer Inst 99:811-22. doi: 99/10/811 [pii]

10.1093/jnci/djk182

12. Yan SR, Joseph RR, Rosen K, Reginato MJ, Jackson A, Allaire N, Brugge JS, Jobin C and Stadnyk AW (2005) Activation of NF-kappaB following detachment delays apoptosis in intestinal epithelial cells. Oncogene 24:6482-91. doi: 10.1038/sj.onc.1208810

13. Lin DC, Zhang Y, Pan QJ, Yang H, Shi ZZ, Xie ZH, Wang BS, Hao JJ, Zhang TT, Xu X, Zhan QM and Wang MR PLK1 Is transcriptionally activated by NF-kappaB during cell detachment and enhances anoikis resistance through inhibiting beta-catenin degradation in esophageal squamous cell carcinoma. Clin Cancer Res 17:4285-95. doi: 1078-0432.CCR-10-3236 [pii]

10.1158/1078-0432.CCR-10-3236 
14. Howe EN, Cochrane DR, Cittelly DM and Richer JK miR-200c Targets a NF-kappaB UpRegulated TrkB/NTF3 Autocrine Signaling Loop to Enhance Anoikis Sensitivity in Triple Negative Breast Cancer. PLoS One 7:e49987. doi: 10.1371/journal.pone.0049987

PONE-D-12-15512 [pii]

15. Calao M, Burny A, Quivy V, Dekoninck A and Van Lint C (2008) A pervasive role of histone acetyltransferases and deacetylases in an NF-kappaB-signaling code. Trends Biochem Sci 33:339-49. doi: S0968-0004(08)00124-2 [pii]

10.1016/j.tibs.2008.04.015

16. Oeckinghaus A, Hayden MS and Ghosh S Crosstalk in NF-kappaB signaling pathways. Nat Immunol 12:695-708. doi: ni.2065 [pii]

10.1038/ni.2065

17. Jeong SJ, Pise-Masison CA, Radonovich MF, Park HU and Brady JN (2005) A novel NF-kappaB pathway involving IKKbeta and p65/RelA Ser-536 phosphorylation results in p53 Inhibition in the absence of NF-kappaB transcriptional activity. J Biol Chem 280:10326-32. doi: M412643200 [pii]

10.1074/jbc.M412643200

18. Sakurai H, Chiba H, Miyoshi H, Sugita T and Toriumi W (1999) IkappaB kinases phosphorylate NF-kappaB p65 subunit on serine 536 in the transactivation domain. J Biol Chem 274:30353-6.

19. Yang F, Tang E, Guan K and Wang CY (2003) IKK beta plays an essential role in the phosphorylation of RelA/p65 on serine 536 induced by lipopolysaccharide. J Immunol 170:5630-5.

20. Adli M, Merkhofer E, Cogswell $\mathrm{P}$ and Baldwin AS IKKalpha and IKKbeta each function to regulate NF-kappaB activation in the TNF-induced/canonical pathway. PLoS One 5:e9428. doi: 10.1371/journal.pone.0009428

21. Zannini L, Buscemi G, Kim JE, Fontanella E and Delia D DBC1 phosphorylation by ATM/ATR inhibits SIRT1 deacetylase in response to DNA damage. J Mol Cell Biol 4:294-303. doi: mjs035 [pii] 10.1093/jmcb/mjs035

22. Hiraike H, Wada-Hiraike O, Nakagawa S, Saji S, Maeda D, Miyamoto Y, Sone K, Tanikawa M, Oda K, Nakagawa K, Yano T, Fukayama M and Taketani Y (2011) Expression of DBC1 is associated with nuclear grade and HER2 expression in breast cancer. Exp Ther Med 2:1105-1109. doi: 10.3892/etm.2011.333

23. Lee H, Kim KR, Noh SJ, Park HS, Kwon KS, Park BH, Jung SH, Youn HJ, Lee BK, Chung MJ, Koh DH, Moon WS and Jang KY Expression of DBC1 and SIRT1 is associated with poor prognosis for breast carcinoma. Hum Pathol 42:204-13. doi: S0046-8177(10)00248-0 [pii]

10.1016/j.humpath.2010.05.023

24. Kim SH, Kim JH, Yu EJ, Lee KW and Park CK (2012) The overexpression of DBC1 in esophageal squamous cell carcinoma correlates with poor prognosis. Histol Histopathol 27:49-58.

25. Zhang Y, Gu Y, Sha S, Kong X, Zhu H, Xu B, Li Y and Wu K DBC1 is over-expressed and associated with poor prognosis in colorectal cancer. Int J Clin Oncol. doi: 10.1007/s10147-012-0506-5

26. Kim JE, Chen J and Lou Z (2009) p30 DBC is a potential regulator of tumorigenesis. Cell Cycle 8. doi: 9473 [pii]

27. Escande C, Chini CC, Nin V, Dykhouse KM, Novak CM, Levine J, van Deursen J, Gores GJ, Chen J, Lou Z and Chini EN Deleted in breast cancer-1 regulates SIRT1 activity and contributes to highfat diet-induced liver steatosis in mice. J Clin Invest 120:545-58. doi: 39319 [pii]

10.1172/JCI39319

28. Debnath J, Muthuswamy SK and Brugge JS (2003) Morphogenesis and oncogenesis of MCF10A mammary epithelial acini grown in three-dimensional basement membrane cultures. Methods 30:256-68. 
29. Kumar S, Park SH, Cieply B, Schupp J, Killiam E, Zhang F, Rimm DL and Frisch SM A pathway for the control of anoikis sensitivity by E-cadherin and epithelial-to-mesenchymal transition. Mol Cell Biol 31:4036-51. doi: MCB.01342-10 [pii]

10.1128/MCB.01342-10

30. Shehzad A, Khan S and Sup Lee Y Curcumin molecular targets in obesity and obesity-related cancers. Future Oncol 8:179-90. doi: 10.2217/fon.11.145

31. Mori N, Yamada Y, Ikeda S, Yamasaki Y, Tsukasaki K, Tanaka Y, Tomonaga M, Yamamoto N and Fujii M (2002) Bay 11-7082 inhibits transcription factor NF-kappaB and induces apoptosis of HTLV-I-infected T-cell lines and primary adult T-cell leukemia cells. Blood 100:1828-34. doi: 10.1182/blood-2002-01-0151

32. Woronicz JD, Gao X, Cao Z, Rothe M and Goeddel DV (1997) IkappaB kinase-beta: NF-kappaB activation and complex formation with IkappaB kinase-alpha and NIK. Science 278:866-9.

33. Boehm JS, Zhao JJ, Yao J, Kim SY, Firestein R, Dunn IF, Sjostrom SK, Garraway LA, Weremowicz S, Richardson AL, Greulich H, Stewart CJ, Mulvey LA, Shen RR, Ambrogio L, HirozaneKishikawa T, Hill DE, Vidal M, Meyerson M, Grenier JK, Hinkle G, Root DE, Roberts TM, Lander ES, Polyak K and Hahn WC (2007) Integrative genomic approaches identify IKBKE as a breast cancer oncogene. Cell 129:1065-79. doi: S0092-8674(07)00532-6 [pii]

10.1016/j.cell.2007.03.052

34. Zhao W, Kruse JP, Tang Y, Jung SY, Qin J and Gu W (2008) Negative regulation of the deacetylase SIRT1 by DBC1. Nature 451:587-90. doi: nature06515 [pii]

10.1038/nature06515

35. Kim JE, Chen J and Lou Z (2008) DBC1 is a negative regulator of SIRT1. Nature 451:583-6. doi: nature06500 [pii]

$10.1038 /$ nature 06500

36. Bouwmeester T, Bauch A, Ruffner H, Angrand PO, Bergamini G, Croughton K, Cruciat C, Eberhard D, Gagneur J, Ghidelli S, Hopf C, Huhse B, Mangano R, Michon AM, Schirle M, Schlegl J, Schwab M, Stein MA, Bauer A, Casari G, Drewes G, Gavin AC, Jackson DB, Joberty G, Neubauer G, Rick J, Kuster B and Superti-Furga G (2004) A physical and functional map of the human TNFalpha/NF-kappa B signal transduction pathway. Nat Cell Biol 6:97-105. doi: 10.1038/ncb1086 ncb1086 [pii]

37. Sakamoto K, Hikiba Y, Nakagawa H, Hirata Y, Hayakawa Y, Kinoshita H, Nakata W, Sakitani K, Takahashi R, Akanuma M, Kamata H and Maeda S (2012) Promotion of DNA repair by nuclear IKKbeta phosphorylation of ATM in response to genotoxic stimuli. Oncogene. doi: 10.1038/onc.2012.192

38. Alfano D, Iaccarino I and Stoppelli MP (2006) Urokinase signaling through its receptor protects against anoikis by increasing BCL-xL expression levels. J Biol Chem 281:17758-67. doi: M601812200 [pii]

10.1074/jbc.M601812200

39. Mawji IA, Simpson CD, Gronda M, Williams MA, Hurren R, Henderson CJ, Datti A, Wrana JL and Schimmer AD (2007) A chemical screen identifies anisomycin as an anoikis sensitizer that functions by decreasing FLIP protein synthesis. Cancer Res 67:8307-15. doi: 67/17/8307 [pii]

10.1158/0008-5472.CAN-07-1687

40. Adli M and Baldwin AS (2006) IKK-i/IKKepsilon controls constitutive, cancer cell-associated NF-kappaB activity via regulation of Ser-536 p65/RelA phosphorylation. J Biol Chem 281:26976-84. doi: M603133200 [pii]

10.1074/jbc.M603133200 
41. Tsuchiya Y, Asano T, Nakayama K, Kato T, Jr., Karin M and Kamata H Nuclear IKKbeta is an adaptor protein for IkappaBalpha ubiquitination and degradation in UV-induced NF-kappaB activation. Mol Cell 39:570-82. doi: S1097-2765(10)00577-0 [pii]

10.1016/j.molcel.2010.07.030

42. Lewander A, Gao J, Carstensen J, Arbman G, Zhang H and Sun XF NF-kappaB p65 phosphorylated at serine-536 is an independent prognostic factor in Swedish colorectal cancer patients. Int J Colorectal Dis 27:447-52. doi: 10.1007/s00384-011-1356-8

43. Bae HJ, Chang YG, Noh JH, Kim JK, Eun JW, Jung KH, Kim MG, Shen Q, Ahn YM, Kwon SH, Park WS, Lee JY and Nam SW DBC1 does not function as a negative regulator of SIRT1 in liver cancer. Oncol Lett 4:873-877. doi: 10.3892/ol.2012.875 ol-04-05-0873 [pii]

44. Yu EJ, Kim SH, Heo K, Ou CY, Stallcup MR and Kim JH Reciprocal roles of DBC1 and SIRT1 in regulating estrogen receptor alpha activity and co-activator synergy. Nucleic Acids Res 39:6932-43. doi: $\mathrm{gkr} 347$ [pii]

10.1093/nar/gkr347

45. Li Z, Chen L, Kabra N, Wang C, Fang J and Chen J (2009) Inhibition of SUV39H1 methyltransferase activity by DBC1. J Biol Chem 284:10361-6. doi: M900956200 [pii]

10.1074/jbc.M900956200

46. Chini CC, Escande C, Nin V and Chini EN (2010) HDAC3 is negatively regulated by the nuclear protein DBC1. J Biol Chem 285:40830-7. doi: 10.1074/jbc.M110.153270

47. Hiraike H, Wada-Hiraike O, Nakagawa S, Koyama S, Miyamoto Y, Sone K, Tanikawa M, Tsuruga T, Nagasaka K, Matsumoto Y, Oda K, Shoji K, Fukuhara H, Saji S, Nakagawa K, Kato S, Yano $\mathrm{T}$ and Taketani Y (2010) Identification of DBC1 as a transcriptional repressor for BRCA1. Br J Cancer 102:1061-7. doi: 10.1038/sj.bjc.6605577

48. Trauernicht AM, Kim SJ, Kim NH and Boyer TG (2007) Modulation of estrogen receptor alpha protein level and survival function by DBC-1. Mol Endocrinol 21:1526-36. doi: 10.1210/me.2007-0064

49. Fu J, Jiang J, Li J, Wang S, Shi G, Feng Q, White E, Qin J and Wong J (2009) Deleted in breast cancer 1, a novel androgen receptor (AR) coactivator that promotes AR DNA-binding activity. J Biol Chem 284:6832-40. doi: M808988200 [pii]

10.1074/jbc.M808988200

50. Close P, East P, Dirac-Svejstrup AB, Hartmann H, Heron M, Maslen S, Chariot A, Soding J, Skehel $M$ and Svejstrup JQ DBIRD complex integrates alternative mRNA splicing with RNA polymerase II transcript elongation. Nature 484:386-9. doi: nature10925 [pii]

10.1038/nature10925

51. Nin V, Escande C, Chini CC, Giri S, Camacho-Pereira J, Matalonga J, Lou Z and Chini EN Role of deleted in breast cancer 1 (DBC1) protein in SIRT1 deacetylase activation induced by protein kinase A and AMP-activated protein kinase. J Biol Chem 287:23489-501. doi: M112.365874 [pii]

10.1074/jbc.M112.365874 

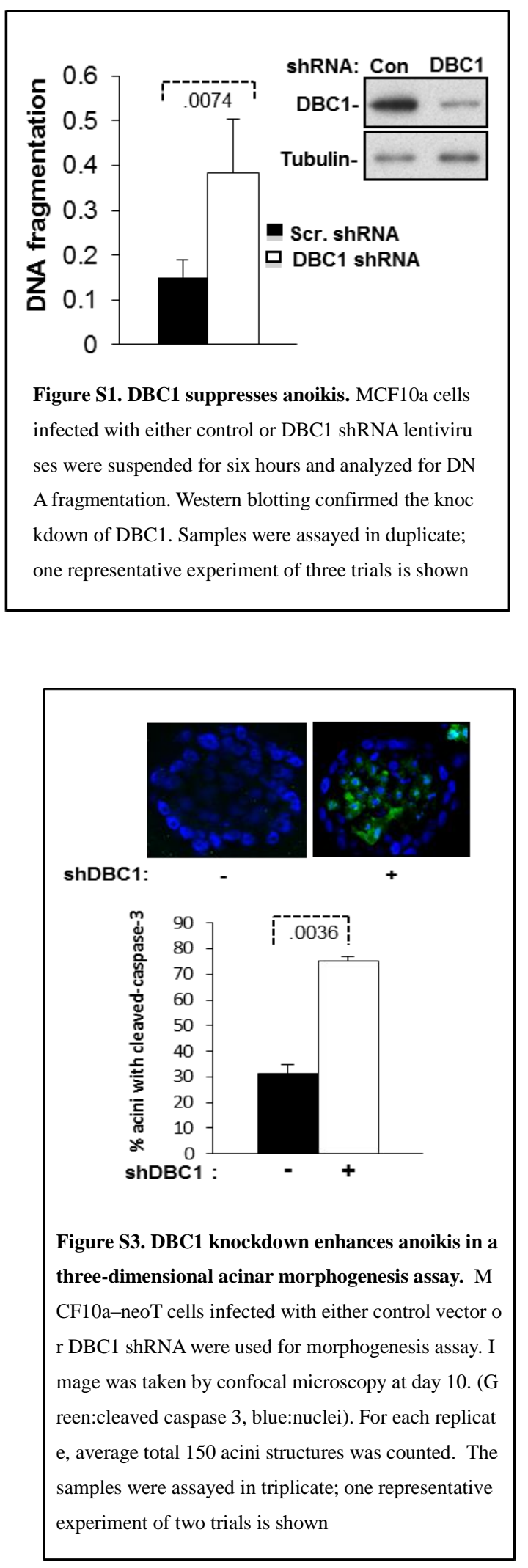
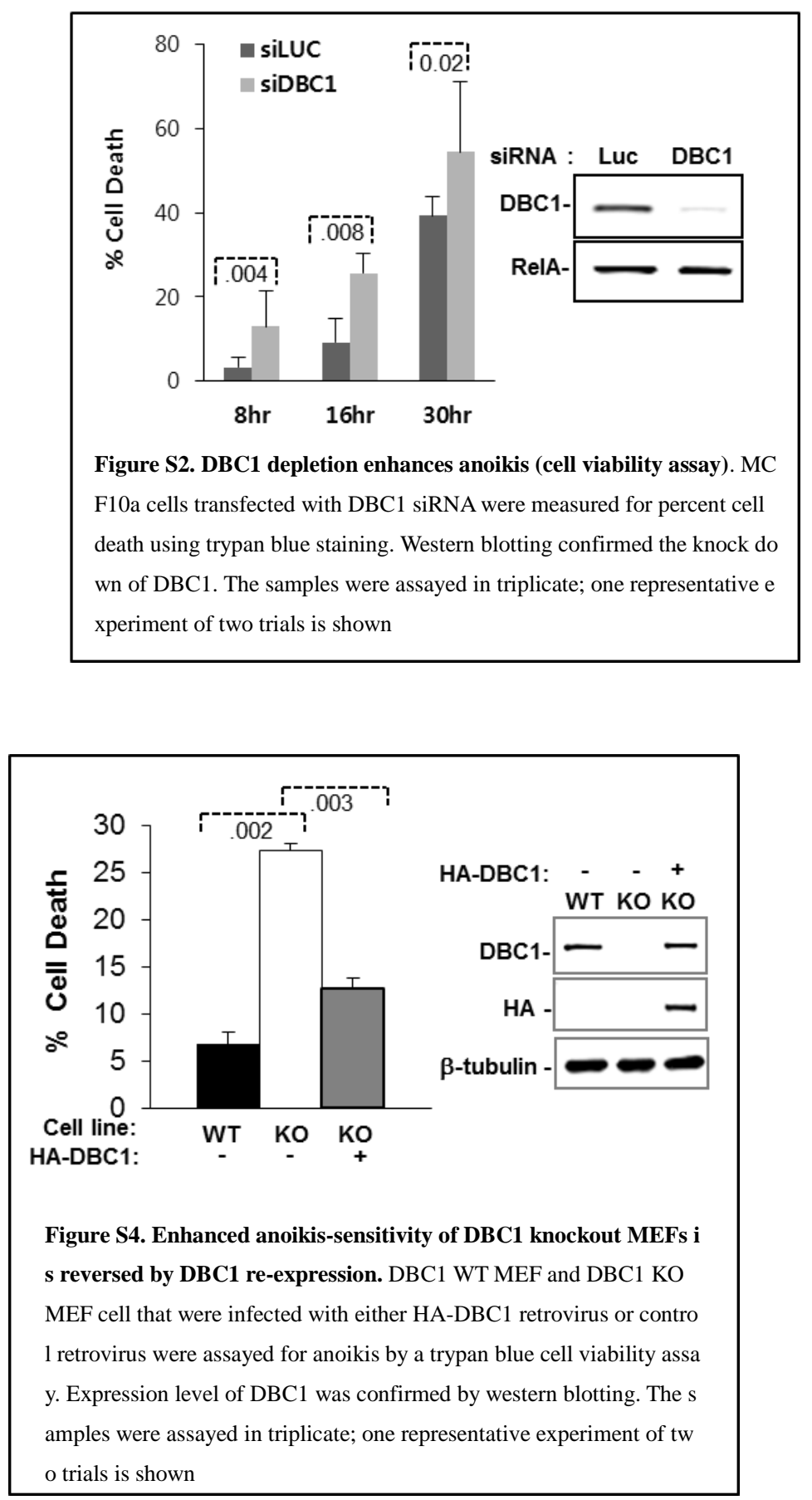


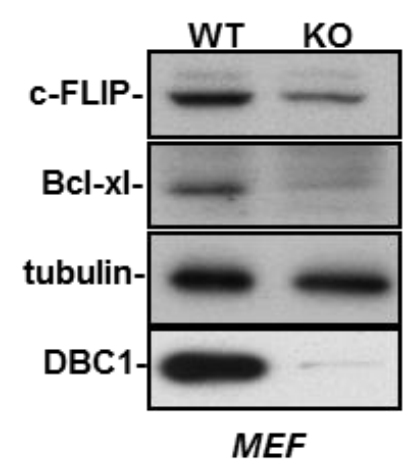

Figure S5. DBC1 knockout reduces the expression of c-FLIP and Bcl-xl. DBC1 WT and KO MEF cells were assayed for western blot to check the 1 evel of c-FLIP and Bcl-xl. The experi ment was representative of three trials

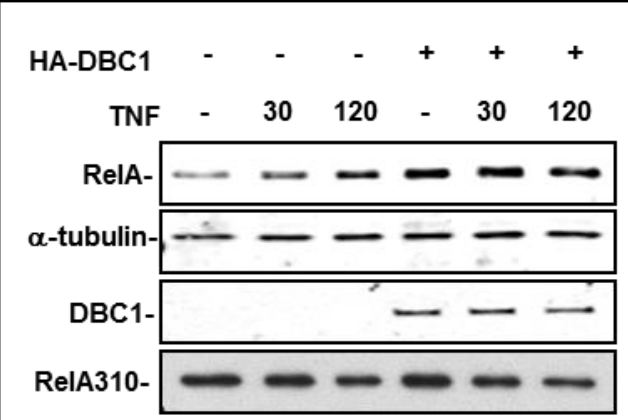

Figure S7. DBC1 does not affect the acetylation state of RelA. MEF -/-DBC1 and HA-DBC1+MEF -/-DBC1 cells treated with TNF were assayed for western blot to measure acetylated RelA at K310 or total relA. The experiment was performed three times, with similar results

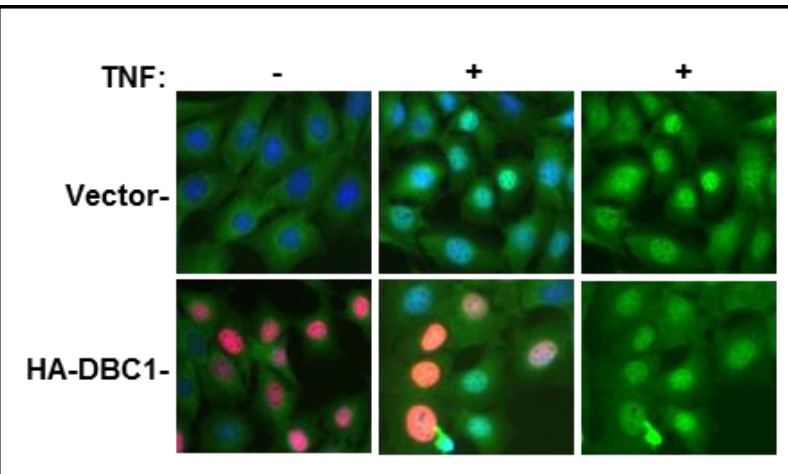

Figure S6. DBC1 does not affect the localization of RelA.

DBC1-/- MEF expressing HA-DBC1 were assayed for relA localization after TNF treatment by immunofluorescence. Green: RelA, red: HA-DBC1, blue: nucleus. The experiment was performed twice with similar results

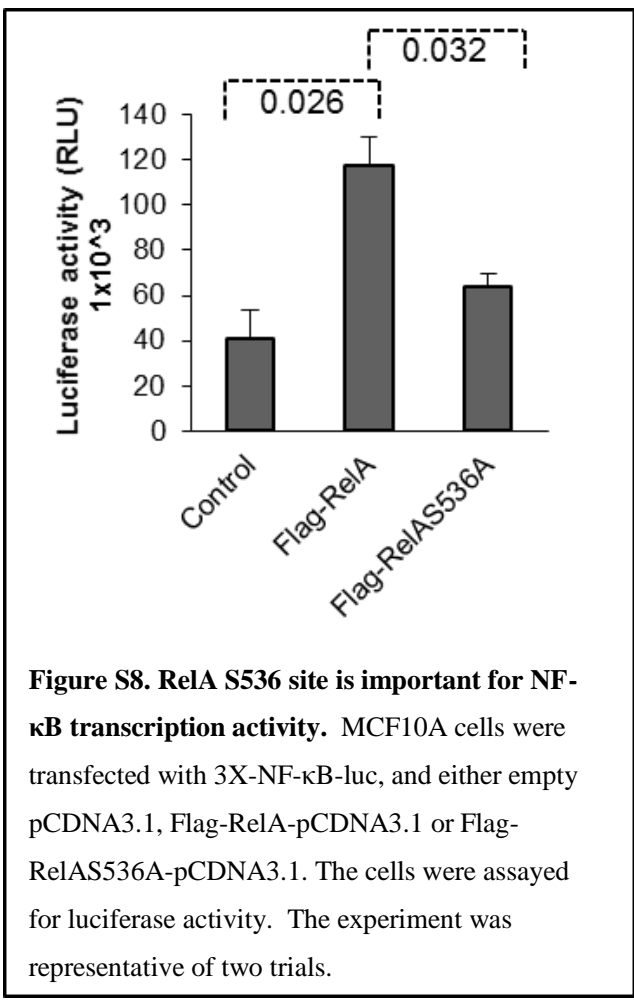


CHAPTER 4

Overall discussion 
This thesis presents the mechanisms of anoikis regulation by two distinct oncogenic signaling pathways: Chapter 2 introduces the novel oncogenic pathway, NRAGE/TBX2/p14ARF, which is critical for linking EMT and anoikis resistance. Chapter 3 introduces the regulation of anoikis by $\mathrm{DBC} 1$ through IKK $\beta / \mathrm{NF}-\kappa \mathrm{B}$, which is a critical signaling pathway that links inflammation and cancer.

\section{PART I: Regulation of anoikis through the cytoskeletal protein ankyrin-G during EMT}

The regulation of anoikis through a novel pathway induced upon EMT was established [1]. Cells undergoing EMT, with loss of Ankyrin-G expression in the lateral membrane, allows NRAGE proteins to localize to the nucleus and directly interact with TBX2. NRAGE-TBX2 complex corepresses p14 ARF, a tumor promoter which results in anoikis resistance.

Cell-cell interaction mediated by E-cadherin is important for anoikis sensitivity, as illustrated in our study and others [1-4]. There is evidence that loss of E-cadherin induces activation of $\beta$ catenin and Wnt signaling which causes EMT and leads to anoikis resistance [3]. Although $\beta$ catenin was necessary for EMT induced by E-cadherin loss, increased $\beta$-catenin alone was not sufficient to cause anoikis-resistance. In our paper, we demonstrated a novel pathway where loss of E-cadherin was also associated with a drop in Ankyrin-G levels. However, knock down of ankyrin-G alone was not found to alter $\beta$-catenin localization (Unpublished data). This implies these pathways are potentially induced in a parallel fashion upon E-cadherin loss, although crosstalk at some other level is possible.

There are some studies demonstrating the potential link between E-cadherin and the polarity protein, scribble: scribble is sequestered to the cell-to-cell junctions in E-cadherin dependent manner and depletion of scribble is known to reduce E-cadherin expression leading to change in 
morphology and migration by inhibiting cell-cell adhesion $[5,6]$. These studies indicate that there is a potential crosstalk between loss of E-cadherin- and Scribble- mediated signaling pathways inducing EMT. Loss of scribble inhibits apoptosis by blocking c-Myc mediated Rac/JNK/Bim pathway and promotes breast cancer development [7]. Therefore, the NRAGE/TBX2/p14ARF pathway might be regulated by scribble to regulate anoikis sensitivity during EMT.

Although presented as two independent studies, a recent report indicates a possible molecular linkage between the NRAGE and DBC1 pathways elucidated here. NRAGE is required for the activation of NF- $\mathrm{KB}$ through phosphorylation of IKK $\alpha / \beta$ in a bone morphogenic protein-4 (BMP-4) signaling pathway, which was previously shown to be critical for cellular process of EMT during embryonic development as well as in pancreatic cancers [8-10]. Therefore, these studies and our interaction data suggest that during EMT, NRAGE

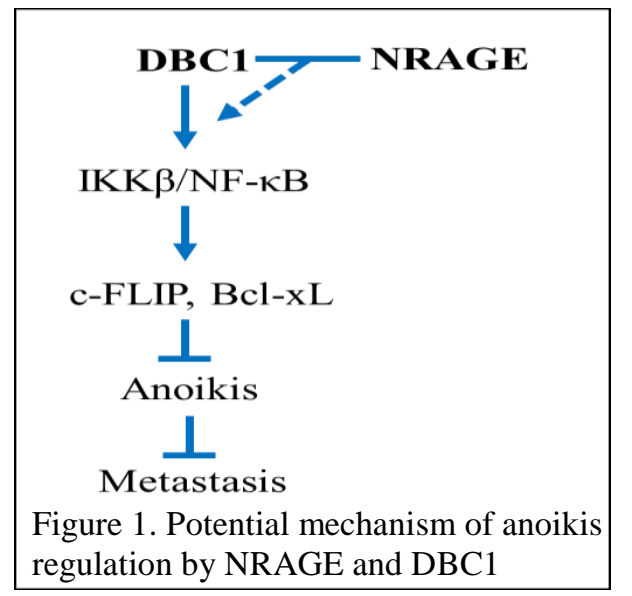
could interact with $\mathrm{DBC} 1$ to induce the $\mathrm{DBC} 1 / \mathrm{IKK} \beta / \mathrm{NF}-\mathrm{\kappa B}$ pathway (chapter 3), leading to anoikis resistance (Fig. 1). Moreover, the potential NRAGE/DBC1/NF-אB pathway could provide us with an important connection between embryonic or/and cancer developmental pathways and anoikis regulation through EMT.

A recent study showed that TBX2 induces cell motility and invasiveness, and promotes metastasis of breast carcinoma cells such as MDA-MB435 cells. This fits conceptually with our earlier observation (chapter 2 and [1]) showing that NRAGE, a novel co-repressor of TBX2, was also critical for anchorage-independent growth of tumor cells that arose from transformation with TBX2 ([11] and chapter 2). Therefore, these studies suggest that NRAGE might be important in tumor metastasis through interacting with TBX2, which may be addressed in the future by the use 
of the appropriate xenograft, transgenic or knockout models. These data further support that coexpression of NRAGE and TBX2 could be developed as an important prognostic marker for some breast cancers and targeting the interaction between NRAGE and TBX2 could be developed as an important anti-cancer therapy.

The transcription repression domain of TBX3 overlaps with that of TBX2 which was important for the interaction with NRAGE. Therefore, there is potential interaction between NRAGE and TBX3. Similar to TBX2, TBX3 is also known to be overexpressed in breast cancers and promote tumorigenesis $[12,13]$. In addition, TBX3 has known to be important in stem cell generation through targeting p14ARF $[14,15]$. These findings implicate that NRAGE might also interact with TBX3 and induce generation of cancer stem cells phenotype, which is the critical cause of recurrence and resistance to therapeutic drugs, the subject of another interesting future study.

The INK4a/ARF gene is frequently inactivated in human cancers by deletion, mutation, or transcriptional silencing [16], abrogating critical cell senescence and apoptotic pathways [17]. Therefore, the novel discovery of p14ARF as an anoikis promoter [1] further supports previous findings and also provides an explanation as to why cancer cells that have depleted p14ARF develop into malignancies. Although the exact mechanism of p14ARF regulation of anoikis is unknown, several studies demonstrating its role in apoptosis provides the potential

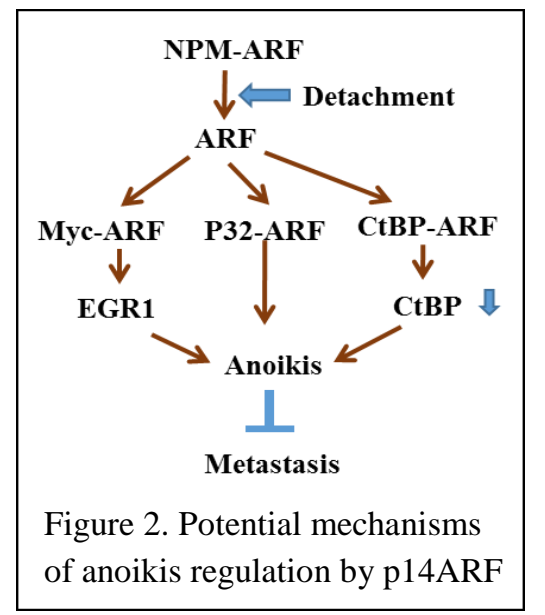
molecular mechanisms by which ARF might regulate anoikis (Fig. 2). First, upon detachment, p14ARF might interact with co-repressor CtBP, which is introduced as an important oncogenic molecule that links EMT and anoikis resistance $[18,19]$, Through direct interaction, p14ARF destabilizes CtBP expression to induce p53 independent apoptosis [20]. Secondly, p14ARF is 
known to regulate apoptosis through interacting with p32 (mitochondria-anchored protein) by reducing mitochondrial membrane potential [21]. Lastly, p14ARF has been known to interact with c-Myc to inhibit c-Myc ubiquitination and promotes c-Myc mediated apoptosis through p53independent pathway by up-regulation of EGR1 (Early growth response 1) transcription factor [22, 23]. All of these studies provide a potential explanation of the frequent mutations of the p14ARF gene in various cancers and their molecular mechanisms leading to anoikis resistance.

In conclusion, this novel pathway of anoikis regulation mediated by EMT and loss of E-cadherin will provide targets for anti-metastatic drugs and should help to advance the development of cancer therapeutics.

\section{PART II: Regulation of anoikis by DBC1 through NF-KB pathway}

In chapter 3, DBC1 enhanced IKK $\beta$ mediated phosphorylation and transcriptional activation of $\mathrm{NF}-\mathrm{\kappa B}$, leading to increased expression of known anoikis suppressors, including c-FLIP and Bcl$\mathrm{xL}$. Interestingly, this effect was achieved through interaction of DBC1 with IKK $\beta$ that was enhanced upon cell-matrix detachment [24]. This pathway will provide the first links between inflammation and anoikis, currently not well established.

As an interesting future study, DBC1 might regulate anoikis through interactions with additional IKK proteins. IKKa, another regulatory subunit of the IKK complex, is shown to be critical for NF- $\mathrm{kB}$ activation mediated by the PI3K/Akt pathway in human salivary adenoid cystic carcinoma (ACC) cells [25]. In addition, phosphorylation of IKK $\alpha$ was induced upon detachment, which activated NF- $\mathrm{KB}$ in suspended intestinal epithelial cells [26]. In addition, IKKe, which is composed

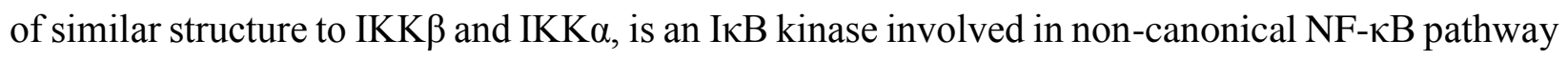


[27]. IKK $\varepsilon$ is overexpressed in multiple cancers (Breast, ovarian, prostate, and glioma) and IKKe induced NF- $\mathrm{KB}$ activity is critical for proliferation, survival and malignant transformation of breast cancer cells $[27,28]$. IKKe may contribute to enhanced NF- $\mathrm{KB}$ activity and tumorigenesis by directly or indirectly phosphorylating RelA/p65 at serine 536 site [29, 30]. Moreover, up-regulated IKK $\varepsilon$ induced the expression of Bcl-2, a known anoikis suppressor [31], through activation of NF$\kappa \mathrm{B}$ signaling [32]. Therefore, these studies suggest the possibility that $\mathrm{DBC} 1 \mathrm{might}$ also interact

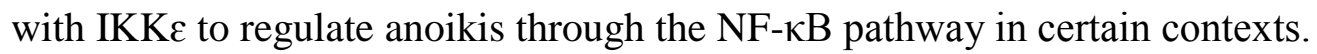

The fact that expression of oncogenic NRAGE is induced upon EMT and the constitutively activated NF- $\mathrm{kB}$ promotes tumor formation [8] and metastasis through EMT in breast cancer [9] suggest that DBC1 could be a potential tumorigenic factor through interaction with NRAGE and activate NF- $\mathrm{kB}$ signaling pathway. Therefore, testing the effect of $\mathrm{DBC} 1$ on anchorage independent survival and tumor metastasis in a xenograft mouse model, would be an interesting future study.

Survivin, a member of IAP family, is one of the downstream target proteins of NF- $\mathrm{kB}$ that is known to be overexpressed in several solid tumors as well as lymphomas and inhibit apoptosis and cell cycle progression. Consistently, survivin whose expression was regulated by DBC1 (chapter 3) is also known to protect cells against anoikis in cell type and context dependent manner [33, 34]. Interestingly, survivin interacts with other IAP members such as XIAP to activate IKK/NF- $\mathrm{kB}$ signaling pathway and suppress anoikis and induce tumor cell invasion and metastasis $[35,36]$. Therefore, it is possible that increased expression of survivin, due to the constitutively active NF$\kappa \mathrm{B}$ signaling, might regulate interaction between $\mathrm{DBC} 1$ and IKK through interaction with other IAPs to further activate the NF- $\mathrm{kB}$ pathway to suppress anoikis by up-regulating $\mathrm{Bcl}-\mathrm{xL}$ and $\mathrm{c}-$ FLIP. 
It is crucial to determine the unknown pathways or molecules affecting the interactions between DBC1 and its binding partner, as these interactions govern the function of DBC1 in anoikis regulation. A recent study showed that the interaction between DBC1 and SIRT1 is regulated by activated AMPK, an important metabolic regulator, upon stimulation [37] . Although the direct mechanism of AMPK action on dissociation of DBC1 and SIRT1 binding is not well understood, this finding provides the possibility that the interaction between DBC1 and IKK $\beta$ might also be regulated by AMPK. Interestingly, recent publications showed that AMPK suppresses anoikis in breast cancer cells and a family of AMPK protein regulates NF-KB activity through IKK in endothelial cells $[38,39]$. Therefore, these studies indicates that determining whether the interaction between DBC1 and IKK $\beta$ can be affected by AMPK in suspension would be useful for discovering a novel pathway of anoikis regulation by metabolic signaling molecules.

Colorectal, esophageal, and breast cancers are known to have overexpressed DBC1 [40-42]. In addition, several studies showed that NF- $\mathrm{KB}$ is constitutively activated and localized in the nucleus [43-45]. This overexpression was correlated with poor prognosis and reduced overall survival. Moreover, phosphorylated RelA at serine 536 was detected in colorectal cancers and was correlated with poor prognosis [46, 47]. A direct study looking at the correlation between DBC1 expression and NF- $\mathrm{kB}$ activity in tumors is clearly warranted.

Although our project focused on cancer, DBC1 has also been shown to be important in other human diseases related to chronic inflammation, such as liver steatosis. Additionally, greater knowledge of the role of $\mathrm{DBC} 1$ in this pathway may prove useful to better understanding the progression of inflammatory diseases in general.

This thesis demonstrated two novel oncogenic pathways that regulate anoikis in two different contexts. Moreover, the interaction between NRAGE and DBC1 suggests potential crosstalk 
between these and additional pathways that might prove critical for anchorage independent survival of tumor cells upon EMT (Fig. 3).

At certain stages of development and tissue repair, cells are required to migrate in an anchorage independent manner, suggesting that anoikis should be regulated stringently. In addition, defects in anoikis regulation during the cellular transformation can lead to metastatic phenotypes. Therefore, appropriate anoikis

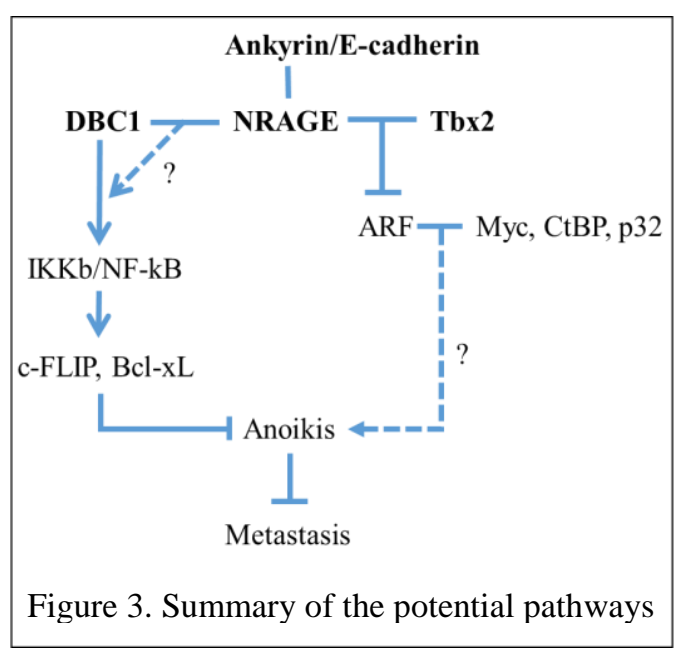
regulation is important. Our novel pathways, both enhance our understanding of this process and provide additional targets for anti-metastatic therapy. 


\section{REFERENCES}

1. Kumar S, Park SH, Cieply B, Schupp J, Killiam E, Zhang F, Rimm DL and Frisch SM A pathway for the control of anoikis sensitivity by E-cadherin and epithelial-to-mesenchymal transition. Mol Cell Biol 31:4036-51. doi: MCB.01342-10 [pii]

10.1128/MCB.01342-10

2. $\quad$ Frisch SM and Francis H (1994) Disruption of epithelial cell-matrix interactions induces apoptosis. J Cell Biol 124:619-26.

3. Onder TT, Gupta PB, Mani SA, Yang J, Lander ES and Weinberg RA (2008) Loss of Ecadherin promotes metastasis via multiple downstream transcriptional pathways. Cancer Res 68:3645-54.

4. Derksen PW, Liu X, Saridin F, van der Gulden H, Zevenhoven J, Evers B, van Beijnum JR, Griffioen AW, Vink J, Krimpenfort P, Peterse JL, Cardiff RD, Berns A and Jonkers J (2006) Somatic inactivation of E-cadherin and p53 in mice leads to metastatic lobular mammary carcinoma through induction of anoikis resistance and angiogenesis. Cancer Cell 10:437-49.

5. Navarro C, Nola S, Audebert S, Santoni MJ, Arsanto JP, Ginestier C, Marchetto S, Jacquemier J, Isnardon D, Le Bivic A, Birnbaum D and Borg JP (2005) Junctional recruitment of mammalian Scribble relies on E-cadherin engagement. Oncogene 24:4330-9. doi: 1208632 [pii]

10.1038/sj.onc. 1208632

6. Qin Y, Capaldo C, Gumbiner BM and Macara IG (2005) The mammalian Scribble polarity protein regulates epithelial cell adhesion and migration through E-cadherin. J Cell Biol 171:106171. doi: jcb.200506094 [pii]

\subsection{3/jcb.200506094}

7. Zhan L, Rosenberg A, Bergami KC, Yu M, Xuan Z, Jaffe AB, Allred C and Muthuswamy SK (2008) Deregulation of scribble promotes mammary tumorigenesis and reveals a role for cell polarity in carcinoma. Cell 135:865-78. doi: S0092-8674(08)01238-5 [pii]

10.1016/j.cell.2008.09.045

8. Matluk N, Rochira JA, Karaczyn A, Adams T and Verdi JM (2010) A role for NRAGE in NF-kappaB activation through the non-canonical BMP pathway. BMC Biol 8:7. doi: 10.1186/1741-7007-8-7

9. Ohta S, Schoenwolf GC and Yamada G (2010) The cessation of gastrulation: BMP signaling and EMT during and at the end of gastrulation. Cell Adh Migr 4:440-6.

10. Hamada S, Satoh K, Hirota M, Kimura K, Kanno A, Masamune A and Shimosegawa T (2007) Bone morphogenetic protein 4 induces epithelial-mesenchymal transition through MSX2 induction on pancreatic cancer cell line. J Cell Physiol 213:768-74. doi: 10.1002/jcp.21148

11. Wang B, Lindley LE, Fernandez-Vega V, Rieger ME, Sims AH and Briegel KJ (2012) The $\mathrm{T}$ box transcription factor TBX2 promotes epithelial-mesenchymal transition and invasion of normal and malignant breast epithelial cells. PLoS One 7:e41355. doi: 10.1371/journal.pone.0041355

12. Rowley M, Grothey E and Couch FJ (2004) The role of Tbx2 and Tbx3 in mammary development and tumorigenesis. J Mammary Gland Biol Neoplasia 9:109-18. doi: 10.1023/B:JOMG.0000037156.64331.3f

490060 [pii] 
13. Yarosh W, Barrientos T, Esmailpour T, Lin L, Carpenter PM, Osann K, Anton-Culver H and Huang T (2008) TBX3 is overexpressed in breast cancer and represses p14 ARF by interacting with histone deacetylases. Cancer Res 68:693-9. doi: 68/3/693 [pii]

\subsection{8/0008-5472.CAN-07-5012}

14. Esmailpour $\mathrm{T}$ and Huang $\mathrm{T}$ (2012) TBX3 promotes human embryonic stem cell proliferation and neuroepithelial differentiation in a differentiation stage-dependent manner. Stem Cells 30:2152-63. doi: 10.1002/stem.1187

15. Liu J, Esmailpour T, Shang X, Gulsen G, Liu A and Huang T (2011) TBX3 over-expression causes mammary gland hyperplasia and increases mammary stem-like cells in an inducible transgenic mouse model. BMC Dev Biol 11:65. doi: 10.1186/1471-213X-11-65

16. Voorhoeve PM and Agami R (2003) The tumor-suppressive functions of the human INK4A locus. Cancer Cell 4:311-9. doi: S153561080300223X [pii]

17. Saporita AJ, Maggi LB, Jr., Apicelli AJ and Weber JD (2007) Therapeutic targets in the ARF tumor suppressor pathway. Curr Med Chem 14:1815-27.

18. Grooteclaes ML and Frisch SM (2000) Evidence for a function of CtBP in epithelial gene regulation and anoikis. Oncogene 19:3823-8.

19. Grooteclaes M, Deveraux Q, Hildebrand J, Zhang Q, Goodman RH and Frisch SM (2003) C-terminal-binding protein corepresses epithelial and proapoptotic gene expression programs. Proc Natl Acad Sci U S A 100:4568-73.

20. Paliwal S, Pande S, Kovi RC, Sharpless NE, Bardeesy N and Grossman SR (2006) Targeting of C-terminal binding protein (CtBP) by ARF results in p53-independent apoptosis. Mol Cell Biol 26:2360-72. doi: 26/6/2360 [pii]

10.1128/MCB.26.6.2360-2372.2006

21. Itahana $\mathrm{K}$ and Zhang Y (2008) Mitochondrial p32 is a critical mediator of ARF-induced apoptosis. Cancer Cell 13:542-53. doi: S1535-6108(08)00122-0 [pii]

10.1016/j.ccr.2008.04.002

22. Li Z and Hann SR (2009) The Myc-nucleophosmin-ARF network: A complex web unveiled. Cell Cycle 8. doi: 9418 [pii]

23. Boone DN, Qi Y, Li Z and Hann SR (2011) Egr1 mediates p53-independent c-Mycinduced apoptosis via a noncanonical ARF-dependent transcriptional mechanism. Proc Natl Acad Sci U S A 108:632-7. doi: 10.1073/pnas. 1008848108

24. Park SH, Riley Pt and Frisch SM (2013) Regulation of anoikis by deleted in breast cancer1 (DBC1) through NF-kappaB. Apoptosis. doi: 10.1007/s10495-013-0847-1

25. Sun ZJ, Chen G, Hu X, Zhang W, Liu Y, Zhu LX, Zhou Q and Zhao YF (2010) Activation of PI3K/Akt/IKK-alpha/NF-kappaB signaling pathway is required for the apoptosis-evasion in human salivary adenoid cystic carcinoma: its inhibition by quercetin. Apoptosis 15:850-63. doi: 10.1007/s10495-010-0497-5

26. Yan SR, Joseph RR, Rosen K, Reginato MJ, Jackson A, Allaire N, Brugge JS, Jobin C and Stadnyk AW (2005) Activation of NF-kappaB following detachment delays apoptosis in intestinal epithelial cells. Oncogene 24:6482-91. doi: 1208810 [pii]

10.1038/sj.onc. 1208810

27. Shen RR and Hahn WC (2011) Emerging roles for the non-canonical IKKs in cancer. Oncogene 30:631-41. doi: 10.1038/onc.2010.493 
28. Qin B and Cheng K (2010) Silencing of the IKKepsilon gene by siRNA inhibits invasiveness and growth of breast cancer cells. Breast Cancer Res 12:R74. doi: 10.1186/bcr2644 29. Guo JP, Coppola D and Cheng JQ (2011) IKBKE protein activates Akt independent of phosphatidylinositol 3-kinase/PDK1/mTORC2 and the pleckstrin homology domain to sustain malignant transformation. J Biol Chem 286:37389-98. doi: 10.1074/jbc.M111.287433

30. Xie X, Zhang D, Zhao B, Lu MK, You M, Condorelli G, Wang CY and Guan KL (2011) IkappaB kinase epsilon and TANK-binding kinase 1 activate AKT by direct phosphorylation. Proc Natl Acad Sci U S A 108:6474-9. doi: 10.1073/pnas.1016132108

31. Frisch SM, Vuori K, Kelaita D and Sicks S (1996) A role for Jun-N-terminal kinase in anoikis; suppression by bcl-2 and crmA. J Cell Biol 135:1377-82.

32. Guan H, Zhang H, Cai J, Wu J, Yuan J, Li J, Huang Z and Li M (2011) IKBKE is overexpressed in glioma and contributes to resistance of glioma cells to apoptosis via activating NFkappaB. J Pathol 223:436-45. doi: 10.1002/path.2815

33. Marconi A, Dallaglio K, Lotti R, Vaschieri C, Truzzi F, Fantini F and Pincelli C (2007) Survivin identifies keratinocyte stem cells and is downregulated by anti-betal integrin during anoikis. Stem Cells 25:149-55. doi: 10.1634/stemcells.2006-0165

34. Hu H, Li Z, Chen J, Wang D, Ma J, Wang W, Li J, Wu H, Li L, Wu M, Qian Q and Su C (2011) P16 reactivation induces anoikis and exhibits antitumour potency by downregulating Akt/survivin signalling in hepatocellular carcinoma cells. Gut 60:710-21. doi: 10.1136/gut.2010.220020

35. Mehrotra S, Languino LR, Raskett CM, Mercurio AM, Dohi T and Altieri DC IAP regulation of metastasis. Cancer Cell 17:53-64. doi: S1535-6108(09)00422-X [pii]

10.1016/j.ccr.2009.11.021

36. Hori M, Miki T, Okamoto M, Yazama F, Konishi H, Kaneko H, Shimamoto F, Ota T, Temme A and Tatsuka M (2013) The detergent-soluble cytoplasmic pool of survivin suppresses anoikis and its expression is associated with metastatic disease of human colon cancer. PLoS One 8:e55710. doi: 10.1371/journal.pone.0055710

37. Nin V, Escande C, Chini CC, Giri S, Camacho-Pereira J, Matalonga J, Lou Z and Chini EN (2012) Role of deleted in breast cancer 1 (DBC1) protein in SIRT1 deacetylase activation induced by protein kinase A and AMP-activated protein kinase. J Biol Chem 287:23489-501. doi: 10.1074/jbc.M112.365874

38. Bess E, Fisslthaler B, Fromel T and Fleming I Nitric oxide-induced activation of the AMPactivated protein kinase alpha2 subunit attenuates IkappaB kinase activity and inflammatory responses in endothelial cells. PLoS One 6:e20848. doi: 10.1371/journal.pone.0020848

PONE-D-11-00116 [pii]

39. Ng TL, Leprivier G, Robertson MD, Chow C, Martin MJ, Laderoute KR, Davicioni E, Triche TJ and Sorensen PH (2012) The AMPK stress response pathway mediates anoikis resistance through inhibition of mTOR and suppression of protein synthesis. Cell Death Differ 19:501-10. doi: 10.1038/cdd.2011.119

40. Kim SH, Kim JH, Yu EJ, Lee KW and Park CK (2012) The overexpression of DBC1 in esophageal squamous cell carcinoma correlates with poor prognosis. Histol Histopathol 27:49-58. 41. Lee H, Kim KR, Noh SJ, Park HS, Kwon KS, Park BH, Jung SH, Youn HJ, Lee BK, Chung MJ, Koh DH, Moon WS and Jang KY Expression of DBC1 and SIRT1 is associated with poor prognosis for breast carcinoma. Hum Pathol 42:204-13. doi: S0046-8177(10)00248-0 [pii]

10.1016/j.humpath.2010.05.023 
42. Zhang Y, Gu Y, Sha S, Kong X, Zhu H, Xu B, Li Y and Wu K DBC1 is over-expressed and associated with poor prognosis in colorectal cancer. Int J Clin Oncol. doi: 10.1007/s10147012-0506-5

43. Rayet B and Gelinas C (1999) Aberrant rel/nfkb genes and activity in human cancer. Oncogene 18:6938-47. doi: 10.1038/sj.onc.1203221

44. Sovak MA, Bellas RE, Kim DW, Zanieski GJ, Rogers AE, Traish AM and Sonenshein GE (1997) Aberrant nuclear factor-kappaB/Rel expression and the pathogenesis of breast cancer. J Clin Invest 100:2952-60. doi: 10.1172/JCI119848

45. Devalaraja MN, Wang DZ, Ballard DW and Richmond A (1999) Elevated constitutive IkappaB kinase activity and IkappaB-alpha phosphorylation in Hs294T melanoma cells lead to increased basal MGSA/GRO-alpha transcription. Cancer Res 59:1372-7.

46. Lewander A, Gao J, Adell G, Zhang H and Sun XF (2011) Expression of NF-kappaB p65 phosphorylated at serine-536 in rectal cancer with or without preoperative radiotherapy. Radiol Oncol 45:279-84. doi: 10.2478/v10019-011-0030-7

47. Lewander A, Gao J, Carstensen J, Arbman G, Zhang H and Sun XF NF-kappaB p65 phosphorylated at serine-536 is an independent prognostic factor in Swedish colorectal cancer patients. Int J Colorectal Dis 27:447-52. doi: 10.1007/s00384-011-1356-8 


\section{SUN PARK}

5 Silver Creek Dr, Morgantown, WV, 26505 | 443-235-4904 |spark7@mix.wvu.edu

\section{EDUCATION}

West Virginia University, Morgantown, WV

2007-2013

Ph.D Cancer Cell Biology

Salisbury University, Salisbury, MD

\section{B.S Chemistry (biochemistry track)}

2002-2007

\section{AWARDS AND RECOGNITIONS}

WVU Doctoral Student Travel Award $(\$ 400)$

2012

Tri Beta National Biological Honor Society

2006-2007

Salisbury University Dean's List

2005-2007

Junior Chemistry Awards (\$500)

2005

\section{PUBLICATIONS}

Journal Article:

Kumar S*, Park SH*, Cieply B*, Schupp J, Killiam E, Zhang F, Rimm DL, Frisch SM. 2011 A Pathway for the Control of Anoikis Sensitivity by E-Cadherin and Epithelial-to-Mesenchymal Transition. Molecular and Cellular Biology.19:4036-51.

*Co-first authors

Park SH, Riley P IV, Frisch SM. 2013 Regulation of Anoikis by DBC1 (Deleted-in-Breast Cancer 1) through NF- $\kappa$ B. Apoptosis.

\section{PRESENTATIONS}

Sun Park, Philip Riley IV, Steven M Frisch. Oral presentation. Regulation of anoikis by DBC1 through NF-KB. Health Sciences Van Liere Memorial Convocation and Research Day, Morgantown, WV, March 2013.

Sun Park, Philip Riley IV, Benjamin Cieply, Steven M Frisch. Poster presentation. Regulation of anoikis by DBC1 through NF-KB. American Association for Cancer Research (AACR), Chicago, IL, April 2012. 
Sun Park, Philip Riley IV, Benjamin Cieply, Steven M Frisch. Poster presentation. Regulation of anoikis by DBC1 through NF-kB. Health Sciences Van Liere Memorial Convocation and Research Day, Morgantown, WV, March 2012.

Sun Park, Steven M Frisch. Poster presentation. Regulation of anoikis by DBC1. School of Pharmacy Research Day. Morgantown, WVU, October, 2011

Sun Park, Steven M Frisch. Poster presentation. Regulation of anoikis by DBC1. 14th Annual Meeting of the Translational Research Cancer Centers Consortium, Seven Springs Mountain Resort, Seven Springs, PA, February, 2011

Sun Park, Steven M Frisch. Poster presentation. Regulation of anoikis by DBC1. School of Pharmacy Research Day. Morgantown, WVU, October, 2010

Sun Park, Steven M Frisch. Poster presentation. Regulation of anoikis by DBC1 (Deleted in Breast Cancer 1). Health Sciences Van Liere Memorial Convocation and Research day, Morgantown, WV, March 2010.

Sun Park, Katherine R. Miller. Poster presentation. Seasonal microbial community diversity in a forested wetland using FAMEs, University of Maryland at Baltimore Annual Convocation, UMBC, October, 2006

\section{COMMUNITY SERVICE AND TEACHING EXPERIENCE}

Worship team, Morgantown, WV

$2010-2013$

Playing as a drummer at Morgantown Korean Church

Muscular Dystrophy Association (MDA) Summer Camp Volunteer 2006

Camp Maria Retreat Center, Leonardtown, MD

Private tutor, Salisbury, MD

2005-2007

Teaching math and general science for middle school students

Volunteer in Peninsula Regional Medical Center, Salisbury, MD 2003-2005

At pharmacy department, pathology laboratory and Emergency Room 


\section{References}

1. Steven M. Frisch, Ph.D

Professor at West Virginia University School of Medicine

Department of Biochemistry and Mary Babb Randolph Cancer Center

Phone: (304) 293-2980

E-Mail: sfrisch@hsc.wvu.edu

Address: Health Sciences Center 2836HSS

West Virginia University

Morgantown, WV 26506

2. William Tse, MD, FACP

Associate Professor at West Virginia University School of Medicine

Hematology/Oncology

Phone: (304) 293-4980

E-Mail: wtse@hsc.wvu.edu

Address: $2^{\text {nd }}$ floor Mary Babb Randolph Cancer Center

P.O. Box 9162

Morgantown, WV 26506

3. Micheal D. Shaller, Ph.D

Professor and Chair of Biochemistry at West Virginia University School of Medicine MBR Cancer Center, Center for Cardiovascular and Respiratory Sciences

Phone: (304) 293-9514

E-Mail: mschaller@hsc.wvu.edu

Address: Health Sciences Center 3124HSN

West Virginia University, Morgantown, WV 26506 